\title{
Mechanistic insights into global suppressors of protein folding defects
}

Gopinath Chattopadhyay ${ }^{1 \#}$, Jayantika Bhowmick ${ }^{1 \#}$, Kavyashree Manjunath ${ }^{2}$, Shahbaz Ahmed $^{1}$, Parveen Goyal ${ }^{2}$, Raghavan Varadarajan ${ }^{1 *}$

\# These authors have contributed equally

${ }^{1}$ Molecular Biophysics Unit, Indian Institute of Science, Bangalore-560012, India

${ }^{2}$ Institute for Stem Cell Science and Regenerative Medicine, Bangalore 560065, India *Corresponding Author

Raghavan Varadarajan, Molecular Biophysics Unit, Indian Institute of Science, Bangalore, 560012 (INDIA), Email: varadar@iisc.ac.in, PHONE: +91-80-22932612, FAX: +91-80-23600535

Running Title: Mechanism of global suppression.

Number of manuscript pages: 86

Number of supplementary figures: 6

Number of figures: 8

Number of supplementary tables: 11

Number of tables: 1 


\section{Abstract:}

\section{Background:}

Most amino acid substitutions in a protein either lead to partial loss of function or are near neutral. Several studies have shown the existence of second-site mutations that can rescue defects caused by diverse loss of function mutations. Such global suppressor mutations are key drivers of protein evolution. However, the mechanisms responsible for such suppression remain poorly understood.

\section{Results:}

To address this, we characterized multiple suppressor mutations both in isolation and in combination with inactive mutants. We examined five global suppressors of the bacterial toxin $\mathrm{CcdB}$, the known M182T global suppressor of TEM-1 $\beta$-lactamase, the N239Y global suppressor of p53-DBD and three suppressors of the SARS-CoV-2 spike Receptor Binding Domain. We observed that the suppressors were able to significantly enhance the thermodynamic stability parameters $\left(T_{m}\right.$ and $\left.C_{m}\right)$ of multiple inactive mutants. Stabilisation enhancement by the suppressor was much higher when present in the background of the inactive mutants than in the wild type (WT) background. We also observe that the inactive mutants showed higher unfolding and lower refolding rates relative to the WT, the suppressors alone and the inactive mutant-suppressor pairs. From in vitro binding studies, we concluded that in the background of the suppressors, the formerly inactive CcdB mutants now showed improved binding to GyrA14 for both native and refolded proteins. An estimation of the in vitro aggregation propensities of the mutants measured from thermal stress studies showed that the inactive mutants in the background of the suppressors had enhanced thermal tolerance relative to the inactive mutants alone. In the case of $\mathrm{CcdB}$, where novel suppressors were isolated, we determined the crystal structures of three such suppressors to obtain insight into the specific molecular interactions responsible for the observed effects. 


\section{Conclusions:}

Our study demonstrates that global suppressors both alone, and in conjunction with inactive mutants, stabilise the protein both thermodynamically and kinetically in-vitro, predominantly through acceleration of the refolding rate parameters. When coupled to inactive mutants they promote increased in-vivo solubilities as well as regain-of-function phenotypes. While most individual suppressors result in small stability enhancements relative to wildtype, which can be combined to yield significant stability increases, thermodynamic stabilisation is neither necessary nor sufficient for suppressor action.

Keywords: protein stability, folding kinetics, differential scanning fluorimetry, vaccine, distal suppressor 


\section{Background}

Certain specific interactions influencing a protein's structure and function are preserved throughout evolution, either by conservation of the interacting pair, or by mutation of the pair in a correlated fashion (1). Correlated mutational data extracted from multiple sequence alignments, can guide structure prediction of a protein (2) or help in the determination of interfacial residues responsible for binding to various partners (3). Experimental studies have often led to the identification of second suppressor mutations which can alleviate the defects in folding, function and stability of the protein caused by an initial deleterious mutation. Such compensatory mutations, often occur within the same gene, highlighting the role of intragenic suppression in evolution (4).

Suppressors can be either spatially proximal or distal to the inactivating mutation. Distal suppressors are typically able to suppress multiple inactivating mutations, not necessarily in proximity to each other. Hence distal suppressors are often referred to as global suppressors. Prior studies on distal suppressors have suggested that such suppressors function either by (a) increasing global thermodynamic stability (5), (b) enhancing the activity of the native protein without any effect on stability (6), or (c) improving the folding of the native protein without substantial enhancement of the thermodynamic stability (7). In laboratory-based evolution experiments, it has been shown that the evolution of new function is accompanied by second-site compensatory mutations, which compensate for the probable destabilizing function altering mutations (8). Previous studies have primarily focused on thermodynamic rather than kinetic effects of mutations on protein stability and function, though the latter may be more relevant in vivo (9).

Here, we endeavour to provide insights into the mechanisms responsible for global suppression. The primary experimental system utilised is a 101-residue homo-dimeric protein, CcdB (Controller of Cell Death protein B), which is a part of the toxin-antitoxin (CcdB-CcdA) module involved in the maintenance of F-plasmid in Escherichia coli (10). We probe effects of multiple global suppressors of $\mathrm{CcdB}$, on the folding kinetics, stability, in vivo solubility and in vivo activity of the protein. The 
suppressors are able to rescue folding defects of the inactive mutants, through thermodynamic and kinetic stabilization, with the largest effects on the refolding rate. We also determined the structure of three of the CcdB suppressors mutants, S12G, V46L and S60E using X-ray crystallography to understand the structural basis of stabilization. We probed the effect of the suppressor mutants on aggregation, binding and thermal tolerance. We also examined the effects on stability and folding of two known global suppressors: M182T of TEM-1 $\beta$-lactamase, an extended spectrum $\beta$-lactamase (ESBL) enzyme conferring antibiotic resistance against third generation cephalosporins and N239Y in the DNA binding domain (DBD) of p53, a critical tumour suppressor protein, which is known to suppress the effect of oncogenic inactive mutants. We additionally examined the effects of suppressor mutations that were recently isolated for RBD (Receptor Binding Domain of spike glycoprotein of SARS-CoV2), on protein stability and folding (11). The analysis of data for these diverse systems provided general insights into the mechanism of action of global suppressors.

\section{Results}

\section{Phenotypic characterisation of putative second-site suppressor mutations in CcdB}

A previously described single site saturation mutagenesis (SSM) library of 1600 mutants includes several single mutants that lead to partial or complete loss of function $(9,12,13)$. Five such mutants, termed parent inactive mutants (PIMs), (namely V5F, V18W, V20F, L36A and L83S) were chosen for further study as these span a range of sizes and polarities. Next, exhaustive second-site saturation mutagenesis libraries were constructed in a yeast surface display vector by incorporating each of the PIMs into the original SSM library. PIMs bound GyrA14 poorly. In order to identify the suppressors of the PIMs, suppressor libraries were then displayed on the yeast surface and screened for improved binding to GyrA14 by FACS and mutations were confirmed by Sanger sequencing (2). In that study, two residues R10 and E11 on an exposed loop region were identified as distal suppressors, located far from the PIMs (Figure 1A). The global suppressor R10G was able to suppress defects in binding to 
GyrA14 ligand at all the five positions and was also shown to increase the $\mathrm{T}_{\mathrm{m}}$ by $8{ }^{\circ} \mathrm{C}$, relative to WT CcdB (2) but E11R was not characterized. Subsequently, another putative global suppressor S12G was identified by analyzing CcdB saturation suppressor libraries using FACS coupled to deep sequencing (14). S12, located on an exposed loop, along with R10 and E11, is involved in hydrogen bonding with the cognate antitoxin CcdA (Figure 1A).

The phenotype of the E11R and S12G CcdB mutants were studied here after cloning the mutants both individually and in combination with PIMs into the E. coli expression vector pBAD24, under the control of the $\mathrm{P}_{\mathrm{BAD}}$ promoter (15). This allows for tuneable expression with glucose (repressor) and arabinose (inducer). The plasmids were individually transformed into the Top10pJAT strain which is sensitive to CcdB toxin action. The cells were allowed to grow at different concentrations of glucose and arabinose $(9,13)$ to allow increasing levels of expression of $\mathrm{CcdB}$ from the $\mathrm{P}_{\mathrm{BAD}}$ promoter. Mutant phenotypes were studied as a function of varying repressor (glucose) and inducer (arabinose) concentration. For WT and the fully active mutants E11R and S12G, the cells fail to grow even at the highest glucose (repressor) concentration ( $0.2 \%$ glucose), because even very low levels of active CcdB result in cell death. The inactive mutants grow even at higher concentrations of arabinose $\left(7 \times 10^{-5} \%\right.$ arabinose). In the background of the E11R or S12G suppressor mutations, with the exception of V18W-S12G, the WT-like phenotype of the remaining (PIM, suppressor) pairs is restored at lower glu concentrations $(\leq 0.2 \%)$, leading to cell death (Figure $1 \mathrm{~B})$.

For proper function, proteins need to fold into their native structure avoiding misfolding or formation of aggregates. To examine the relative solubility levels, E. coli strain Top10GyrA was individually transformed with each mutant. The solubilities of the PIMs were significantly lower than that of WT CcdB and suppressors E11R and S12G (Additional file 7: Table S1). However, the solubilities of the inactive mutants in the background of the suppressors was significantly enhanced (Additional file 1: Figure S1A). These results reveal that lowered activity and decrease in solubility of the inactive proteins are both improved in the background of the suppressors. 


\section{Enhancement of thermal and chemical stability of multiple inactive mutants by global}

\section{suppressors}

The WT and CcdB mutants were purified by affinity purification against immobilised ligand CcdA. Yield for all mutants varied from $0.3-12 \mathrm{mg} / \mathrm{L}$ depending upon the amount of protein in the soluble fraction. V5F and V5F-S12G could not be purified because of their low expression, solubility and inability to bind to the CcdA column. V18W-E11R and V20F-E11R could not be used for further biophysical studies owing to their high tendency to aggregate.

The purified proteins $(4 \mu \mathrm{M})$ were subjected to thermal denaturation using nanoDSF and the apparent $\mathrm{T}_{\mathrm{m}}$ was calculated (Figure 1D). $\mathrm{S} 12 \mathrm{G}$ had a $2{ }^{\circ} \mathrm{C}$ higher $\mathrm{T}_{\mathrm{m}}$, indicating that the mutation is stabilising (Additional file 7: Table S1). Further the inactive mutant-suppressor pairs showed increased apparent thermal stabilities $\left(\sim 5-12{ }^{\circ} \mathrm{C}\right)$ relative to the inactive mutants. The ability of the purified proteins to bind to CcdA peptide $(8 \mu \mathrm{M})$ was also examined by monitoring thermal denaturation using binding of Sypro orange dye (16), both in the absence and presence of CcdA peptide (45-72). Relative to the free proteins, apparent $\mathrm{T}_{\mathrm{m}}$ 's of the CcdA-bound complexes showed increments (Additional file 1: Figure S1B) due to stability-enhancements of the proteins in the presence of peptide (2).

Equilibrium unfolding experiments for the CcdB mutants were carried out by nanoDSF. The data were fitted to $\mathrm{N}_{2} \leftrightarrow 2 \mathrm{D}$ unfolding models for homo-dimeric CcdB as described $(15,17)$. The fraction unfolded of different CcdB mutants (200 mM HEPES, $\mathrm{pH} 8.4$ ) in the presence of $\mathrm{GdnCl}$ is plotted as a function of denaturant concentration (Figure 1C). The midpoint of chemical denaturation $\left(\mathrm{C}_{\mathrm{m}}\right), \Delta \mathrm{G}^{0}$ and $\mathrm{m}$ values were measured for all the CcdB mutants (Additional file 11: Table S5). The suppressor S12G alone is $0.8 \mathrm{kcal} / \mathrm{mol}$ more stable than the WT, and the double mutants are apparently $2.5-5.0 \mathrm{kcal} / \mathrm{mol}$ more stable than the inactive mutants (Figure 1D). The significant difference in the apparent effect of the suppressor in the context of PIM relative to WT, is likely due to the high tendency of inactive mutants to aggregate over time thereby reducing the amount of functionally folded form. The E11R is $3.1 \mathrm{kcal} / \mathrm{mol}$ less stable than the WT protein. This is surprising because their thermal stabilities are 
similar and E11R is able to enhance the stability of multiple PIMs by $4-5 \mathrm{kcal} / \mathrm{mol}$. Being a charge reversal mutation, the $\mathrm{pI}$ of the protein was changed significantly (6.1 to 8.1) which accounts for the visible aggregation of the E11R mutant at $200 \mathrm{mM}$ HEPES at higher concentrations of $1-2 \mathrm{mg} / \mathrm{mL}, \mathrm{pH}$ 8.4. Hence, the chemical denaturation and folding kinetics of E11R and WT were repeated in PBS (pH 7.4) where E11R behaves similarly to the WT protein (Additional file 1: Figure S1 C-H, Additional file 10: Table S4).

\section{Suppressor substitutions accelerate the refolding rate and reduce the unfolding rate of the WT}

\section{and multiple inactive mutants}

Refolding and unfolding kinetics for $\mathrm{CcdB}$ mutants were also monitored by time-course fluorescence spectroscopy at $25{ }^{\circ} \mathrm{C}$ using nanoDSF (17). Refolding was performed at $\mathrm{pH} 8.4$, at final $\mathrm{GdnCl}$ concentrations ranging from 0.5 M-1.5 M. During refolding, the two monomers rapidly associate in a diffusion limited process (18). Refolding for the WT occurs with a fast and a slow phase as observed earlier (18). The suppressors E11R and S12G refold at a faster rate compared to the WT. Relative to the WT, the inactive mutants refold slowly, whereas their refolding rates were enhanced (both fast and slow phase) in the background of the suppressor (Figure 2A, Additional file 8: Table S2).The fast phase of refolding for L83S-E11R could not be captured owing to its fast refolding kinetics. The noise associated with refolding kinetics of L36A-S12G in the presence of $1 \mathrm{M} \mathrm{GdnCl}$ is because of the faster kinetics of refolding of the mutant and high dead time of about $\sim 15$ seconds associated with the instrument.

The unfolding trace of WT CcdB when fitted to the three-parameter unfolding equation, gives a fitted unfolding rate of $0.05 \mathrm{~s}^{-1}$. S12G shows a much slower rate of unfolding. For all the PIMs, we observed very fast unfolding even at low $\mathrm{GdnCl}$ concentrations, whereas the mutant-suppressor pairs had slower unfolding rates relative to the individual PIMs, though typically faster than the rates for WT and the suppressors E11R and S12G (Figure 2B, Additional file 8: Table S2). Refolding and unfolding reactions were carried out at three different $\mathrm{GdnCl}$ concentrations and the observed rate constants and 
$\mathrm{m}$ values were plotted as a function of $\mathrm{GdnCl}$ concentration (Additional file 2: Figure S2, Additional

file 9: Table S3). Using this, the refolding rate constants for both fast and slow phases, and unfolding rate constants were calculated at $0 \mathrm{M} \mathrm{GdnCl}$ as described previously (17) for relative comparison (Additional file 9: Table S3). These experiments correlate with other results and indicate that the suppressors E11R and S12G have similar to marginally higher thermal stabilities than WT and that all the mutant-suppressor pairs are both kinetically and thermodynamically more stable than the corresponding PIMs.

\section{$\underline{\text { Rescue of activity and stability of refolded CcdB proteins by the global suppressors }}$}

The affinity of fluorescently labeled GyrA14 to $\mathrm{CcdB}$ mutant proteins (native, native in $\mathrm{GdnCl}$ and refolded proteins) was analysed using MST. The assays were carried out with a fixed concentration of the labeled GyrA14 (70 nM), which was titrated with different concentrations of the unlabeled CcdB mutants. The obtained data indicates that WT CcdB, S12G and E11R bind GyrA14 with KD's of about 2.2, 2.3 and $1.2 \mathrm{nM}$ respectively which is consistent with the SPR binding studies (Figure 2C, Additional file 3: Figure S3A, Additional file 7: Table S1). Labeled GyrA14 also bound with similar affinity to the native and refolded proteins in $1.5 \mathrm{M} \mathrm{GdnCl}$ (Figure 2C, Additional file 3: Figure S3BC, Additional file 7: Table S1), indicating that refolding was reversible. The $\mathrm{C}_{\mathrm{m}}$ of GyrA14 was determined to be $4.48 \mathrm{M}$, confirming that it was folded at $1.5 \mathrm{M} \mathrm{GdnCl}$ used in the above refolding assay (Additional file 3: Figure S3D).

The refolded $\mathrm{CcdB}$ proteins and the native proteins in the presence of $1.5 \mathrm{M} \mathrm{GdnCl}$ were also subjected to thermal denaturation, and the apparent $\mathrm{T}_{\mathrm{m}}$ was calculated (Figure 2D, Additional file 11: Table S5). The near identicality of the $\mathrm{T}_{\mathrm{m}}$ 's for native and refolded proteins, further confirms that the mutants refold reversibly. Except for the PIMs V18W and V20F, all the other mutants showed clear thermal transitions confirming that they were in a folded conformation in the presence of $\mathrm{GdnCl}$. The suppressors improved the $\mathrm{T}_{\mathrm{m}}$ of the refolded proteins, relative to the PIMs. 


\section{Enhancement of thermal tolerance of the CcdB mutants by the global suppressors}

The binding of purified CcdB mutants to their target GyrA14, was also probed using SPR. WT CcdB, S12G and E11R bind to GyrA14 with $\mathrm{K}_{\mathrm{D}}$ 's of about 1.4, 2.6 and $2.5 \mathrm{nM}$ respectively (Additional file 4: Figure S4, Additional file 7: Table S1). An increased affinity for DNA Gyrase for the inactive mutant-suppressor pairs was observed in all the cases. This explains the ability of these suppressors to rescue the activity of the inactive mutants, which are defective in binding and poisoning DNA Gyrase. The apparent low affinity of these inactive mutants may also arise due to the inability to estimate the fraction of active protein for these purified mutants. The SEC profile of the PIM L36A, shows a significant amount of aggregation as well as degradation as compared to the WT, suppressor S12G and the double mutant L36A-S12G (Figure 2F). All the SEC experiments were carried out using $100 \mu \mathrm{g}$ of protein at a flow rate of $0.5 \mathrm{~mL} / \mathrm{min}$. For the other mutants, due to poor yields and high tendency to aggregate, SEC was not performed. Thermal tolerance of the mutants E11R, S12G, L36A, L36AE11R,L36A-S12G and WT CcdB, was also assessed by determining the binding of CcdB proteins to GyrA14 after prolonged heat stress followed by cooling to room temperature (Figure 2E, Additional file 11: Table S5). The $\mathrm{S} 12 \mathrm{G}$ mutant retained $4 \%$ activity after incubation at $80{ }^{\circ} \mathrm{C}$ for $1 \mathrm{hr}$, representing a five-fold improvement over WT, whereas the double mutants L36A-E11R and L36A-S12G showed three-fold and ten-fold improvement over WT respectively. Surprisingly, L36A-E11R had residual activity at $40{ }^{\circ} \mathrm{C}$, as compared to E11R alone.

\section{Thermodynamic and kinetic stabilisation mediated by the M182T global suppressor substitution}

\section{in extended spectrum TEM-1 $\beta$ lactamases conferring antibiotic resistance}

TEM-1 $\beta$-lactamase, a 263 residue monomeric enzyme confers resistance to $\beta$-lactam antibiotics (19). There have been several studies on its stability and folding kinetics making it a suitable system to study the effect of global suppressor substitutions $(20,21)$. M182T found frequently in clinical isolates in combination with other mutations (R164, E104, M69I, R244) is far from the active site but it restores the stability defects caused by the substitutions near the active site, resulting in increased protein 
expression and thereby conferring drug-resistance in clinical isolates, resulting in extended spectrum $\beta$-lactamase (ESBL) (22). It was previously shown that M182T was able to rescue the folding defect in a naturally isolated variant M69I, thus conferring resistance to inhibitors such as clavulanate (Inhibitor-resistant TEM $\beta$-lactamases, IRTs) as well as in a core engineered substitution L76N, a position which has been shown to be sensitive to substitutions $(7,23)$ with M182T being distant from the primary mutation (Figure 3A).

In the present study, we characterized the global suppressor M182T and observed its effect on stability and folding of known inactive mutants (Figure 3). We determined the MIC and IC 90 of the TEM-1 WT, M182T, M69I, M69I-M182T, L76N and L76N-M182T for both ampicillin and cefotaxime, a third-generation cephalosporin (Figure 3B-C, Additional file 12: Table S6). In line with a previous study, we found that the M182T suppressor alone and the M69I-M182T double mutant have comparable values to that of the WT (24) and M69I respectively (25), however M182T rescues the activity of the inactive enzyme mutant L76N (Figure 3B-C, Additional file 12: Table S6) $(23,26)$. Further the activity of the purified mutants was monitored in vitro with nitrocefin (Figure 3D). The results obtained showed similar effects of the M182T substitution on WT or M69I or L76N background as observed in vivo (Figure 3D and Additional file 5: Figure S5C-E).

The M182T suppressor substitution enhanced both the thermal and chemical stability of the WT protein as well as the inactive mutants M69I and L76N (Figure 3E-F, Additional file 12: Table S6), in agreement with previously published results (27). When compared with WT, M69I and L76N are less stable (Figure 3G). The suppressor alone is $6{ }^{\circ} \mathrm{C}, 1.8 \mathrm{kcal} / \mathrm{mol}$ more stable than the WT, and M69IM182T and L76N-M182T are $7{ }^{\circ} \mathrm{C}, 2 \mathrm{kcal} / \mathrm{mol}$ and $8{ }^{\circ} \mathrm{C}, 1.7 \mathrm{kcal} / \mathrm{mol}$ more stable than the inactive mutants M69I and L76N respectively (Figure 3G).

Refolding (in $0.5 \mathrm{M} \mathrm{GdnCl}$ ) and unfolding (in $2.5 \mathrm{M} \mathrm{GdnCl})$ kinetics for all the mutants $(5 \mu \mathrm{M})$ were also monitored using nanoDSF, in $10 \mathrm{mM}$ HEPES, $300 \mathrm{mM} \mathrm{NaCl}, 10 \%$ glycerol, $\mathrm{pH} 7.0$, at $25^{\circ} \mathrm{C}$. The unfolding trace of WT TEM-1 when fitted to the three-parameter unfolding equation, gives a fitted 
unfolding rate of $0.03 \mathrm{~s}^{-1}$. M182T shows a slightly slower rate of unfolding whereas the inactive mutants M69I and L76N, had two and three fold faster unfolding rates respectively as compared to the WT. The mutant-suppressor pairs however had a slower rate of unfolding as compared to the individual inactive mutants (Figure 3H and Additional file 5: Figure S5B, Additional file 12: Table S6). The refolding rate constants for each of these mutants, were also calculated for both fast and slow phases. The M182T suppressor alone, refolds at a faster rate compared to the WT. The inactive mutants showed slower refolding kinetics than the WT. In the background of the suppressor, however the inactive mutants refold at a faster rate (both fast and slow phase) (Figure 3I and Additional file 5: Figure S5A, Additional file 12: Table S6).

The refolded TEM-1 proteins and the native proteins in the presence of $0.5 \mathrm{M} \mathrm{GdnCl}$ were also subjected to thermal denaturation, and the apparent $\mathrm{T}_{\mathrm{m}}$ was calculated (Figure 3J, Additional file 12: Table S6) which was similar in both the cases. Except for the inactive mutant L76N, all the other mutants showed a proper transition indicating that they were in a folded conformation in the presence of $\mathrm{GdnCl}$ and the $\mathrm{T}_{\mathrm{m}}$ of the refolded suppressors were also higher than the corresponding inactive mutants (Figure 3J). Further, lactamase activity of native and refolded proteins, both in $0.5 \mathrm{M} \mathrm{GdnCl}$, monitored by nitrocefin hydrolysis yielded results consistent with the other studies (Figure 3D and Additional file 5: Figure S5C-E).

These experiments indicate that the M182T suppressor alone and in the mutant-suppressor pairs (M69I-M182T and L76N-M182T) rescues the folding defects of inactive mutants and confers higher thermodynamic and kinetic stability relative to the inactive mutants. This is in contrast to a previous study (7) which indicated that the L76N-M182T double mutant was destabilized relative to the L76N inactive mutant, despite the fact that the double mutant showed higher activity in vivo. We show that the major contribution to stability mediated by the M182T suppressor substitution is a high refolding rate which allows reversible refolding, even in the background of the inactive mutants. 


\section{$\underline{\text { Rescue of common oncogenic mutations by an N239Y global suppressor in p53-DBD }}$}

The transcription factor, p53, acts as a tumor suppressor with multiple anti-proliferative functions upon activation in response to various upstream cellular stress signals (28). Owing to the low thermodynamic stability (29) of its core , DNA Binding Domain (DBD), nearly half of all the human cancers are associated with inactivated p53 proteins, where the mutations primarily located in this domain, destabilise or distort the DBD (30). The basis of such oncogenic mutations can be structural or functional (31). Previous studies have identified second-site suppressor mutations in the DBD which could restore the WT p53 functionality (32). One such suppressor mutation, N239Y in the L3 loop of the DBD, could globally rescue multiple missense mutations located at varying regions of the protein by thermodynamic stabilisation of the inactivated core $(29,31)$. The activity of two of the destabilising oncogenic mutations, located in the core of the DBD, V143A and V157F, were restored by N239Y $(28,29,31,33)$.

In the current study, we aimed to obtain mechanistic insight into the N239Y-mediated suppression of the inactivating p53 mutations, V143A and V157F (Figure 4A). The double mutants V143A-N239Y and V157F-N239Y showed enhanced expression in the soluble fraction in vivo in E. coli, relative to their corresponding inactive mutants. WT and N239Y single suppressor mutant showed comparable soluble expression and yield (Figure 4B). The inactive mutants, V143A and V157F, owing to their low expression levels and aggregation-prone natures, could not be purified or characterised. N239Y, in isolation and in conjunction with the inactive mutants, marginally enhanced the thermal and chemical stabilities of the WT p53 (Figure 4C-D, Additional file 13: Table S7). Relative to the WT protein, the suppressor N239Y alone, and the mutants, V143A-N239Y, V157F-N239Y enhance the apparent thermal stabilities by $\sim 1.3{ }^{\circ} \mathrm{C}, 1{ }^{\circ} \mathrm{C}$ and $3{ }^{\circ} \mathrm{C}$ respectively. The N239Y, V143A-N239Y and V157FN239Y have marginal increments in their thermodynamic stabilities over the WT protein in the range of $\sim 0.1-0.4 \mathrm{kcal} / \mathrm{mol}$ (Figure $4 \mathrm{E}$ ). 
Refolding (in $2 \mathrm{M}$ urea) and unfolding (in 4.4 M urea) kinetics for the WT and mutants were monitored using nanoDSF at $15^{\circ} \mathrm{C}$. The unfolding traces, fitted to five-parameter unfolding equations, yielded comparable slow-phase unfolding rates for the WT and N239Y proteins $\left(0.003 \mathrm{~s}^{-1}\right.$ and $0.0025 \mathrm{~s}^{-1}$ respectively), whereas the unfolding rates for the double mutants were slightly lower than that for the WT $\left(0.0017 \mathrm{~s}^{-1}\right.$ for V143A-N239Y and $0.0019 \mathrm{~s}^{-1}$ for V157F-N239Y) (Figure 4F and Additional file 5: Figure S5G, Additional file 13: Table S7). The fast-phase unfolding rates for the single and double mutants were marginally lower than that for the WT (Additional file 13: Table S7). The refolding traces, also fitted to five-parameter equations, yielded slow-phase refolding rates which were remarkably increased by $\sim 20$ and $\sim 10$ folds for N239Y and V143A-N239Y respectively, relative to the WT. V157F N239Y refolded with a similar slow-phase rate constant, when compared with the WT. With respect to the fast phase, V157F-N239Y refolds faster than the WT by $\sim 3.5$ folds, whereas the N239Y and V143A-N239Y refold with similar or marginal increments when compared with the WT (Figure 4G and Additional file 5: Figure S5F, Additional file 13: Table S7).

The thermal denaturation of the refolded p53 proteins, along with the native proteins in $0.5 \mathrm{M}$ urea as controls were also studied (Figure 4H). All the mutants showed a proper transition indicating that they were in a folded conformation in the presence of Urea. $~ 3{ }^{\circ} \mathrm{C}$ increment was observed for the apparent $\mathrm{T}_{\mathrm{m}}$ of refolded V157F-N239Y relative to that of the refolded WT, whereas the apparent $\mathrm{T}_{\mathrm{m}}$ 's for the refolded proteins of N239Y and V143A-N239Y were similar to that for the refolded WT (Figure 4H, Additional file 13: Table S7).

These observations indicated that the N239Y suppressor mutation likely rescues the inactivated destabilised p53 core by marginal enhancement of the thermodynamic and more importantly the kinetic stability of the proteins containing the suppressor, with the largest effect on the refolding rates.

\section{Effect of global suppressor substitutions in WT background}

In order to further, investigate the role of suppressors on protein stability in the WT background, we performed detailed thermodynamic and kinetic studies of the suppressors alone in CcdB and mRBD 
proteins (Figure 5). In a recent study employing the PIMs L36A, V18D, V18G and V20G (chosen to span a range of stabilities), several other CcdB suppressor substitutions were also identified using yeast surface display coupled to deep sequencing (14). In the present study, we selected three such suppressor substitutions, Y8D, V46L and $\mathrm{S} 60 \mathrm{E}$ with $\Delta \mathrm{T}_{\mathrm{m}}>3{ }^{\circ} \mathrm{C}$ (Figure $5 \mathrm{~A}$ ). The purified proteins were subjected to chemical denaturation (Figure 5B). The suppressors Y8D, V46L and the suppressor S60E were $\sim 3 \mathrm{kcal} / \mathrm{mol}$ and $\sim 4 \mathrm{kcal} / \mathrm{mol}$ respectively more stable than the WT (Figure $5 \mathrm{C}$, Additional file 14: Table S8). The suppressors were also subjected to unfolding (in $4.5 \mathrm{M} \mathrm{GdnCl}$ ) and refolding (in $2 \mathrm{M} \mathrm{GdnCl}$ ) kinetic studies. The unfolding rates of the suppressors were 2-2.5 times slower than the WT (Figure 5D and Additional file 6: Figure S6B, Additional file 15: Table S9), whereas the fast and slow phase refolding rates of the suppressors were 2-5 times and 9-14 times faster than the WT respectively (Figure 5E and Additional file 6: Figure S6A, Additional file 15: Table S9). Further, the proteins were refolded in 1,2, 3 and $4 \mathrm{M} \mathrm{GdnCl}$ and subjected to thermal denaturation. Native protein at the same $\mathrm{GdnCl}$ concentrations was used as control (Figure 5F and Additional file 6: Figure S6EH). The WT could refold back till $2 \mathrm{M} \mathrm{GdnCl,} \mathrm{whereas} \mathrm{the} \mathrm{suppressors} \mathrm{Y8D,} \mathrm{V46L} \mathrm{and} \mathrm{suppressor}$ S60E could refold even at 3 and $4 \mathrm{M} \mathrm{GdnCl}$ respectively (Additional file 6: Figure S6E-H). In all cases, the refolded proteins have a broader transition than the native proteins in $\mathrm{GdnCl}$, likely due to the formation of aggregates during refolding.

Next, we investigated the role of the suppressor substitutions in the context of the receptor binding domain (RBD) of SARS-CoV-2 (34). Using similar saturation suppressor methodology, we recently identified three suppressors of folding defective mutants in this protein (11). These suppressors, D389E, L390M and P527I are located on the protein surface (Figure 5G). When individually introduced into WT mRBD, they show a $\Delta \mathrm{T}_{\mathrm{m}}$ of $\sim 3{ }^{\circ} \mathrm{C}$ (Figure $5 \mathrm{H}$ ) (11). The suppressors were also subjected to unfolding (in $3 \mathrm{M} \mathrm{GdnCl}$ ) and refolding (in $0.5 \mathrm{M} \mathrm{GdnCl}$ ) kinetic studies. The unfolding rates of the suppressors were $\sim 4$ times slower than the WT for the fast and 2 times slower than the WT for slow phases (Figure 5I and Additional file 6: Figure S6D, Additional file 15: Table S9), whereas 
the refolding rates of the suppressors were 2.5-7 times faster than the WT (Figure 5J and Additional file 6: Figure S6C, Additional file 15: Table S9). Further, the proteins were refolded in 0.5, 1, and $2 \mathrm{M}$ $\mathrm{GdnCl}$ and subjected to thermal denaturation with native proteins in the same $\mathrm{GdnCl}$ concentrations as control (Figure 5K). The WT could refold till $1 \mathrm{M} \mathrm{GdnCl,} \mathrm{whereas} \mathrm{the} \mathrm{suppressors} \mathrm{D389E,} \mathrm{L390M}$ and P527I refolded back to the native state even at $2 \mathrm{M} \mathrm{GdnCl}$ (Additional file 6: Figure S6I-K). The binding of the native proteins, native proteins in $0.5 \mathrm{M} \mathrm{GdnCl}$ and refolded proteins in $0.5 \mathrm{M} \mathrm{GdnCl}$ with ACE2-hFc neutralizing antibody were also measured using ProteOn (Figure 5L). All the refolded proteins showed binding to the $\mathrm{ACE} 2 \mathrm{-hFc}$, indicating that the proteins were properly refolded back to their functional conformation (Additional file 6: Figure S6L-O) and that chemical denaturation of RBD was reversible.

\section{$\underline{\text { Structural insights into stabilization by CcdB suppressor mutants }}$}

The structure of the S12G, V46L and S60E mutants of CcdB was solved to resolutions of $1.63 \AA$, 1.35 $\AA$ and $1.93 \AA$ A respectively. (Figure 6).

The structures of S12G, V46L and S60E (Figure 6A, 6D, 6G) consist of a single chain in the asymmetric unit, with two chloride ions. One of the ions, which is also present in the WT structure 3VUB, interacts electrostatically with $\mathrm{H} 85[\mathrm{~N} \varepsilon 2], \mathrm{R} 86[\mathrm{NH} 1], \mathrm{H} 55[\mathrm{~N}]$ and a hydrogen bonding interaction with a symmetry equivalent $\mathrm{T} 7[\mathrm{O} \gamma 1]$. The second $\mathrm{Cl}^{-}$ion in $\mathrm{S} 12 \mathrm{G}$ interacts with $\mathrm{S} 38[\mathrm{~N}]$, $\mathrm{R} 15[\mathrm{NH} 2]$ and a water $\mathrm{O}[220]$. Although there is a water molecule at this position in the WT structure (3VUB), addition of a water in $\mathrm{S} 12 \mathrm{G}$ resulted in an unusually low B-factor whereas a $\mathrm{Cl}^{-}$ion fits well without any negative density and a B-factor of $20 \AA^{2}$. The density for the last residue I101 was not visible in the map for S12G. The electron density map in the region of residues $40-45$ for S12G, 43 45 for V46L and 41-42 for S60E was very poor, as a result the side chains could not be fitted. One of the residues in S12G, R40 lies outside but close to the allowed region of the Ramachandran Plot. The mutant structures are very similar to the WT structure (3VUB) with an RMSD of $0.26,0.39$ and 0.39 Å for S12G (Figure 6B), V46L (Figure 6E) and S60E (Figure 6H) respectively. 
For S12G, the variation is mainly in the loop region between Y8-Y14 and A39-V46, indicated in Figure $6 \mathrm{~B}$ by a star. There are two water molecules (254 and 228) in S12G in place of the two conformers of $\mathrm{S} 12[\mathrm{OH}]$ of $3 \mathrm{VUB}$ (Figure 6C). A cluster of water molecules at a hydrogen bonding distance from G12 stabilizes the loop and anchors it via interactions with the backbone atoms of neighbouring residues (Figure 6C) reducing the average B-factor in this region (Figure 6J). These two water molecules substitute for the hydroxyl group of both the conformers of serine in the WT structure. Since the $\mathrm{S} 12 \mathrm{G}$ has an additional $\mathrm{Cl}^{-}$ion, an additional comparison was done with the structure 4VUB (WT $\mathrm{CcdB}$ ) which has the second $\mathrm{Cl}^{-}$ion in the same position as found in $\mathrm{S} 12 \mathrm{G}$. It was found that although the absolute B-factor of S12G and 4VUB were similar in the 8-12 region and lower than that of 3VUB, it was lowest for S12G in the region 39-46 amongst the three structures. The relative B-factors are very similar in both 3 VUB and 4VUB when normalized, so the 3VUB structure was used as a reference. For V46L, the loop region A39-V46, exhibits a major deviation from WT CcdB, as indicated in Figure $6 \mathrm{E}$ by a star. L46 is involved in a hydrogen-bond interaction with R62 and hydrophobic interactions with M64 (Figure 6F). The hydrogen-bond interactions are formed between the main chain oxygen atom of L46 and side chain nitrogen atoms of R62 (NH1, NH2). The average B-factors of the V46L structure are lower than the WT with the most reductions in the loops 8-14 and 39-46 (Figure 6J). For S60E also the major deviation, is in the starred loop region A39-V46 (Figure 6H). E60 is involved in a series of salt-bridge interactions with R48, H55 and R62 (Figure 6I). The salt bridge interactions are formed between the side chain oxygen atoms of E60 (OE1 and OE2) and side chain nitrogen atoms of R48 (NE, NH1), H55 (ND1, NE1) and R62 (NE). There is a change in the orientation of the mobile R48 side chain resulting in salt bridge interactions with E60 (Figure 6I). The S60E mutation has resulted in reduced B-factor differences between the side chain and main chain in many regions, including R48, resulting in overall stabilisation of the structure. The average B-factors of the S60E structure are also lower than the WT with the most reductions in the loops 8-14 and 39-46 (Figure 6J). 


\section{Thermally stabilized L42E CcdB is not a global suppressor}

While most suppressor mutations described above confer enhanced stability in the WT background, it is not known if all stabilized mutants will act as suppressors. One such CcdB mutant, L42E, that enhanced the thermodynamic stability was characterised. From our previous studies that have characterised a large number of CcdB mutants, L42E was identified to enhance the thermal stability of WT CcdB, but was not identified as a suppressor using yeast surface display $(14,35)$. We therefore introduced the L42E individually in the background of five inactive mutants and the binding to GyrA14 was measured by FACS as described previously $(35,36)$. It was observed that L42E failed to enhance the binding to GyrA14 of any of the inactive mutants (Figure 7A). Next, we characterised the thermodynamic and kinetic stability of the purified L42E protein. We observed that though the thermal and chemical stability of the mutant was higher than the WT (Figure 7B-D, Additional file 16: Table S10), the folding kinetic parameters were similar to WT (Figure 7E-F, Additional file 16: Table S10). We also measured the thermal stability of the refolded proteins in $1.5 \mathrm{M} \mathrm{GdnCl}$ and subjected them to thermal denaturation (Figure 7G, Additional file 16: Table S10). The refolded L42E also had a higher thermal stability than the refolded WT protein (Figure 7G, Additional file 16: Table S10). These observations demonstrate that enhanced thermal stability alone is insufficient to confer a global suppressor property to a mutant. 


\section{Discussion}

In this work we examine the mechanisms by which a second (suppressor) mutation alleviates the protein defects caused by the initial loss of function causing point mutant. Previous studies have shown physically interacting residues to coevolve (37). For a pair of residues in contact, the compensation of stability caused by a defect at one position occurs by shape or charge complementarity at a nearby site in the protein core (2). The location of suppressor mutations may be either spatially proximal or distal from the site of the original mutation. Unlike their proximal counterparts, distal suppressors are generally found on the surface of the protein (38), and are expected to have a WT like phenotype, when present as single mutants (2). Global suppressors are versatile mutations that can rescue the protein from damage caused by a number of non-functional point mutants, located in diverse regions of the structure. Some plausible mechanisms responsible for global suppression are: a) improving the foldability of the protein without impacting stability (7), b) increasing global thermodynamic stability $(5,39,40)$ thereby compensating a folding defect caused by an initial destabilising albeit function altering mutation $(8,26,41), c)$ improving the specific activity of the protein, for example through a mutation at a functionally important residue (6).

In previous studies, we identified several global suppressors of inactivating mutations of the bacterial toxin, $\mathrm{CcdB}(2,14)$. In the present study we characterised the mechanisms of suppression by the E11R and S12G global suppressors in considerable detail, and extended these studies to three other global suppressors, Y8D, V46L and S60E. Non active-site, buried mutations typically affect the levels of correctly folded protein (42). The presence of low levels of active, folded CcdB protein is sufficient to kill the cells and rescue the inactive phenotype caused by the PIMs. This was confirmed in vivo by growth assays and estimation of solubility levels. Equilibrium thermal and chemical denaturation studies reveal a large enhancement in the apparent stability of PIM-suppressor proteins with respect to the PIMs in isolation. Surprisingly, the suppressor mutation E11R shows slightly decreased stability, relative to $\mathrm{WT} \mathrm{CcdB}$, and the remaining suppressors shows marginal improvements in stability. There 
is however, a surprising non-additivity of the apparent stabilising effect of E11R and S12G in the presence and absence of the PIM. This might be attributed to the fact that the stability of the PIMs are difficult to measure accurately because of their aggregation-prone nature.

Kinetic studies were used to further elucidate the mechanism of action of such distal global suppressors. For a protein to remain functional on biologically-relevant time scales, apart from thermodynamic stability, kinetic stabilization plays a significant role (43). Several studies have shown the importance of kinetic stability in the evolutionary optimization of the protein function (44); regulation of activity of several membrane fusion proteins and transcription factors (45-47), functioning of collagen under physiological conditions $(48,49)$ and as a phenotypic determinants $(9)$. Kinetic destabilisation leads to diseases associated with protein misfolding $(50,51)$. Therefore, a mutation which enhances kinetic stability is indeed important in both physiological and biopharmaceutical contexts, for example increasing shelf life of monoclonal antibodies (52).

Relative to the WT protein, in general for the individual suppressors the increment in the folding rate parameters is typically larger than the decrement in the unfolding rate parameters. The ability to refold back faster than WT is consistently observed across all the systems used in this study. This suggests that additional favourable interactions resulting from the mutation are formed prior to the folding transition state, lowering its energy, relative to the unfolded state. In the case of the CcdB S12G, V46L and S60E; $\beta$-lactamase M182T and p53 N329Y mutants, for which crystal structures are available, additional non-covalent interactions present, relative to corresponding WT structure are seen. For these CcdB suppressors, the structural changes are complex and unlikely to be predicted from modelling studies.

The exact mechanism responsible for E11R suppressor-mediated structural stabilisation cannot be currently assigned due to the unavailability of structures. In order to probe the electrostatics of this charge-reversal stabilising mutation, Tanford-Kirkwood electrostatic calculations have been performed using the TKSA-MC server. A significant stabilisation of E11R is observed across a wide 
$\mathrm{pH}$ range from 2 to 12, relative to the WT (53). Electrostatic potential surface maps generated using the UCSF Chimera package show the appearance of a substantial positive - potential surface patch in the loop from residues 8 - 15 harbouring the E11R mutation (Additional file 1: Figure S1I-J) (54). Thus, it can be speculated that the cluster of positive charges in this loop may prevent the formation of misfolded intermediates during folding of the suppressor.

None of the CcdB suppressor mutations are seen in naturally occurring paralogs. The positions 10,12 and 46 in $\mathrm{CcdB}$ are involved in interactions with one of the ligands- the antitoxin CcdA. The loop from residues 9 to $15\left({ }^{9} \mathrm{KRESRYR}^{15}\right)$ between the two $\beta$-strands contains four residues with their side chains directed towards the CcdA helix. E11 points away from the CcdA helix and mutating it to arginine will abolish the E11- R15 H-bond within the loop and may alter loop conformation. The presence of R10 and S12 in CcdB, in spite of the enhanced stabilities of R10G and S12G proteins, compared to WT, can be explained by the loss of native H-bonds that R10 and S12 make with CcdA, on mutations to glycine. S60E, though not involved directly in CcdA interaction, alters the conformation and rigidity of the 39-46 loop that contacts CcdA and might therefore affect CcdB function. V46L also similarly affects the rigidity of the 8-14 and 39-46 loops important for CcdA binding and GyrA14 rejuvenation (55). In $\mathrm{CcdB}$, the E11R suppressor mutation had lower stability than WT and conversely, the L42E mutant which is more stable than WT, failed to act as a suppressor. These data demonstrate that while most suppressor mutations show small stabilization effects in the WT background, increased stability is neither necessary nor sufficient for global suppressor mutations.

In the present work, we focus on protein folding kinetics studied in vitro whereas in vivo, for several proteins, folding occurs co-translationally and/or is assisted by molecular chaperones (56). How suppressor mutations affect the kinetics and yield of co-translational or chaperone mediated folding/unfolding is beyond the scope of the present work and it is likely that the different proteins studied make use of different chaperone systems and span both cytoplasmic and periplasmic folding compartments. Nevertheless, it is clear from the present studies that acceleration in folding kinetics in 
vitro is associated with enhanced yield of active protein in vivo whether in the context of E. coli or yeast $(14,35)$. A previous study from our laboratory, which looked at the effects of overexpression of a number of different chaperones on ccdB mutant phenotypes reported the rescue of inactive, folding defective $\mathrm{CcdB}$ mutants occurred exclusively in the two E. coli strains overexpressing ATPindependent chaperones (SecB and Trigger factor), that act early in in vivo folding and not in the strains overexpressing ATP-dependent chaperones that act in the later stages of the folding pathway (9). One of the important inferences from our study was that mutational effects on folding, rather than stability influenced $\mathrm{CcdB}$ mutant activity in vivo, consistent with the present results. Till date, there have been reports on the detailed investigation of the Hsp70 and Hsp90-mediated stability and activity of p53 DBD (57-59), the GroEL/ES chaperonin system making transient interactions and inhibiting the folding of $\beta$-lactamase precursor $(60,61)$, and of a strongly bound complex of the GroEL chaperone with the receptor-binding domain of the SARS CoV2 spike protein (62). However, none of these discuss the effects of suppressor mutations on chaperone mediated folding kinetics.

We have summarized the effect of the suppressor mutations characterized in the present study on various thermodynamic and kinetic parameters in the background of both WT and inactive mutants (Figure 8, Table 1). For the PIM/Suppressor pair analysis, we excluded the p53DBD double mutants since we did not have the corresponding inactive mutants for comparison. For the thermodynamic parameters, we observed that as compared to the WT, the individual suppressors have marginal enhancement in thermal stability $\left(\Delta \mathrm{T}_{\mathrm{m}}\right)$ and significant changes in the chemical stability $\left(\Delta \Delta \mathrm{G}^{\circ}\right)$ (Figure 8A). However, in the background of the inactive mutants, the suppressors caused significant enhancement in both the thermal $\left(\Delta \mathrm{T}_{\mathrm{m}}\right)$ and chemical stabilities $\left(\Delta \Delta \mathrm{G}^{\circ}\right)$ (Figure $\left.8 \mathrm{~B}\right)$. For the kinetic parameters, we observe that except for one suppressor which has a similar rate constant as the WT for the slow phase of refolding and one PIM-suppressor pair which had a similar burst phase of refolding as compared to the inactive mutant, all other suppressors or PIM-suppressor pairs have an effect on both the refolding and unfolding kinetic parameters. To further delineate the parameters which are 
most effected by the suppressor mutations we calculate the average fold change of each parameter by the suppressor mutations (Table 1) as follows:

$\mathrm{P}_{\mathrm{avg}}=\frac{\sum_{1}^{n} P \boldsymbol{i}}{n}, \ldots \ldots$ Equation 1

where $\mathrm{P}_{\mathrm{avg}}$ is the average fold change of a parameter $\mathrm{P}$,

$\mathrm{P}_{\mathrm{i}}$ is the fold change of that parameter in the background of the suppressor which is $=\mathrm{P}_{\mathrm{i}}=\mathrm{P}_{\text {supp }} / \mathrm{P}_{\mathrm{wt}}$, or

$\mathrm{P}_{\mathrm{i}}=\mathrm{P}_{\text {(inactive, suppressor) }} / \mathrm{P}_{\text {inactive }}$

and $\mathrm{n}$ is the number of mutants. A non-parametric Mann Whitney test is performed to show that the mean of the distributions of each of these values of $P_{i}$ is significantly higher (or lower) than 1 (Figure 8C-D).

Values of $\mathrm{P}_{\mathrm{i}}$ are summarized in Table 1. and confirm that the effect of the suppressor mutants is statistically significant for the refolding rates in background of both WT and inactive mutations.

For relatively stable proteins such as $\mathrm{CcdB}\left(\mathrm{T}_{\mathrm{m}}=66{ }^{\circ} \mathrm{C}\right)$ and $\mathrm{mRBD}\left(\mathrm{T}_{\mathrm{m}}=50.4{ }^{\circ} \mathrm{C}\right)$ which are not folding defective or aggregation prone, it is not easy to isolate mutants with improved stability, or to screen for suppressors. This can be overcome by first introducing a destabilizing mutation (Parent Inactive Mutation or PIM) into a saturation mutagenesis library, followed by screening for suppressors (2). We have recently shown that such an approach $(11,14)$ can robustly be used to identify multiple individual suppressor mutations. While each suppressor significantly improves the activity of the PIM, as seen in the present work, these typically have only a small stabilization effect when introduced in the WT background i.e. the apparent stabilization of PIM by suppressor is not quantitatively transferable to WT. Despite this, when these individual suppressors are combined into the WT background, substantial and largely additive stabilization of the protein can be achieved $(11,14,35)$. Further, the effects of suppressors on the refolding rate parameters were larger than on the unfolding 
rate parameters. This was observed across multiple suppressors in multiple proteins, suggesting this to be the primary mechanism through which such suppressors function.

\section{Conclusions}

Most individual, global suppressors result in small stability enhancements relative to WT, which can be combined to yield significant stability increases. However, thermodynamic stabilisation is neither necessary nor sufficient for suppressor action. Individual suppressors greatly enhance the foldability of folding defective, loss of function mutants, primarily through an increase in the refolding rate constants and burst phase amplitude. The much larger apparent stabilization of suppressors in the context of folding defective mutants relative to wildtype is likely because the true thermodynamic stabilities of the folding defective mutants are difficult to measure accurately because of their aggregation-prone nature. Suppressors promote increased in-vivo solubility and yield, as well as regain-of-function phenotypes. These observations hold true across these diverse protein systems with proteins from both prokaryotes and eukaryotes, including both cytoplasmic and secreted proteins, suggesting these are general results. The results also show that such mutations cannot be easily predicted by existing computational predictors of protein stability effects, and thus genetic screens remain essential to isolate such mutants. 


\section{Materials and Methods}

\section{Plasmids and Host Strains}

CcdB: The ccdB gene was cloned under the control of $\mathrm{P}_{\mathrm{BAD}}$ promoter in pBAD24 vector (15). Two Escherichia coli host strains Top10pJAT and Top 10GyrA were used. Top10pJAT is a CcdB sensitive strain and was used for screening the phenotypes. The pJAT8araE plasmid which encodes for the arabinose transporter area was introduced into the TOP10 strains to ensure that in all cells there is approximately equal amounts of arabinose uptake (63). Top10GyrA is resistant to the action of CcdB toxin and was used for monitoring the expression of mutant proteins. The strain contains a GyrA462 mutation in its genome that prevents CcdB from binding to Gyrase (10). The Saccharomyces cerevisiae strain EBY100 was used for yeast surface display to monitor the binding and expression of the displayed proteins cloned in the yeast surface display vector pPNLS (64).

TEM-1 and p53-DBD: WT and mutant TEM-1 $\beta$ lactamase with a C-terminal 6xHistidine tag were cloned and expressed under the control of the T7 promoter in the pET-24a vector. The native signal sequence was used for efficient secretion in the Escherichia coli host strain BL21 (DE3) pLysE. WT and mutant p53-DBD genes with N-terminal 6xHistidine tag were cloned and expressed under the control of the T7 promoter in the pET-15b vector. Escherichia coli host strain BL21 Rosetta (DE3) was used for expressing the p53-DBD proteins.

mRBD: mRBD WT and mutants were expressed from mammalian cell culture as described previously (34) under the control of the CMV promoter along with a tPA signal sequence for efficient secretion.

\section{$\underline{\text { Mutagenesis }}$}

CcdB: For single mutants V5F, Y8D, E11R, S12G, V18W, V20F, L36A, V46L, S60E and L83S, as well as for double mutants, V18W-E11R, V20F-E11R, L36A-E11R and L83S-E11R, the ccdB gene was amplified in two fragments with the desired point mutations. The fragments had overlapping regions (introduced during PCR) of 15-20 nucleotides, which were then recombined using Gibson assembly or in vivo recombined with pPNLS vector for YSD as described earlier (36). Amplification 
was done using Phusion Polymerase from NEB as per the manufacturer's protocol. The double mutants V5F-S12G, V18W-S12G, V20F-S12G, L36A-S12G and L83S-S12G were synthesized by GeneArt (Germany).

TEM-1 and p53-DBD: The TEM-1 $\beta$ lactamase WT and mutants M182T, M69I, M69I-M182T, L76N, L76N-M182T and p53-DBD WT and mutants N239Y, V143A, V157F, V143A-N239Y, V157F-N239Y were synthesized by GenScript (USA).

mRBD (331-532): The mRBD (331-532) codon optimised for human cell expression was synthesized by GenScript (USA) (34). For single mutants D389E, L390M and P527I, the RBD gene was amplified in two fragments with the desired point mutations. The fragments had overlapping regions (introduced during PCR) of 15-20 nucleotides, which were then recombined using Gibson assembly. Amplification was done using Phusion Polymerase from NEB as per the manufacturer's protocol.

\section{Protein expression and purification}

CcdB: WT CcdB and all mutants were expressed from the arabinose promoter $\mathrm{P}_{\mathrm{BAD}}$ in the pBAD24 vector in the $\mathrm{CcdB}$ resistant Top10Gyrase strain of $E$. coli. The purification of the $\mathrm{CcdB}$ mutants were carried out as described previously (17). Briefly, $500 \mathrm{~mL}$ of LB medium (HiMedia) was inoculated with $1 \%$ of the primary inoculum and grown at $37{ }^{\circ} \mathrm{C}$ until the $\mathrm{OD}_{600}$ reached 0.6 . Cells were then induced with $0.2 \%(\mathrm{w} / \mathrm{v})$ arabinose and grown at $37^{\circ} \mathrm{C}$ for 5 hours for WT CcdB, Y8D, E11R, S12G, V46L, S60E and the double mutants V18W-S12G, V20F-S12G, L36A-S12G and L83S-S12G, at 25 ${ }^{\circ} \mathrm{C}$ overnight for the inactive mutants V18W, V20F, L36A and L83S and at $20{ }^{\circ} \mathrm{C}$ overnight for the double mutants L36A-E11R and L83S-E11R. Cells were harvested, re-suspended in HEG resuspension buffer pH 7.4 (10 mM HEPES, 50 mM EDTA, 10\% glycerol containing 10 mM PMSF) and lysed by sonication. The supernatant was incubated with Affi-gel15 (Biorad) coupled to CcdA peptide (residues 46-72) and incubated overnight at $4{ }^{\circ} \mathrm{C}$. The unbound fraction was removed and washed with five times the bed volume of coupling buffer $\mathrm{pH} 8.3$ (0.05 M Sodium Bicarbonate, $0.5 \mathrm{M}$ 
Sodium Chloride). The elutions were carried out with $0.2 \mathrm{M}$ Glycine, $\mathrm{pH} 2.5$ into a tube containing an equal volume of $400 \mathrm{mM}$ HEPES, $\mathrm{pH} 8.4,4{ }^{\circ} \mathrm{C}(9,17)$. The eluted fractions were subjected to $15 \%$ Tricine SDS-PAGE and the protein concentration was determined. Fractions containing pure protein were pooled and stored at $-80{ }^{\circ} \mathrm{C}$.

TEM-1 $\beta$ lactamase: The TEM-1 $\beta$ lactamase mutants were purified as described previously (23) with slight modifications. The recombinant BL-21 ( $\lambda \mathrm{DE} 3$, plysE) strains were grown in TB medium at 37 ${ }^{\circ} \mathrm{C}$ containing $50 \mu \mathrm{g} / \mathrm{mL}$ kanamycin until the $\mathrm{OD}_{600}$ reached 0.8 and protein expression was induced by addition of $1.0 \mathrm{mM}$ IPTG. The induced cultures were grown overnight with shaking at $30{ }^{\circ} \mathrm{C}$ and were harvested by centrifugation. The periplasmic fraction was obtained by osmotic shock by resuspending first in lysis buffer, pH 7.0 (10 mM HEPES, 0.5 mM EDTA, 20\% sucrose, 0.05\% SDS, lysozyme and protease inhibitor) at $37{ }^{\circ} \mathrm{C}$ with shaking for $1 \mathrm{hr}$, followed by addition of an equal volume of ice cold milliQ water, incubated at $4{ }^{\circ} \mathrm{C}$ for an hour, followed by addition of $100 \mu \mathrm{L}$ of $2 \mathrm{M}$ $\mathrm{MgCl}_{2}$. The clarified lysates were loaded on $2 \mathrm{ml}$ of Q-Sepharose fast flow (Amersham Biosciences, Uppsala, Sweden). The elutes obtained by a gradient of 100-500mM NaCl in $10 \mathrm{mM}$ HEPES, $10 \%$ glycerol $\mathrm{pH}$ 7.0, were further subjected to Ni-NTA purification by mixing with $2 \mathrm{~mL}$ of Ni-Sepharose resin (GE Healthcare) for $4 \mathrm{hrs}$ and the bound proteins were eluted with a gradient of 100-500 $\mathrm{mM}$ imidazole in $10 \mathrm{mM}$ HEPES, $300 \mathrm{mM} \mathrm{NaCl}, 10 \%$ glycerol ( $\mathrm{pH}$ 7.0). The purified proteins were subjected to $15 \%$ Tricine SDS-PAGE, concentrated, buffer exchanged to remove imidazole, and finally stored in storage buffer (10 mM HEPES, $300 \mathrm{mM} \mathrm{NaCl}, 10 \%$ glycerol, $\mathrm{pH} 7.0)$ at $-80{ }^{\circ} \mathrm{C}$ until further use. Yield for all mutants varied from $0.5-10 \mathrm{mg} / \mathrm{L}$.

p53-DBD: The p53-DBD mutants were purified as described previously (65) with slight modifications. The recombinant BL-21 Rosetta (DE3) strains were grown in TB medium at $37{ }^{\circ} \mathrm{C}$ containing $100 \mu \mathrm{g} / \mathrm{mL}$ ampicillin until the $\mathrm{OD}_{600}$ reached 1.0. $100 \mu \mathrm{M} \mathrm{ZnSO}_{4}$ was added and incubated at $25{ }^{\circ} \mathrm{C}$ for 30 mins. Protein expression was induced by addition of $1.0 \mathrm{mM}$ IPTG. The induced cultures were grown for 20 hours with shaking at $25^{\circ} \mathrm{C}$ and were harvested by centrifugation. Cells 
were harvested, re-suspended in ly sis buffer pH $7.2\left(50 \mathrm{mM} \mathrm{NaH}_{2} \mathrm{PO}_{4}, 100 \mathrm{mM} \mathrm{NaCl}\right.$, containing 10 $\mathrm{mM}$ PMSF and $10 \mathrm{mM}$ DTT) and lysed by sonication. The clarified lysates were loaded first with 2 $\mathrm{ml}$ of DEAE Sepharose fast flow (GE Healthcare) and the elutes obtained by a gradient of 100-500 $\mathrm{mM} \mathrm{NaCl}$ in $50 \mathrm{mM} \mathrm{NaH}_{2} \mathrm{PO}_{4}, \mathrm{pH}$ 7.2, were further subjected to Ni-NTA purification by mixing with $2 \mathrm{~mL}$ of Ni-Sepharose resin (GE Healthcare) for $4 \mathrm{hrs}$. The bound proteins were eluted with a gradient of $100-500 \mathrm{mM}$ imidazole in $50 \mathrm{mM} \mathrm{NaH}_{2} \mathrm{PO}_{4}, 500 \mathrm{mM} \mathrm{NaCl}$, (pH 7.2) containing $10 \mathrm{mM}$ DTT. The purified proteins were subjected to $15 \%$ Tricine SDS-PAGE, concentrated and finally stored in storage buffer $\left(50 \mathrm{mM} \mathrm{NaH} \mathrm{PO}_{4}, 500 \mathrm{mM} \mathrm{NaCl}, 500 \mathrm{mM}\right.$ imidazole, $10 \mathrm{mM}$ DTT, pH 7.2) at $-80{ }^{\circ} \mathrm{C}$ until further use. The inactive mutants V143A, V157F, could not be used for biophysical studies because of their low expression, solubility, poor yields and high tendencies towards aggregation after purification. Yield for the WT and the mutants varied from $0.5-2 \mathrm{mg} / \mathrm{L}$.

mRBD (331-532): Expression and purification of the mRBD and the single mutants D389E, L390M and P527I was carried out as described previously (34). Briefly, proteins were expressed by transient transfection of Expi293 cells and purified by Ni-NTA chromatography. The eluted fractions were pooled and dialysed thrice using a 3-5 kDa (MWCO) dialysis membrane (40mm flat width) (Spectrum Labs) against 1XPBS, $\mathrm{pH} 7.4$ (storage buffer). The eluted fractions were subjected to $15 \%$ Tricine SDS-PAGE and the protein concentration was determine by measuring the $\mathrm{A}_{280}$ and using an extinction coefficient of $33850 \mathrm{M}^{-1} \mathrm{~cm}^{-1}$.

\section{$\underline{\text { In vivo activity of the different CcdB mutants }}$}

WT and mutant CcdB were transformed into E. coli Top10pJAT, grown for 1 hour in $1 \mathrm{ml} \mathrm{LB}$ media containing $0.2 \%$ glucose (highest repressor level to avoid leaky expression). After 1 hour, the cells were pelleted and glucose was removed by subjecting cells to three washes with $1 \mathrm{ml}$ LB. Finally, equal amounts of cells resuspended in $1 \mathrm{ml}$ of LB media and serially diluted were spotted on seven agar plates (LB agar plates containing $100 \mu \mathrm{g} / \mathrm{mL}$ ampicillin, $20 \mu \mathrm{g} / \mathrm{mL}$ gentamycin) containing various amounts $(\%)$ of glucose (repressor) and arabinose (inducer) concentrations (i.e. $2 \times 10^{-1} \%$ glu, 
$4 \times 10^{-2} \%$ glu, $7 \times 10^{-3} \%$ glu, $0 \%$ glu/ara, $2 \times 10^{-5} \%$ ara, $7 \times 10^{-5} \%$ ara and $2 \times 10^{-2} \%$ ara) at $37^{\circ} \mathrm{C}$. Since active CcdB protein kills the cells, colonies are obtained only for mutants that show an inactive phenotype under the above conditions (9).

\section{$\underline{\text { In vivo Solubility Estimation }}$}

CcdB: Solubility levels were monitored for all the single and double mutants in E. coli Top10Gyrase in the presence of $0.2 \%$ arabinose as described previously (9). Cultures were grown in LB media, induced with $0.2 \%$ arabinose at an $\mathrm{OD}_{600}$ of 0.6 and grown for 5 hours at $37^{\circ} \mathrm{C} .2 \times 10^{9}$ cells were centrifuged (1800g, $10 \mathrm{~min}, \mathrm{RT})$. The pellet was resuspended in $500 \mu \mathrm{L}$ HEG buffer $\mathrm{pH} 7.4(10 \mathrm{mM}$ HEPES, 50 mM EDTA, 10\% glycerol containing $10 \mathrm{mM}$ PMSF) and sonicated. $250 \mu \mathrm{L}$ was taken as Total Cell Lysate and the remaining $250 \mu \mathrm{L}$ was centrifuged $\left(11000 \mathrm{~g}, 10 \mathrm{~min}, 4^{\circ} \mathrm{C}\right) .250 \mu \mathrm{L}$ was taken as supernatant and the pellet was resuspended in $250 \mu \mathrm{L}$ HEG buffer $\mathrm{pH} 8.4$ and all the fractions were subjected to $15 \%$ Tricine SDS-PAGE. Solubility of all mutants was quantitated by estimating relative amounts of $\mathrm{CcdB}$ in supernatant and pellet fractions by the geldoc software (Quantity One) $(9,66)$.

p53 DBD: Solubility levels were monitored for all the single and double mutants in E. coli BL-21 Rosetta (DE3) cells. Cultures were grown in LB media till they attain $\mathrm{OD}_{600}$ values of 1.0, followed by incubation with $100 \mu \mathrm{M} \mathrm{ZnSO}_{4}$ at $25^{\circ} \mathrm{C}$ for 30 minutes and induction with $1.0 \mathrm{mM}$ IPTG, for 20 hours at $25^{\circ} \mathrm{C} .2 \times 10^{9}$ cells were centrifuged $(1800 \mathrm{~g}, 10 \mathrm{~min}, \mathrm{RT})$ and the pellet was resuspended in $500 \mu \mathrm{L}$ lysis buffer $\mathrm{pH} 7.2\left(50 \mathrm{mM} \mathrm{NaH}{ }_{2} \mathrm{PO}_{4}, 100 \mathrm{mM} \mathrm{NaCl}\right.$, containing $1 \mathrm{mM}$ PMSF and $10 \mathrm{mM}$ DTT) and sonicated. $250 \mu \mathrm{L}$ was taken as Total Cell Lysate and the remaining $250 \mu \mathrm{L}$ was centrifuged $\left(11000 \mathrm{~g}, 10 \mathrm{~min}, 4{ }^{\circ} \mathrm{C}\right) .250 \mu \mathrm{L}$ was taken as supernatant and the pellet was resuspended in $250 \mu \mathrm{L}$ lysis buffer $\mathrm{pH} 7.2$ and all the fractions were subjected to $15 \%$ Tricine SDS-PAGE. Solubility of all mutants was quantitated by estimating relative amounts of the p53 DBD protein in supernatant and pellet fractions by the geldoc software (Quantity One) $(9,66)$. 


\section{Thermal stability measurements by TSA and nanoDSF}

CcdB: The thermal shift assay was conducted in an iCycle Q5 Real Time Detection System (Bio-Rad, Hercules, CA) using $4 \mu \mathrm{M}$ of the CcdB protein in $200 \mathrm{mM}$ HEPES, pH 8.4 and 2.5X Sypro orange dye in a 96-well iCycleiQPCR plate. The plate was heated from 20 to $90^{\circ} \mathrm{C}$. with a ramp of $0.5^{\circ} \mathrm{C} / \mathrm{min}$. The fluorescence data following CCD detection was plotted as a function of temperature and fitted to a standard, four parameter sigmoidal equation $y=L L+\{U L-L L\} /\{1+\exp ((T m-T) / a)\}$, where $y$ is the observed fluorescence signal, LL and UL are the minimum and maximum intensities in the transition region respectively, ' $a$ ' is the slope of the transition, $T_{m}$ is the melting temperature, and $T$ is the experimental temperature (16).

nanoDSF (Prometheus NT.48) was also used to carry out thermal unfolding experiments of the CcdB mutants. The assays were carried out with $4 \mu \mathrm{M}$ of each protein and the apparent thermal stability $\left(\mathrm{T}_{\mathrm{m}}\right)$ was determined by monitoring the changes in the fluorescence ratio $(\mathrm{F} 350 / \mathrm{F} 330)$ as a function of temperature as described earlier (17).

Briefly, the first derivative of the ratio $\left(F^{\prime}=\frac{d \frac{F 350}{F 330}}{d T}\right)$ is normalised using Equation 2:

Normalised Fluorescence $\left(F_{N}{ }^{\prime}\right)=\frac{y-y_{\min }}{y_{\max }-y_{\min }} \ldots(2)$,

where $y$ is the first derivative of the observed fluorescence (F350/F330 ratio), $\mathrm{y}_{\min }$ is value of the first derivative minimum and $y_{\max }$ is the value of the first derivative maximum.

A subset of the $\mathrm{CcdB}$ mutants were also refolded in $1.5 \mathrm{M} \mathrm{GdnCl}$ and subjected to thermal denaturation with native protein in $1.5 \mathrm{M} \mathrm{GdnCl}$ as a control. For thermal denaturation, the samples were filled into capillaries and then placed the instrument. The capillaries were then heated from 20 to $90{ }^{\circ} \mathrm{C}$ with a ramp of $1{ }^{\circ} \mathrm{C} / \mathrm{min}$. For the highly stable mutants Y8D, V46L and S60E as well as WT, refolding was carried out in 1, 2, 3, 4 and $5 \mathrm{M} \mathrm{GdnCl}$ and refolded protein subjected to thermal denaturation. Native protein in 1, 2, 3, 4 and $5 \mathrm{M} \mathrm{GdnCl}$ was also taken as control.

TEM-1 $\beta$ lactamase, p53-DBD, and mRBD (331-532): nanoDSF (Prometheus NT.48) was also used 
to probe the thermal unfolding of the TEM-1 $\beta$ lactamase, p53-DBD and mRBD mutants. The assays were carried out with $4 \mu \mathrm{M}$ of each protein and the apparent thermal stability ( $\left.\mathrm{T}_{\mathrm{m}}\right)$ was determined by monitoring the changes in the fluorescence ratio (F350/F330) as a function of temperature.

For the TEM-1 $\beta$ lactamase, the ratio F350/F330 is normalised using Equation 3:

$$
\text { Normalised Fluorescence }\left(F_{N}\right)=\frac{y-y_{\min }}{y_{\max }-y_{\min }} \ldots(3)
$$

where $\mathrm{y}$ is the observed fluorescence (F350/F330 ratio), $\mathrm{y}_{\min }$ is value of the ratio minimum and $\mathrm{y}_{\max }$ is the value of the ratio maximum.

For the p53-DBD, the first derivative of the 330 wavelength $\left(F 330^{\prime}=\frac{d F 330}{d T}\right)$ is normalised using Equation 4:

$$
\text { Normalised Fluorescence }\left(F 330_{N}{ }^{\prime}\right)=\frac{y-y_{\min }}{y_{\max }-y_{\min }} \ldots(4) \text {, }
$$

where $y$ is the first derivative of the observed fluorescence (F330), $y_{\min }$ is value of the first derivative minimum and $y_{\max }$ is the value of the first derivative maximum at 330 .

For the mRBD mutants, normalization was carried out similar to $\mathrm{CcdB}$ mutants using Equation 2.

Samples were heated from 20 to $90{ }^{\circ} \mathrm{C}$ with a ramp of $1{ }^{\circ} \mathrm{C} / \mathrm{min}$. TEM-1 $\beta$ lactamase and $\mathrm{p} 53 \mathrm{DBD}$ were refolded in $0.5 \mathrm{M} \mathrm{GdnCl}$ and $0.5 \mathrm{M}$ urea respectively and subjected to thermal denaturation along with the native proteins in $0.5 \mathrm{M} \mathrm{GdnCl}$ and $0.5 \mathrm{M}$ urea as their respective controls. For the highly stable mRBD mutants D389E, L390M and P527I as well as WT, refolding was carried out in 0.5, 1, 2, and $3 \mathrm{M} \mathrm{GdnCl}$ and refolded protein subjected to thermal denaturation with native protein in $0.5,1$, 2, and $3 \mathrm{M} \mathrm{GdnCl}$ as controls.

\section{Isothermal denaturation}

CcdB: Equilibrium unfolding experiments of the CcdB mutants were carried out by nanoDSF (Prometheus NT.48) as described previously (17). Briefly, all the CcdB mutant proteins were overnight dialysed four times in total of 2 litres of $200 \mathrm{mM}$ HEPES, pH 8.4 using Tube-O-Dialyser (4kDa MWCO, GBiosciences). The chemical stability $\left(\mathrm{C}_{\mathrm{m}}\right)$ was then determined using $5 \mu \mathrm{M}$ of proteins by 
monitoring the changes in the fluorescence ratio (F350/F330), after overnight incubation at $25{ }^{\circ} \mathrm{C}$ containing various concentrations of the denaturant $(\mathrm{GdnCl})$. The $\mathrm{GdnCl}$ concentrations were estimated from refractive index measurements using a refractometer. The data was analyzed using Sigmaplot ${ }^{\mathrm{TM}}$ for Windows ${ }^{\mathrm{TM}}$ scientific graphing software, and the plots were fitted to a two-state unfolding model $\left(\mathrm{N}_{2} \leftrightarrow 2 \mathrm{U}\right)$. The fraction unfolded for all CcdB mutants was calculated as described $(15,17)$ and is summarized below.

The spectroscopic signal $(Y)$ of a protein solution $\left(\mathrm{F}_{350} / \mathrm{F}_{330}\right.$ ratio by nano-DSF) is related to the fraction of unfolded protein $\left(f_{\mathrm{u}}\right)$ by:

$$
f_{\mathrm{u}}=\left(Y-Y_{\mathrm{f}}\right) /\left(Y_{\mathrm{u}}-Y_{\mathrm{f}}\right)(5)
$$

where $Y_{\mathrm{f}}$ and $Y_{\mathrm{u}}$ are the values of $Y$ for the folded and unfolded protein respectively. These change linearly with the denaturant concentration ([D]), as follows:

$$
\begin{gathered}
Y_{\mathrm{f}}=y_{\mathrm{f}}+m_{\mathrm{f}}[\mathrm{D}](6) \\
Y_{\mathrm{u}}=y_{\mathrm{u}}+m_{\mathrm{u}}[\mathrm{D}](7)
\end{gathered}
$$

where $y_{\mathrm{f}}$ and $y_{\mathrm{u}}$ are the folded and unfolded parameters at zero denaturant concentration. $m_{\mathrm{f}}$ and $m_{\mathrm{u}}$ are the denaturation dependence of $Y$ for the folded and unfolded state respectively. $\mathrm{C}_{\mathrm{M}}$ is the denaturant concentration at which $f_{u}=1$. The data are analyzed to yield to obtain the free energy of unfolding at zero denaturant, $\Delta \mathrm{G}^{\mathrm{o}}=\Delta \mathrm{G}^{\mathrm{o}} \mathrm{D}^{-} \mathrm{m}_{\text {equi }}[\mathrm{D}]$, where $\Delta \mathrm{G}^{\mathrm{o}}{ }_{\mathrm{D}}$ is the measured free energy of denaturation at denaturant concentration $[D]$ and $m_{\text {equi }}$ encapsulates the denaturant dependence of $\Delta \mathrm{G}^{\mathrm{o}} \mathrm{D}(67)$. For homodimeric $\mathrm{CcdB}, \Delta \mathrm{G}^{\mathrm{o}} \mathrm{D}$ is related to $\mathrm{f}_{\mathrm{u}}$ by the following equation:

$f_{u}=1 / 2\left[-z \pm \sqrt{ }\left(z^{2}+4 z\right)\right]$, where $z=e^{-\Delta G^{\circ}}{ }_{D} / R T / 2 P_{t}$, where $P_{t}$ is the total protein concentration in terms of monomer units, $\mathrm{R}$ is the universal gas constant and $\mathrm{T}$ is the absolute temperature (15).

TEM-1 $\beta$ lactamase and p53-DBD: Equilibrium unfolding experiments of the monomeric TEM-1 $\beta$ lactamase and p53-DBD mutants were also carried out by nanoDSF (Prometheus NT.48). The stability to chemical denaturation $\left(\mathrm{C}_{\mathrm{m}}\right)$ was determined by monitoring the changes in the fluorescence ratio (F350/F330), after overnight incubation at $25{ }^{\circ} \mathrm{C}$ in the final storage buffer for TEM-1mutants 
containing various concentrations of the denaturant $(\mathrm{GdnCl})$ and overnight incubation at $15{ }^{\circ} \mathrm{C}$ in the final storage buffer for p53-DBD mutants containing various concentrations of the denaturant (Urea). The data was analyzed using Sigmaplot ${ }^{\mathrm{TM}}$ for Windows ${ }^{\mathrm{TM}}$ scientific graphing software, and the data were fit to a two-state unfolding model $(\mathrm{N} \leftrightarrow \mathrm{U})$. Isothermal denaturation was carried out at a fixed protein concentration of $5 \mu \mathrm{M}$ for all the proteins. The fraction unfolded for all the TEM-1 $\beta$ lactamase and p53-DBD mutants were calculated in a similar way as described above.

For all the various classes of proteins used in the study (CcdB, p53-DBD and TEM-1- $\beta$-lactamase), the isothermal equilibrium denaturation experiments (for a particular protein) are performed in the same nanoDSF instrument (Prometheus NT.48) at the same LED settings (100\%) and at identical temperatures and buffer conditions for each set of WT and mutant proteins.

\section{$\underline{\text { Refolding and unfolding kinetics }}$}

CcdB: Refolding and unfolding kinetics for all the mutants were monitored by nanoDSF using PR.Time Control software (Prometheus NT.48) at $25^{\circ} \mathrm{C}$, pH 8.4 as described previously (17). Briefly, the refolding rates were measured using different concentrations $(1 \mu \mathrm{M}-5 \mu \mathrm{M})$ of the dialysed proteins in $200 \mathrm{mM}$ HEPES, $\mathrm{pH} 8.4$ denatured in $0.2-4 \mathrm{M} \mathrm{GdnCl}$ and subsequently diluted to final denaturant concentrations varying from $0.1 \mathrm{M}$ to $1.5 \mathrm{M}$ of $\mathrm{GdnCl}$, and the changes in the fluorescence ratio (F350/F330) were monitored as a function of time. To measure the unfolding kinetics, protein in native buffer (200 mM HEPES, $\mathrm{pH}$ 8.4) was diluted into the same buffer containing $8 \mathrm{M} \mathrm{GdnCl}$ to a final concentration of $\mathrm{GdnCl}$ varying from 2 to $4 \mathrm{M}$ and the changes in the fluorescence ratio (F350/F330) were monitored as a function of time. Refolding kinetic traces of fluorescence intensity from $0.1 \mathrm{M}$ to 1.5 $\mathrm{M} \mathrm{GdnCl}$ as a function of time for different $\mathrm{CcdB}$ mutants were normalized from 0 to 1 between native and denatured baseline, as described previously $(9,17,18)$. Unfolding kinetic traces of fluorescence intensity from 2 to $4 \mathrm{M} \mathrm{GdnCl}$ as a function of time for different $\mathrm{CcdB}$ mutants in 200 $\mathrm{mM}$ HEPES, $\mathrm{pH} 8.4$ were normalized from 0 to 1 between native and denatured baseline, as described previously $(17,18)$. For the stable CcdB mutants (Y8D, V46L and S60E as well as WT CcdB) refolding 
and unfolding was carried out in $2 \mathrm{M}$ and 4.5 M GdnCl respectively in $200 \mathrm{mM}$ HEPES, pH 8.4 at 25 ${ }^{\circ} \mathrm{C}$ and normalisation was done as described above. The data was analyzed using Sigmaplot ${ }^{\mathrm{TM}}$ for Windows ${ }^{\mathrm{TM}}$ scientific graphing software and plots were fitted to a 5 parameter equation for exponential decay for refolding $\left(\mathrm{y}=\mathrm{a} 0+\mathrm{a} 1 * \exp \left(-\mathrm{kf}_{1} * \mathrm{x}\right)+\mathrm{a} 2 * \exp \left(-\mathrm{kf}_{2} * \mathrm{x}\right)\right)$, and a 3 parameter exponential rise for unfolding $\left(\mathrm{y}=\mathrm{A}_{0}+\mathrm{A} 1 *\left(1-\exp \left(-\mathrm{ku}_{1} * \mathrm{x}\right)\right)\right)$ as described previously $(18)$, where $\mathrm{x}$ is the time of refolding/unfolding. Both refolding and unfolding studies of all the mutants were also carried out at three different denaturant concentration and the observed rates were plotted as a function of denaturant condition to determine the refolding and unfolding $\mathrm{m}$ values $\left(\mathrm{M}^{-1} \mathrm{~s}^{-1}\right)$. This was further used to extrapolate the unfolding and refolding rates of all the mutants to $0 \mathrm{M} \mathrm{GdnCl}$ concentration for relative comparison as described by the following equation $\mathrm{k}_{\mathrm{obs}}=\mathrm{k}_{0}+\mathrm{m}_{\mathrm{kinetic}(\mathrm{F} / \mathrm{U})}[\mathrm{D}]$, where $\mathrm{k}_{\mathrm{obs}}$ is the observed refolding/unfolding rate constant in $\mathrm{s}^{-1}$ at a particular denaturant concentration, $\mathrm{k}_{0}$ is the extrapolated refolding/unfolding rate constant at $0 \mathrm{M}$ denaturant in $\mathrm{s}^{-1}, \mathrm{~m}_{\text {kinetic(F) }}, \mathrm{m}_{\text {kinetic(U) }}$ is the slope of a plot of the refolding or unfolding rate constant respectively as a function of denaturant concentration in units of $\mathrm{M}^{-1} \mathrm{~S}^{-1}$ and $\mathrm{D}$ is the denaturant concentration in units of $\mathrm{M}$.

TEM-1 $\beta$ lactamase, p53-DBD and mRBD (331-532): Refolding and unfolding kinetics of the TEM$1 \beta$ lactamase and mRBD mutants at $25^{\circ} \mathrm{C}$ and of the p53-DBD mutants at $15^{\circ} \mathrm{C}$ were also monitored by nanoDSF using PR.Time Control software (Prometheus NT.48). Briefly, the refolding rates for the TEM-1 $\beta$ lactamase and the mRBD mutants were measured using $5 \mu \mathrm{M}$ of the proteins denatured in storage buffer containing $3 \mathrm{M} \mathrm{GdnCl}$ and subsequently diluted to a final concentration of $0.5 \mathrm{M}$ of $\mathrm{GdnCl}$, and the changes in the fluorescence ratio (F350/F330) were monitored as a function of time. For the p53 DBD mutants, the refolding rates were measured using $4 \mu \mathrm{M}$ of the proteins denatured in the final storage buffer containing $4 \mathrm{M}$ urea and subsequently diluted to a final concentration of $2 \mathrm{M}$ urea.

To measure the unfolding kinetics, protein in native storage buffer was diluted into buffer containing 2.5 M GdnCl for TEM-1 $\beta$ lactamase and $3 \mathrm{M} \mathrm{GdnCl}$ for mRBD mutants and 4.4 M Urea for p53- 
DBD and the changes in the fluorescence ratio (F350/F330) were monitored as a function of time. Refolding and unfolding kinetic traces were normalized from 0 to 1 between native and denatured baselines. The data for the TEM-1 $\beta$ lactamase mutants was analyzed using Sigmaplot ${ }^{\mathrm{TM}}$ for Windows ${ }^{\mathrm{TM}}$ scientific graphing software and plots were fitted to a 5 parameter equation for exponential decay for refolding $\left(\mathrm{y}=\mathrm{a} 0+\mathrm{a} 1 * \exp \left(-\mathrm{kf}_{1} * \mathrm{x}\right)+\mathrm{a} 2 * \exp \left(-\mathrm{kf}_{2} * \mathrm{x}\right)\right)$, yielding slow and fast phase rate constants and a 3 parameter exponential rise for unfolding $\left(\mathrm{y}=\mathrm{A}_{0}+\mathrm{A} 1 *\left(1-\exp \left(-\mathrm{ku}_{1} * \mathrm{x}\right)\right)\right)$ as described above, where $\mathrm{x}$ is the time of refolding/unfolding. The data for the mRBD mutants was analyzed using Sigmaplot $^{\mathrm{TM}}$ for Windows ${ }^{\mathrm{TM}}$ scientific graphing software and plots were fitted to a 3 parameter equation for exponential decay for refolding $\left(\mathrm{y}=\mathrm{a}_{0}+\mathrm{a} 1 * \exp \left(-\mathrm{kf}_{1} * \mathrm{x}\right)\right)$, and a 5 parameter exponential rise for unfolding $\left(\mathrm{y}=\mathrm{A}_{0}+\mathrm{A} 1 *\left(1-\exp \left(-\mathrm{ku}_{1} * \mathrm{x}\right)\right)+\mathrm{a} 2 *\left(1-\exp \left(-\mathrm{ku}_{2} * \mathrm{x}\right)\right)\right)$, yielding slow and fast phase rate constants as described above, where $\mathrm{x}$ is the time of refolding/unfolding. The data for the p53 DBD mutants was analyzed using Sigmaplot ${ }^{\mathrm{TM}}$ for Windows ${ }^{\mathrm{TM}}$ scientific graphing software and plots were fitted to a 5 parameter equation for exponential decay for refolding $\left(y=a_{0}+a 1 * \exp \left(-k f_{1} * x\right)+a 2 * \exp (-\right.$ $\left.\mathrm{kf}_{2} * \mathrm{x}\right)$ ), yielding slow and fast phase rate constants and a 5 parameter equation for exponential rise for unfolding $\left(\mathrm{y}=\mathrm{A}_{0}+\mathrm{A} 1 *\left(1-\exp \left(-\mathrm{ku}_{1} * \mathrm{x}\right)\right)+\mathrm{a} 2 *\left(1-\exp \left(-\mathrm{ku}_{2} * \mathrm{x}\right)\right)\right)$, yielding slow and fast phase rate constants as described above, where $\mathrm{x}$ is the time of refolding or unfolding.

For all the various classes of proteins used in the study $(\mathrm{CcdB}, \mathrm{p} 53-\mathrm{DBD}, \mathrm{TEM}-1-\beta$-lactamase and mRBD), the kinetics experiments (for a particular protein) are performed in the same nanoDSF instrument (Prometheus NT.48) at the same LED settings (100\%) and at identical temperatures and buffer conditions for each set of WT and mutant proteins.

\section{Binding of native and refolded CcdB proteins to GyrA14 by MicroScale Thermophoresis (MST)}

6.6 $\mu \mathrm{M}$ GyrA14 (in 1X PBS) was labeled using the RED-NHS Monolith ${ }^{\mathrm{TM}}$ Protein Labeling Kit (NanoTemper Technologies) according to the manufacturer's instructions. After labeling, the protein was eluted by gravity flow using a PD MiniTrap ${ }^{\text {TM }}$ G-25 (GE Healthcare) Sephadex column into 200 mM HEPES, pH 8.4 which was also used as assay buffer for MST experiments. Labeled GyrA14 was 
used as target at a concentration of $70 \mathrm{nM}$, while non-fluorescent CcdB proteins were titrated in a 1:1 dilution series (highest concentrations range between $100 \mathrm{nM}$ and $10 \mu \mathrm{M}$ ). The binding of labeled GyrA14 to refolded CcdB mutants in $1.5 \mathrm{M} \mathrm{GdnCl}$ (also in $0.1 \mathrm{M} \mathrm{GdnCl}$ for V18W, V18W-S12G, V20F and V20F-S12G) as well as native CcdB proteins, not subjected to refolding, in presence of 1.5 M GdnCl (also in 0.1 M GdnCl for V18W, V18W-S12G, V20F and V20F-S12G) was measured. Samples were loaded into Monolith ${ }^{\mathrm{TM}}$ NT.115 MST Standard Capillaries (NanoTemper Technologies) and binding measured using a Monolith NT.115 instrument with MO.Control software at room temperature (LED/excitation power setting 100\%, MST power setting 80-100\%). Data was analyzed using MO.Affinity Analysis software (version 2.2.5, NanoTemper Technologies) at different standard MST-off times.

Affinity and thermal tolerance of the CcdB proteins measured by Surface Plasmon Resonance $\underline{(\text { SPR })}$

All SPR experiments were performed with a Biacore 2000 (Biacore, Uppsala, Sweden) optical biosensor at $25{ }^{\circ} \mathrm{C} .35 \mu \mathrm{g} / \mathrm{mL}$ of GyrA14 was used for immobilization at $30 \mu \mathrm{l} / \mathrm{min}$ flow rate for 180 s. 1000 resonance units of GyrA14 were attached by standard amine coupling to the surface of a research-grade CM5 chip. A sensor surface (without GyrA14) that had been activated and deactivated served as a negative control for each binding interaction. The E11R CcdB mutant proteins (E11R, L36A-E11R and L83S-E11R) were overnight dialysed three times against a total 6 litres of 1XPBS, pH 7.4 using Tube-O-Dialyser (4 kDa MWCO, GBiosciences). The remaining proteins were in 200 mM HEPES-0.1 M glycine, $\mathrm{pH}$ 8.4. Different concentrations of the dialysed CcdB mutants were run across each sensor surface in a running buffer of PBS ( $\mathrm{pH} 7.4$ ) containing $0.005 \%$ Tween surfactant. Protein concentrations ranged from $3 \mathrm{nM}$ to $5 \mu \mathrm{M}$. Both association and dissociation were measured at a flow rate of $30 \mu \mathrm{l} / \mathrm{min}$. In all cases, the sensor surface was regenerated between binding reactions by one to two washes with $4 \mathrm{M} \mathrm{MgCl}_{2}$ for $10-30 \mathrm{~s}$ at $30 \mu \mathrm{L} / \mathrm{min}$. Each binding curve was corrected for nonspecific binding by subtraction of the signal obtained from the negative control flow cell. The 
kinetic parameters were obtained by fitting the data to a simple 1:1 Langmuir interaction model by using BIA EVALUATION 3.1 software as described previously $(9,68)$. Thermal tolerance of the CcdB mutants E11R, S12G, L36A, L36A-E11R and L36A-S12G and WT CcdB using $500 \mathrm{nM}$ of protein was assessed by their ability to bind GyrA14 after heat stress. The protein sample was incubated at 40 ${ }^{\circ} \mathrm{C}$ and $80{ }^{\circ} \mathrm{C}$ respectively for $1 \mathrm{~h}$ in a PCR cycler (BioRad) with a heated lid to prevent evaporation. The samples were cooled to $25^{\circ} \mathrm{C}$ and binding affinity to GyrA14 was determined by SPR experiments as described above The fraction of active protein following thermal stress was quantitated by measuring the RUs at the end of the association time period relative to those for the same protein incubated throughout at $25^{\circ} \mathrm{C}$. This was designated as Residual activity.

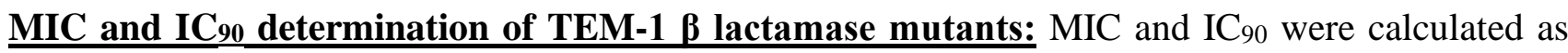
described previously (23). Briefly, E. coli BL-21 ( $\lambda \mathrm{DE} 3$, plysE) was used as the host strain for determining the ampicillin and cefotaxime MIC of the pET24a-TEM-1-WT, M182T, M69I, M69IM182T, L76N, L76N-M182T constructs. Cultures were grown overnight at $37^{\circ} \mathrm{C}$ in LB broth with 50 $\mu \mathrm{g} / \mathrm{mL}$ kanamycin. . The overnight cultures were diluted $1: 10^{4}$ and $30 \mu \mathrm{L}$ was inoculated into $500 \mu \mathrm{L}$ of fresh LB broth supplemented with $50 \mu \mathrm{g} / \mathrm{mL}$ kanamycin, $100 \mu \mathrm{M}$ IPTG inducer, and various concentrations of ampicillin and cefotaxime. The concentrations of ampicillin used for MIC determination were $0,25,50,100,200,300,400,500,600,800,1000,1500,2000,2500,3000$ and $4000 \mu \mathrm{g} / \mathrm{mL}$. The concentrations of cefotaxime tested were $0,1,2,3,4,5,6,8,10,15,20$ and 30 $\mu \mathrm{g} / \mathrm{mL}$. The cultures were then incubated at $37{ }^{\circ} \mathrm{C}$ with shaking for $24 \mathrm{hrs}$ following which $\mathrm{OD}_{600}$ measurements were carried out on Varioskan Flash (ThermoScientific) using Nunclon delta surface plates (ThermoScientific). and the MIC was determined by recording the lowest concentration of ampicillin or cefotaxime on which no growth was observed. In practice, this was an all or none phenomenon (25). 
$\mathrm{IC}_{90}$ was derived directly from the plate data measurements. Briefly, E. coli BL-21 ( $\lambda \mathrm{DE} 3$, plysE) containing the pET24a plasmid that encodes TEM-1 $\beta$-lactamase mutants was grown overnight in LB broth with $50 \mu \mathrm{g} / \mathrm{mL}$ kanamycin. Overnight cultures were diluted 1:100 into LB broth with $50 \mu \mathrm{g} / \mathrm{mL}$ kanamycin and incubated for $4 \mathrm{hrs}$ at $37^{\circ} \mathrm{C}$ to mid-log phase (OD $\left.600 \sim 0.6\right)$. Ten-fold serial dilutions of each culture were made, and $100 \mu \mathrm{L}$ of each dilution was spread onto LB agar plates containing 100 $\mu \mathrm{M}$ IPTG inducer and 0-4000 $\mu \mathrm{g} / \mathrm{mL}$ ampicillin and $0-50 \mu \mathrm{g} / \mathrm{mL}$ of cefotaxime, in a series of twofold increases. After incubation for $24 \mathrm{hrs}$ at $37{ }^{\circ} \mathrm{C}$, colony forming units (cfu) on each plate were counted to calculate the $\mathrm{cfu} / \mathrm{mL}$ of culture, and $\mathrm{IC}_{90}$ was defined as the concentration of ampicillin or cefotaxime that reduces $\mathrm{cfu} / \mathrm{mL}$ of culture by $\geq 90 \%$ (23).

Nitrocefin assay of TEM-1 $\beta$ lactamase mutants: TEM-1 $\beta$-lactamase activity was assayed as described previously (7). Briefly the rate of nitrocefin $(50 \mu \mathrm{M})$ hydrolysis was observed at $486 \mathrm{~nm}$ at $25{ }^{\circ} \mathrm{C}$ for 60 minutes in $10 \mathrm{mM}$ HEPES, $300 \mathrm{mM} \mathrm{NaCl}, 10 \%$ glycerol (pH 7.0) using $10 \mathrm{nM}$ native protein, native protein in $0.5 \mathrm{M} \mathrm{GdnCl}$ and refolded protein in $0.5 \mathrm{M} \mathrm{GdnCl}$. Activity measurements were carried out on Varioskan Flash (ThermoScientific) using Nunclon delta surface plates (ThermoScientific).

\section{SPR-binding of native, native in presence of $\mathrm{GdnCl}$ and refolded $\mathrm{mRBD}$ proteins with}

immobilized ACE2-hFc: Binding studies of various mRBD mutants with ACE2-hFc neutralizing antibody were carried out using the ProteOn XPR36 Protein Interaction Array V.3.1 from Bio-Rad as described previously (34). Briefly, following activation of the GLM sensor chip with EDC and sulfoNHS (Sigma), Protein G (Sigma) was coupled at $10 \mu \mathrm{g} / \mathrm{mL}$ in the presence of $10 \mathrm{mM}$ sodium acetate buffer $\mathrm{pH} 4.5$ at $30 \mu \mathrm{L} / \mathrm{min}$ for 300 seconds until $~ 3500-4000 \mathrm{RU}$ was immobilized. After quenching the excess sulfo-NHS esters using $1 \mathrm{M}$ ethanolamine, $1000 \mathrm{RU}$ of ACE2-hFc was immobilized at a flow rate of $5 \mu \mathrm{g} / \mathrm{mL}$ for 100 seconds on various channels except one blank channel that served as the reference channel. Native mRBD proteins, proteins in $0.5 \mathrm{M} \mathrm{GdnCl}$ and refolded protein in $0.5 \mathrm{M}$ 
$\mathrm{GdnCl}$ were passed at a flow rate of $30 \mu \mathrm{L} / \mathrm{min}$ for 200 seconds over the chip surface, followed by a dissociation step of 400 seconds. A lane without any immobilization was used to monitor non-specific binding. After each kinetic assay, the chip was regenerated in $0.1 \mathrm{M}$ Glycine- $\mathrm{HCl}$ (pH 2.7). $50 \mathrm{nM}$ of the mRBD proteins in $1 \mathrm{X}$ PBS were used in all cases for the binding studies. The response units for each of the native protein, native protein in $0.5 \mathrm{M} \mathrm{GdnCl}$ and refolded proteins in $0.5 \mathrm{M} \mathrm{GdnCl}$ was used for relative comparisons. For the studies carried out in $\mathrm{GdnCl}$, the running buffer did not have any $\mathrm{GdnCl}$ and the jumps obtained in all the channels were removed after reference subtraction.

\section{Crystallization of CcdB mutants}

The purified mutants of CcdB, S12G, V46L and S60E CcdB, in 1xPBS pH 7.4 and $1 \mathrm{mM}$ EDTA at a concentration of $5 \mathrm{mg} / \mathrm{ml}$ was screened for crystallization with Hampton Research screens by the sitting drop method using the Mosquito crystallization robot facility at NCBS/Instem. Plates were incubated at $18{ }^{\circ} \mathrm{C}$. Crystals appeared in a few conditions after approximately 20 days. Two conditions had mountable crystals: $0.2 \mathrm{M}$ calcium chloride dihydrate, 20\% w/v PEG 3350, pH 5.1 (PEG/Ion 1, condition 7) and 0.2 M ammonium chloride, 20\% w/v PEG 3350, pH 6.3 (PEG/Ion 1, condition 9). The initial crystals diffracted to $\sim 2.5 \AA$. Conditions were further optimized to obtain single crystals for better diffraction quality. The best crystals were obtained in the condition $0.15 \mathrm{M}$ calcium chloride dihydrate, 20\% w/v PEG 3350 for S12G; 0.20 M calcium chloride dihydrate, 25\% w/v PEG 3350, pH 5.1 with $20 \%$ glycerol (cryo) for V46L; $0.20 \mathrm{M}$ calcium chloride dihydrate, $10 \% \mathrm{w} / \mathrm{v}$ PEG 3350; pH 5.1 with $20 \%$ glycerol (cryo) for S60E, with a protein:precipitant ratio of $1: 2$ at $18^{\circ} \mathrm{C}$ using the hanging drop method.

\section{$\underline{\text { Data collection and processing of CcdB mutants }}$}

Diffraction data was collected at 100K using Rigaku FR-X with R-AXIS IV++ detector facility at NCBS/Instem for S12G. For V46L, diffraction data was collected at 100K using XRD2 beamline with Dectris Pilatus-6M detector facility at Elettra synchrotron, Trieste, Italy. For S60E, diffraction data 
was collected at $100 \mathrm{~K}$ using Rigaku MicroMax-007HF with mar345dtb detector facility at homesource MBU, IISc. The crystals diffracted to $1.63 \AA$, $1.35 \AA$ and $1.93 \AA$ for S12G, V46L and S60E respectively. Data was processed using iMosflm $(69,70)$ with an overall completeness of $90.6 \%$ for S12G, 100\% for V46L and 97.5\% for S60E. For S12G, the crystal belonged to the C2 space group, with the unit cell parameters, while the pointless predicted I2. Thus, the data was re-scaled in I 2 with unit cell parameters $\mathrm{a}=35.57 ; \mathrm{b}=36.53 ; \mathrm{c}=67.53$ and $\beta=93.69^{\circ}$. The V46L and S60E crystals belonged to the $\mathrm{C} 2$ space group with unit cell parameters $\mathrm{a}=75.10 ; \mathrm{b}=36.76 ; \mathrm{c}=35.91$ and $\beta=$ $115.19^{\circ}$ for $\mathrm{V} 46 \mathrm{~L}$ and $\mathrm{a}=74.81 ; \mathrm{b}=36.64 ; \mathrm{c}=35.67$ and $\beta=114.97^{\circ}$ for $\mathrm{S} 60 \mathrm{E}$. The structure was solved by molecular replacement using PHASER (71) with 3VUB (72) as the starting model. After iterative cycles of refinement using Refmac $(73,74)$ and manual model building using Coot $(75,76)$, the final model consisted of 816 protein atoms, 95 water and two $\mathrm{Cl}^{-}$ion with an $\mathrm{R}_{\text {factor }}$ and $\mathrm{R}_{\text {free }}$ of 22.8 and 26.9 respectively for S12G. For V46L, the final model consisted of 814 protein atoms, 167 water and two $\mathrm{Cl}^{-}$ion with an $\mathrm{R}_{\text {factor }}$ and $\mathrm{R}_{\text {free }}$ of 16.2 and 18.4 respectively. For $\mathrm{S} 60 \mathrm{E}$, the final model consisted of 820 protein atoms, 98 water and two $\mathrm{Cl}^{-}$ion with an $\mathrm{R}_{\text {factor }}$ and $\mathrm{R}_{\text {free }}$ of 17.0 and 21.4 respectively. Composite omit maps were calculated around the $12^{\text {th }}, 46^{\text {th }}$ and $60^{\text {th }}$ residue for $S 12 \mathrm{G}$ and S60E respectively. The final model was validated using the validation server (https://validate.wwpdb.org). Data processing and refinement statistics are given in Additional file 17: S1. The server "https://swift.cmbi.umcn.nl/servers/html/listavb.html" was used for calculating the average B-factors.

\section{Analysis of expression and GyrA14 binding of CcdB mutants on the yeast cell surface}

Plasmids expressing Aga2p fusions of L42E, inactive mutants (V5F, V18W, V20F, L36A, L83S), the double mutants of L42E made in the background of the inactive mutants, and WT CcdB were transformed into Saccharomyces cerevisiae EBY100 cells as described (35). Briefly, the amount of CcdB protein expressed on the yeast cell surface was estimated by chicken anti-HA antibodies from Bethyl labs (1:600 dilution) and the GyrA14 binding activity on the yeast cell surface was estimated 
by incubating the induced CcdB mutants with 100 nM FLAG tagged GyrA14, followed by washing with FACS buffer and subsequent incubation with mouse anti-FLAG antibodies, at a dilution ratio of 1:300 as described previously (35). This was followed by washing the cells twice with FACS buffer, and incubating with goat anti-chicken antibodies conjugated to Alexa Fluor 488 (1:300 dilution) for expression, and rabbit anti-mouse antibodies conjugated to Alexa Fluor 633 (1:1600 dilution) for binding, for 20 minutes at $4{ }^{\circ} \mathrm{C}$. The flowcytometry was performed using a BD Aria III instrument. 


\section{Declarations:}

Conflict of interest statement: None.

Ethics Approval and consent to participate: Not Applicable.

Consent for publication: Not Applicable.

Data availability: The crystal structures of the CcdB mutants have been deposited in PDB with PDB IDs: 7EPG (CcdB S12G), 7EPJ (CcdB V46L) and 7EPI (CcdB S60E). The validation reports of the structures are submitted along with the manuscript. The structures will be available after publication. The data relevant to the figures in the paper have been made available within the article and in the supplementary information section. Further information and requests for resources and reagents should be directed to and will be fulfilled by the Lead Contact, Prof. Raghavan Varadarajan (varadar@iisc.ac.in). Lead contact for the material availability: Prof. Raghavan Varadarajan (varadar@iisc.ac.in). All unique/stable reagents generated in this study are available from the Lead Contact without restriction.

\section{Competing interests: None.}

Funding: This work was funded in part by a grant to RV from the Department of Biotechnology, grant number-BT/COE/34/SP15219/2015, DT.20/11/2015), Government of India and from the Bill and Melinda Gates Foundation (INV-005948). We also acknowledge funding for infrastructural support from the following programs of the Government of India: DST FIST, UGC Centre for Advanced study, Ministry of Human Resource Development (MHRD), and the DBT IISc Partnership Program. The NCBS X-ray Facility was supported by Grant BT/PR5081/INF/156/2012 from the DBT. The MBU, IISc X-ray Facility is supported by DST-SERB grant IR/SO/LU-003/2010. The funders had no role in study design, data collection and interpretation, or the decision to submit the work for publication. 
Author Contributions: R.V. G.C. and J.B. designed the experiments. G.C. performed the experiments and analyzed the data for Parent inactive mutants, single and double mutants of S12G, single mutants Y8D, V46L, L42E, S60E of CcdB and TEM-1 $\beta$-lactamase mutants and mRBD mutants. J.B. performed the experiments and analyzed the data for, single and double mutants of E11R. G.C. and J.B. purified the p53-DBD mutants and J.B. performed the experiments and analyzed the data for the p53-DBD mutants. G.C. and J.B. purified the S12G, V46L and S60E for crystal set up and K.M. and P.G. screened the conditions, set up the crystals and solved the structure for S12G, V46L and S60E. S.A. cloned and purified the Y8D, V46L, L42E, S60E, CcdB mutants and the mRBD mutants. S.A. cloned the double mutants of L42E CcdB and performed the FACS studies. R.V, G.C., J.B. wrote most of the manuscript with critical inputs and review from all other authors.

Acknowledgements: G.C. and J.B. acknowledge Ministry of Human Resource Development for their fellowships. S.A. is thankful to Department of Biotechnology (BT/IN/EU-INF/15/RV/19-20) for his research fellowship. K.M. is thankful to Department of Science and Technology (DST)-Science and Engineering Research Board for financial support, sanction order no: PDF/2017/002641. Dr. Parveen Goyal is supported by the DBT/Wellcome Trust India Alliance Fellowship [grant number IA/E/16/1/502999]. We are thankful to Dr. Sivaramaiah Nallapeta, Head Business Operations, Nano Temper Technologies and Dr. Saji Menon, Application Specialist, Nano Temper Technologies for the nano-DSF and MST facility. Prof. S. Ramaswamy, Senior Professor, Institute of Stem cell Science and Regenerative Medicine is acknowledged for the use the X-ray crystallography facility for the diffraction data collection for the S12G mutant. For the V46L mutant, data was collected at the Elettra synchrotron facility, for S60E data was collected at home source, MBU, IISc. We acknowledge them all. We thank the beamline staff at the Elettra XRD2 particularly Dr. Raghurama Hegde for beamline support. Access to the XRD2 beamline at the Elettra synchrotron, Trieste was made possible through a grant-in-aid from the Department of Science and Technology, India, vide grant number DSTO-1668. We thank Dr. Mahavir Singh, (Indian Institute of Science) for providing the BL21-Rosetta (DE3) 
strain. Transfection of the mRBD was carried out by Mohammad Suhail Khan and Kawkab Kanjo assisted with ProteOn Studies. We thank them both. The assistance of Nonavinakere Seetharam Srilatha is duly acknowledged for the SPR experiments. We thank Arunabh Athreya for helping with the data collection for V46L mutant at the synchrotron facility. We also thank all the members of the RV lab for their valuable suggestions.

Statistical analysis: All the experiments are carried out in biological replicates $(n=2)$, and the listed errors are the standard error derived from the values obtained for individual replicates. For the nanoDSF and MST measurements, each experiment has been carried out twice, each time with two sets of capillaries $(n=4)$ and the listed errors are the standard error derived from the values obtained for individual replicates. The SPR experiments in Additional file 4: Figure S4 have been performed once at each concentration with four different concentrations of the protein and the listed error is the standard error derived from the values at multiple concentrations. The $\mathrm{P}$ values for comparing the kinetic parameters, were analysed with a two-tailed Mann Whitney test using the GraphPad Prism software 8.0.0 (* indicates $\mathrm{P}<0.05, * *$ indicates $\mathrm{P}<0.005$, *** indicates $\mathrm{P}<0.0005$ ).

Abbreviations: WT: Wild type; CcdB: Controller of Cell Division or Death B Protein; DBD: DNA Binding Domain; RBD: Receptor Binding Domain; ESBL: extended spectrum $\beta$-lactamase; PIMs: parent inactive mutants; nanoDSF: nano Differential Scanning Fluorimeter; SPR: Surface Plasmon Resonance; MST: MicroScale Thermophoresis; GdnCl: Guanidinium Hydrochloride 


\section{References:}

1. Melero C, Ollikainen N, Harwood I, Karpiak J, Kortemme T. Quantification of the transferability of a designed protein specificity switch reveals extensive epistasis in molecular recognition. Proc Natl Acad Sci. 2014;111(43):15426-31.

2. Sahoo A, Khare S, Devanarayanan S, Jain PC. Residue proximity information and protein model discrimination using saturation-suppressor mutagenesis. Elife. 2015;4:e09532.

3. Melamed D, Young DL, Miller CR, Fields S. Combining Natural Sequence Variation with High Throughput Mutational Data to Reveal Protein Interaction Sites. PLoS Genet. 2015;11(2):1-21.

4. Poon A, Davis BH, Chao L. The coupon collector and the suppressor mutation: Estimating the number of compensatory mutations by maximum likelihood. Genetics. 2005;170(3):1323-32.

5. Araya CL, Fowler DM, Chen W, Muniez I, Kelly JW, Fields S. A fundamental protein property, thermodynamic stability, revealed solely from large-scale measurements of protein function. Proc Natl Acad Sci. 2012;109(42):16858-63.

6. Hecht MH, Sauer RT. Phage lambda repressor revertants. Amino acid substitutions that restore activity to mutant proteins. J Mol Biol. 1985;186(1):53-63.

7. Sideraki V, Huang W, Palzkill T, Gilbert HF. A secondary drug resistance mutation of TEM-1 $\beta$-lactamase that suppresses misfolding and aggregation. Proc Natl Acad Sci. 2001;98(1):2838.

8. Bershtein S, Goldin K, Tawfik DS. Intense Neutral Drifts Yield Robust and Evolvable Consensus Proteins. J Mol Biol. 2008;379(5):1029-44.

9. Tripathi A, Gupta K, Khare S, Jain PC, Patel S, Kumar P, et al. Molecular Determinants of Mutant Phenotypes, Inferred from Saturation Mutagenesis Data. Mol Biol Evol. 2016;33(11):2960-75.

10. Bernard P CM. Cell killing by the F plasmid CcdB protein involves poisoning of DNAtopoisomerase II complexes. J Mol Biol. 1992;226(3):735-745.

11. Ahmed S, Khan MS, Gayathri S, Singh R, Kumar S, Patel UR, et al. A Stabilized, Monomeric, Receptor Binding Domain Elicits High-Titer Neutralizing Antibodies Against All SARS-CoV2 Variants of Concern. Front Immunol. 2021;12:5214.

12. Jain PC, Varadarajan R. A rapid, efficient, and economical inverse polymerase chain reactionbased method for generating a site saturation mutant library. Anal Biochem. 2014;449(1):90-8.

13. Adkar B V., Tripathi A, Sahoo A, Bajaj K, Goswami D, Chakrabarti P, et al. Protein model discrimination using mutational sensitivity derived from deep sequencing. Structure. 2012;20(2):371-81. 
14. Ahmed S, Manjunath K, Chattopadhyay G, Varadarajan R. Stabilizing proteins through saturation suppressor mutagenesis. bioRxiv 2022 Jan 1;2021.08.07.455542.

15. Bajaj K, Chakshusmathi G, Bachhawat-Sikder K, Surolia A, Varadarajan R. Thermodynamic characterization of monomeric and dimeric forms of $\mathrm{CcdB}$ (controller of cell division or death B protein). Biochem J. 2004;380(2):409-17.

16. Niesen FH, Berglund H VM. The use of differential scanning fluorimetry to detect ligand interactions that promote protein stability. Nat Protoc. 2007;9(2):2212-21.

17. Chattopadhyay G, Varadarajan R. Facile measurement of protein stability and folding kinetics using a nano differential scanning fluorimeter. Protein Sci. 2019;28(6):1127-34.

18. Baliga C, Varadarajan R, Aghera N. Homodimeric Escherichia coli Toxin CcdB (Controller of Cell Division or Death B Protein) Folds via Parallel Pathways. Biochemistry. 2016;55(43):6019-31.

19. Huang W, Petrosino J, Hirsch M, Shenkin PS, Palzkill T. Amino acid sequence determinants of $\beta$-lactamase structure and activity. J Mol Biol. 1996;258(4):688-703.

20. Vanhove $\mathbf{M}$, Raquet $\mathrm{X}$, Frère $\mathbf{J}$-M. Investigation of the folding pathway of the TEM-1 $\beta$ lactamase. Proteins Struct Funct Bioinforma. 1995;22(2):110-8.

21. Vanhove M, Lejeune A, Pain RH. $\beta$-Lactamases As Models for Protein-Folding Studies. Cell Mol Life Sci. 1998;54(4):372-7.

22. Wang X, Minasov G, Shoichet BK. Evolution of an antibiotic resistance enzyme constrained by stability and activity trade-offs. J Mol Biol. 2002;320(1):85-95.

23. Marciano DC, Pennington JM, Wang X, Wang J, Chen Y, Thomas VL, et al. Genetic and Structural Characterization of an L201P Global Suppressor Substitution in TEM-1 $\beta$ Lactamase. J Mol Biol. 2008;384(1):151-64.

24. Knies JL, Cai F, Weinreich DM. Enzyme Efficiency but Not Thermostability Drives Cefotaxime Resistance Evolution in TEM-1 $\beta$-Lactamase. Mol Biol Evol. 2017;34(5):1040-54.

25. Huang W, Palzkill T. A natural polymorphism in $\beta$-lactamase is a global suppressor. Proc Natl Acad Sci. 1997;94(16):8801-6.

26. Brown NG, Pennington JM, Huang W, Ayvaz T, Palzkill T. Multiple Global Suppressors of Protein Stability Defects Facilitate the Evolution of Extended-Spectrum TEM $\beta$-Lactamases. J Mol Biol. 2010;404(5):832-46.

27. Wang X, Minasov G, Shoichet BK. The structural bases of antibiotic resistance in the clinically derived mutant $\beta$-lactamases TEM-30, TEM-32, and TEM-34. J Biol Chem. 2002;277(35):32149-56.

28. Baroni TE, Wang T, Qian H, Dearth LR, Truong LN, Zeng J, et al. A global suppressor motif 
for p53 cancer mutants. Proc Natl Acad Sci. 2004;101(14):4930-5.

29. Nikolova P, Henckel J, Lane D, Fersht A. Semirational design of active tumor suppressor p53 DNA binding. Proc Natl Acad Sci. 1998;95:14675-80.

30. Pérez Cañadillas JM, Tidow H, Freund SM V, Rutherford TJ, Ang HC, Fersht AR. Solution structure of p53 core domain: Structural basis for its instability. Proc Natl Acad Sci. 2006;103(7):2109-14.

31. Nikolova P V, Wong K, Dedecker B, Henckel J, Fersht AR. Mechanism of rescue of common p53 cancer mutations by second-site suppressor mutations. EMBO J. 2000;19(3):370-8.

32. Brachmann RK, Yu K, Eby Y, Pavletich NP, Boeke JD. Genetic selection of intragenic suppressor mutations that reverse the effect of common p53 cancer mutations. EMBO J. 1998;17(7):1847-59.

33. Wallentine BD, Wang Y, Tretyachenko-Ladokhina V, Tan M, Senear DF, Luecke H. Structures of oncogenic, suppressor and rescued p53 core-domain variants: Mechanisms of mutant p53 rescue. Acta Crystallogr Sect D Biol Crystallogr. 2013;69(10):2146-56.

34. Malladi SK, Singh R, Pandey S, Gayathri S, Kanjo K, Ahmed S, et al. Design of a highly thermotolerant, immunogenic SARS-CoV-2 spike fragment. J Biol Chem. 2021;296(2021): 10025.

35. Ahmed S, Bhasin M, Manjunath K, Varadarajan R. Prediction of Residue-specific Contributions to Binding and Thermal Stability Using Yeast Surface Display. Frontiers in Molecular Biosciences. 2022;8.

36. Chandra S, Chattopadhyay G, Varadarajan R. Rapid Identification of Secondary Structure and Binding Site Residues in an Intrinsically Disordered Protein Segment. Front Genet. 2021;12:2173.

37. Shindyalov IN, Kolchanov NA, Sander C. Can three-dimensional contacts in proteins structures be predicted by analysis of correlated mutations? Protein Eng. 1994;7(3):349-58.

38. Bank C, Hietpas RT, Jensen JD, Bolon DNA. A Systematic Survey of an Intragenic Epistatic Landscape. Mol Biol Evol. 2015;32(1):229-38.

39. Shortle D. Guanidine hydrochloride denaturation studies of mutant forms of staphylococcal nuclease. J Cell Biochem. 1986;30(4):281-9.

40. Pakula AA, Sauer RT. Amino Acid Substitutions That Increase the Thermal Stability of the lambda Cro Protein. Proteins Struct Funct Bioinforma. 1989;5(3):202-210.

41. Tokuriki N, Tawfik DS. Protein dynamism and evolvability. Science. 2009;324(5924): 203-7.

42. Bajaj K, Dewan PC, Chakrabarti P, Goswami D, Barua B, Baliga C, et al. Structural correlates of the temperature sensitive phenotype derived from saturation mutagenesis studies of CcdB. 
Biochemistry. 2008;47(49):12964-73.

43. Sanchez-Ruiz JM. Protein kinetic stability. Vol. 148, Biophysical Chemistry. 2010. p. 1-15.

44. Jaswal SS, Sohl JL, Davis JH, Agard DA. Energetic landscape of $\alpha$-lytic protease optimizes longevity through kinetic stability. Nature. 2002;415(6869):343-6.

45. Bullough PA, Hughson FM, Skehel JJ, Wiley DC. Structure of influenza haemagglutinin at the pH of membrane fusion. Nature. 1994;371(6492):37-43.

46. Chan DC, Fass D, Berger JM, Kim PS. Core structure of gp41 from the HIV envelope glycoprotein. Cell. 1997;89(2):263-73.

47. Lee C, Park SH, Lee MY, Yu MH. Regulation of protein function by native metastability. Proc Natl Acad Sci. 2000;97(14):7727-31.

48. Leikina E, Mertts M V., Kuznetsova N, Leikin S. Type I collagen is thermally unstable at body temperature. Proc Natl Acad Sci. 2002;99(3):1314-8.

49. Persikov A V., Brodsky B. Unstable molecules form stable tissues. Proc Natl Acad Sci. 2002;99(3):1101-3.

50. Lynch SM, Boswell SA, Colón W. Kinetic stability of $\mathrm{Cu} / \mathrm{Zn}$ superoxide dismutase is dependent on its metal ligands: Implications for ALS. Biochemistry. 2004;43(51):16525-31.

51. Lynch SM, Colón W. Dominant role of copper in the kinetic stability of $\mathrm{Cu} / \mathrm{Zn}$ superoxide dismutase. Biochem Biophys Res Commun. 2006;340(2):457-61.

52. Ionescu RM, Vlasak J, Price C, Kirchmeier M. Contribution of variable domains to the stability of humanized IgG1 monoclonal antibodies. J Pharm Sci. 2008;97(4):1414-26.

53. Contessoto VG, de Oliveira VM, Fernandes BR, Slade GG, Leite VBP. TKSA-MC: A web server for rational mutation through the optimization of protein charge interactions. Proteins Struct Funct Bioinforma. 2018;86(11):1184-8.

54. Pettersen E., Goddard T., Huang C., Couch G., Greenblatt D., Meng E., et al. UCSF Chimera - A visualization system for exploratory research and analysis. J Comput Chem. 2004;25(13):1605-12.

55. Aghera NK, Prabha J, Tandon H, Chattopadhyay G, Vishwanath S, Srinivasan N, et al. Mechanism of CcdA-Mediated Rejuvenation of DNA Gyrase. Structure. 2020;28(5):562-572.e4.

56. Fedorov AN, Baldwin TO. Cotranslational protein folding. J Biol Chem.1997;272(52):327158.

57. Boysen M, Kityk R, Mayer MP. Hsp70- and Hsp90-Mediated Regulation of the Conformation of p53 DNA Binding Domain and p53 Cancer Variants. Mol Cell. 2019;74(4):831-843.e4.

58. Butler JS, Loh SN. Kinetic partitioning during folding of the p53 DNA binding domain. J Mol 
Biol. 2005;350(5):906-18.

59. Walerych D, Olszewski MB, Gutkowska M, Helwak A, Zylicz M, Zylicz A. Hsp70 molecular chaperones are required to support p53 tumor suppressor activity under stress conditions. Oncogene. 2009;28(48):4284-94.

60. Bochkareva ES, Lissin NM, Girshovich AS. Transient association of newly synthesized unfolded proteins with the heat-shock GroEL protein. Nature. 1988;336(6196):254-7.

61. Laminet AA, Ziegelhoffer T, Georgopoulos C, Pluckthun A. The Escherichia coli heat shock proteins GroEL and GroES modulate the folding of the $\beta$-lactamase precursor. EMBO J. 1990;9(7):2315-9.

62. Consortium AA. Structural and functional comparison of SARS-CoV-2-spike receptor binding domain produced in Pichia pastoris and mammalian cells. Sci Rep. 2020;10(1):21779.

63. Khlebnikov A, Datsenko KA, Skaug T, Wanner BL, Keasling JD. Homogeneous expression of the PBADpromoter in Escherichia coli by constitutive expression of the low-affinity highcapacity araE transporter. Microbiology. 2001;147(12):3241-7.

64. Chao G, Lau WL, Hackel BJ, Sazinsky SL, Lippow SM, Wittrup KD. Isolating and engineering human antibodies using yeast surface display. Nat Protoc. 2006;1(2):755-68.

65. Bullock AN, Henckel J, Fersht AR. Quantitative analysis of residual folding and DNA binding in mutant p53 core domain: Definition of mutant states for rescue in cancer therapy. Oncogene. 2000;19(10):1245-56.

66. Tripathi A, Swaroop S, Varadarajan R. Molecular Determinants of Temperature-Sensitive Phenotypes. Biochemistry. 2019;58(13):1738-50.

67. Greene RF, Pace CN. Urea and guanidine hydrochloride denaturation of ribonuclease, lysozyme, alpha-chymotrypsin, and beta-lactoglobulin. J Biol Chem. 1974;249(17):5388-93.

68. Rathore U, Saha P, Kesavardhana S, Kumar AA, Datta R. Glycosylation of the core of the HIV1 envelope subunit protein gp120 is not required for native trimer formation or viral infectivity. J Biol Chem. 2017;292:10197-219.

69. Winn MD, Ballard CC, Cowtan KD, Dodson EJ, Emsley P, Evans PR, et al. Overview of the CCP4 suite and current developments. Acta Crystallogr Sect Biol Crystallogr 2011;67(Pt 4):235-242.

70. Battye TGG, Kontogiannis L, Johnson O, Powell HR, Leslie AGW. iMOSFLM: A new graphical interface for diffraction-image processing with MOSFLM. Acta Crystallogr Sect D Biol Crystallogr. 2011;67(4):271-81.

71. McCoy AJ, Grosse-Kunstleve RW, Adams PD, Winn MD, Storoni LC, Read RJ. Phaser crystallographic software. J Appl Crystallogr. 2007;40(4):658-74. 
72. Loris R, Dao-Thi M-H, Bahassi EM, Van Melderen L, Poortmans F, Liddington R, et al. Crystal structure of CcdB, a topoisomerase poison from E.coli. J Mol Biol. 1999;285(4):1667-77.

73. Murshudov GN, Vagin AA, Dodson EJ. Refinement of macromolecular structures by the maximum-likelihood method. Acta Crystallogr Sect D Biological Crystallogr. 1997;53(Pt 3):240-255.

74. Murshudov GN, Skubák P, Lebedev AA, Pannu NS, Steiner RA, Nicholls RA, et al. REFMAC5 for the refinement of macromolecular crystal structures. Acta Crystallogr Sect D Biol Crystallogr. 2011;67(4):355-67.

75. Emsley P, Cowtan K. Coot: Model-building tools for molecular graphics. Acta Crystallogr Sect D Biol Crystallogr. 2004;60(12 I):2126-32.

76. Emsley P, Lohkamp B, Scott WG, Cowtan K. Features and development of Coot. Acta Crystallogr Sect D Biol Crystallogr. 2010;66(4):486-501.

77. Fonze E, Charlier P, To'th Y, Vermeire M, Raquet X, Dubus A, et al. TEM1 beta-lactamase structure solved by molecular replacement and refined structure of the S235A mutant. Acta Crystallogr Sect D Biol Crystallogr. 1995;51(5):682-94.

78. Wang Y, Rosengarth A, Luecke H. Structure of the human p53 core domain in the absence of DNA. Acta Crystallogr Sect D Biol Crystallogr. 2007;63(3):276-81.

79. Zhou D, Duyvesteyn HME, Chen CP, Huang CG, Chen TH, Shih SR, et al. Structural basis for the neutralization of SARS-CoV-2 by an antibody from a convalescent patient. Nat Struct Mol Biol. 2020;27(10):950-8

80. Wienken CJ, Baaske P, Rothbauer U, Braun D, Duhr S. Protein-binding assays in biological liquids using microscale thermophoresis. Nat Commun. 2010;1(7):1-7. 


\section{Figures}

A

B

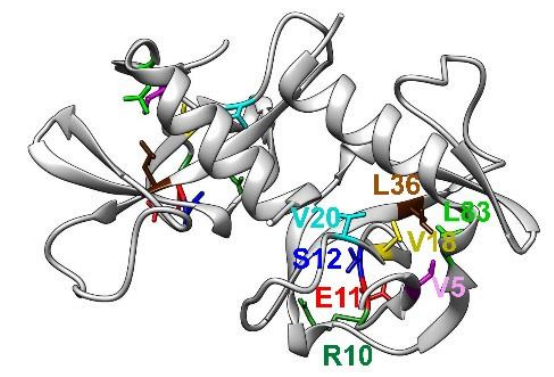

V18W V20F L36A L83S

V18W E11R V20F E11R L36A E11R L83S E11R E11R WT G100T TRX
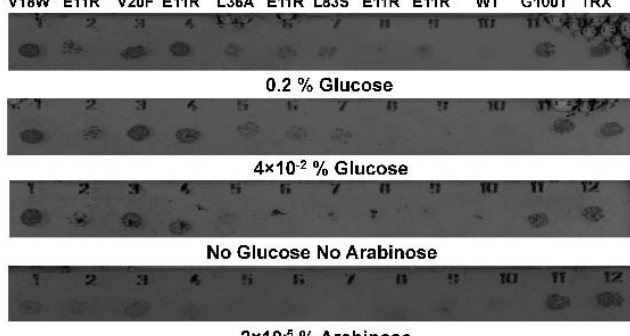

VSF V18W V20F L36A L83S
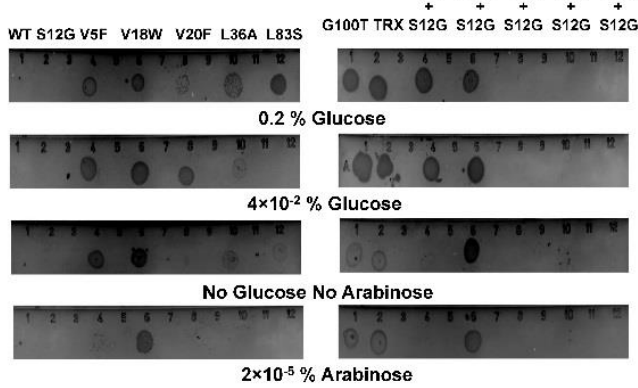
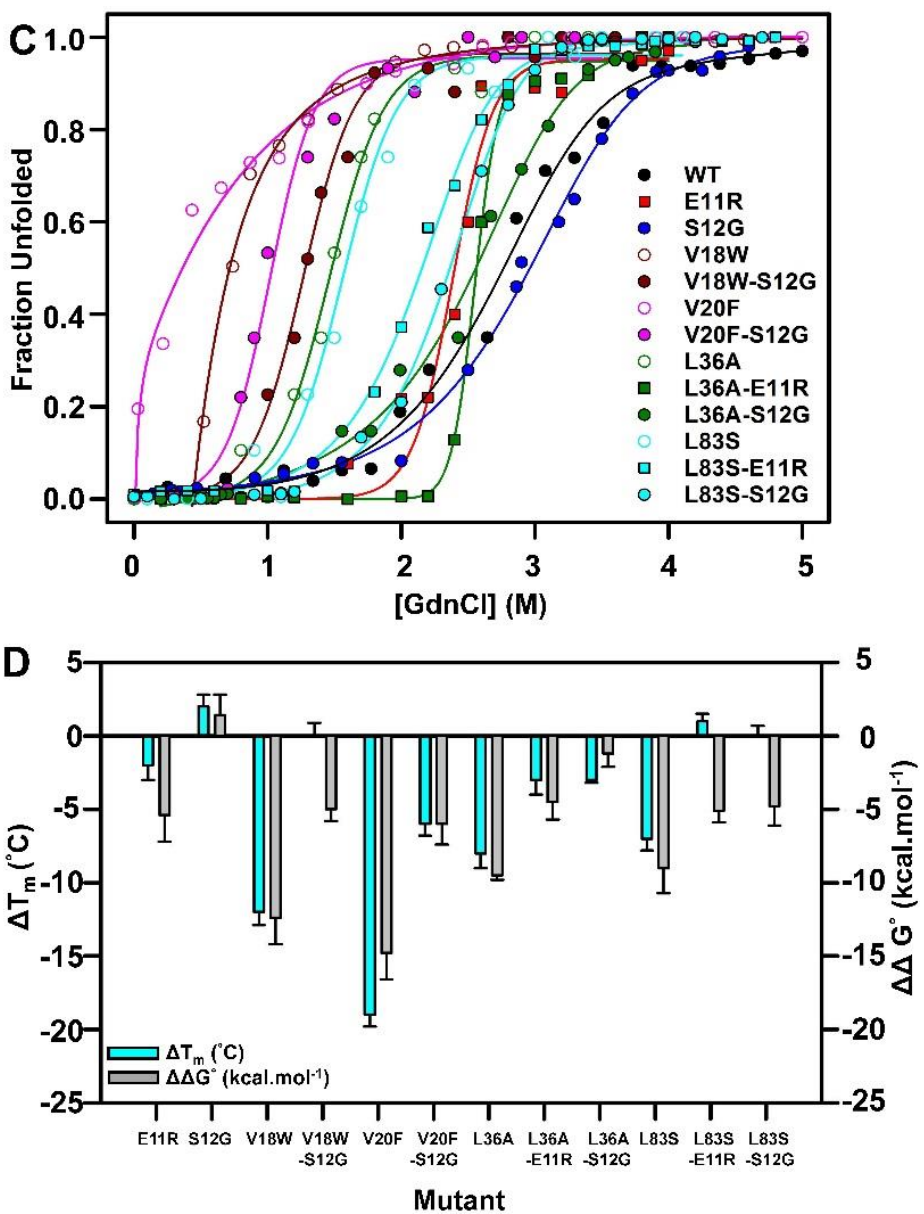

Figure 1. Folding defects rescued by suppressors. (A) Experimentally obtained inactive mutants and distal suppressors mapped onto the crystal structure of CcdB (PDB ID 3VUB [Loris et al., 1999]). The CcdB protein is shown in ribbon with the distal suppressors R10, E11and S12 mapped on an exposed loop region while the PIMs V5, V18 V20, L36A and L83S are present in the core of the protein. The residues highlighted are shown in the context of the CcdB homodimer. (B) In-vivo activity of the PIMs at $37{ }^{\circ} \mathrm{C}$ in the background of the suppressor E11R and S12G. The condition where growth ceased was reported as the active condition. Four representative conditions are shown. Cells transformed with G100T, inactive mutant and E. coli thioredoxin (TRX) expressing plasmids are shown as non-toxic controls which grow under all conditions. (C) Equilibrium $\mathrm{GdnCl}$ denaturation profiles carried out in $200 \mathrm{mM}$ HEPES $\mathrm{pH} 8.4$, at $25{ }^{\circ} \mathrm{C}$ using $5 \mu \mathrm{M}$ of purified proteins using nanoDSF is shown. The experimental data are shown in symbols, while the fits are shown in solid lines. (D) The difference in 
thermal stability, $\Delta \mathrm{T}_{\mathrm{m}}$ (in cyan), and thermodynamic stability assayed by chemical denaturation, $\Delta \Delta \mathrm{G}^{\circ}$ (in grey) of the different CcdB mutants (Mutant-WT). The error bars wherever shown represent the standard deviation from two independent experiments, each performed in duplicates. See also Additional file 1: Figure S1. 


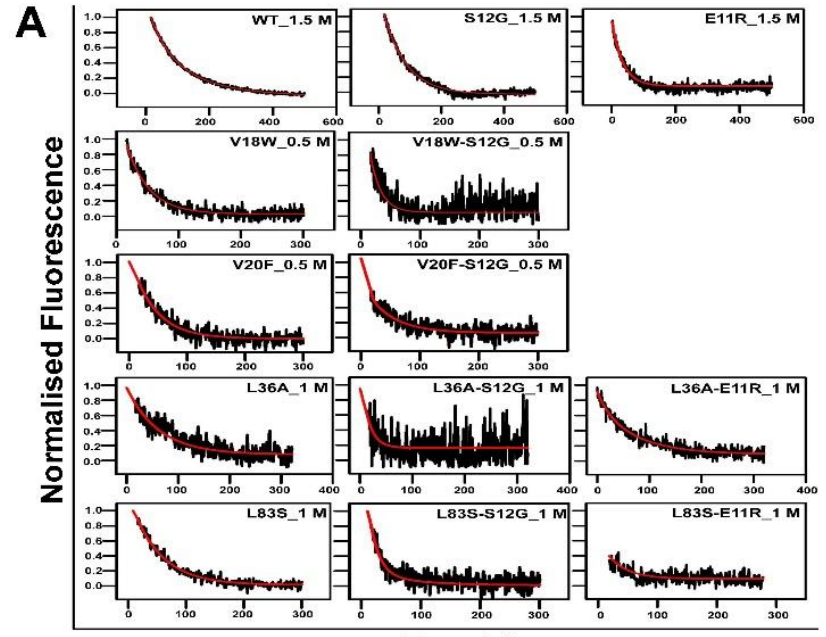

Time (s)
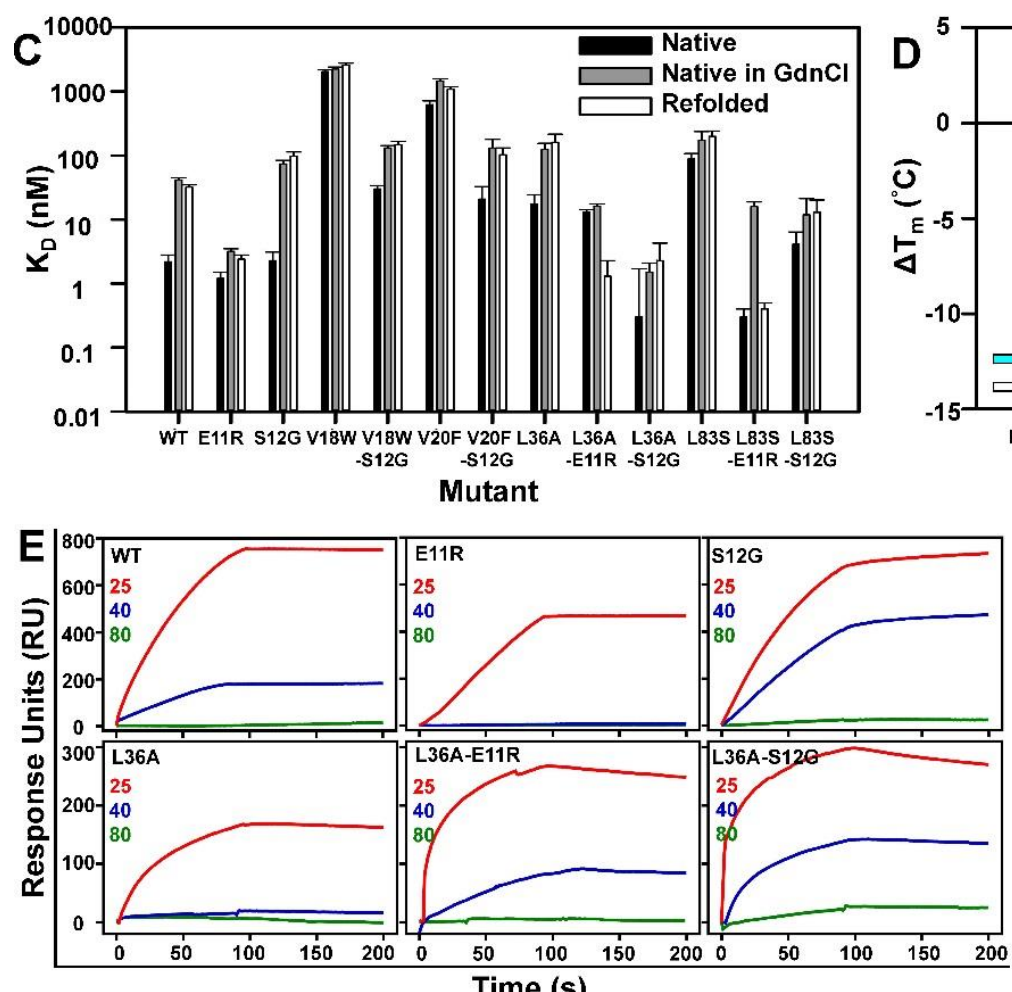

Time (s)

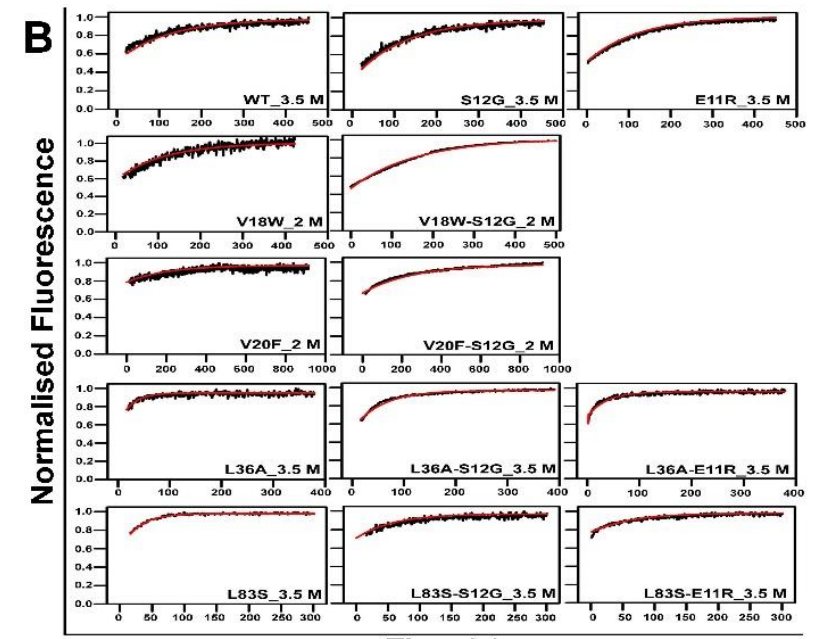

Time (s)
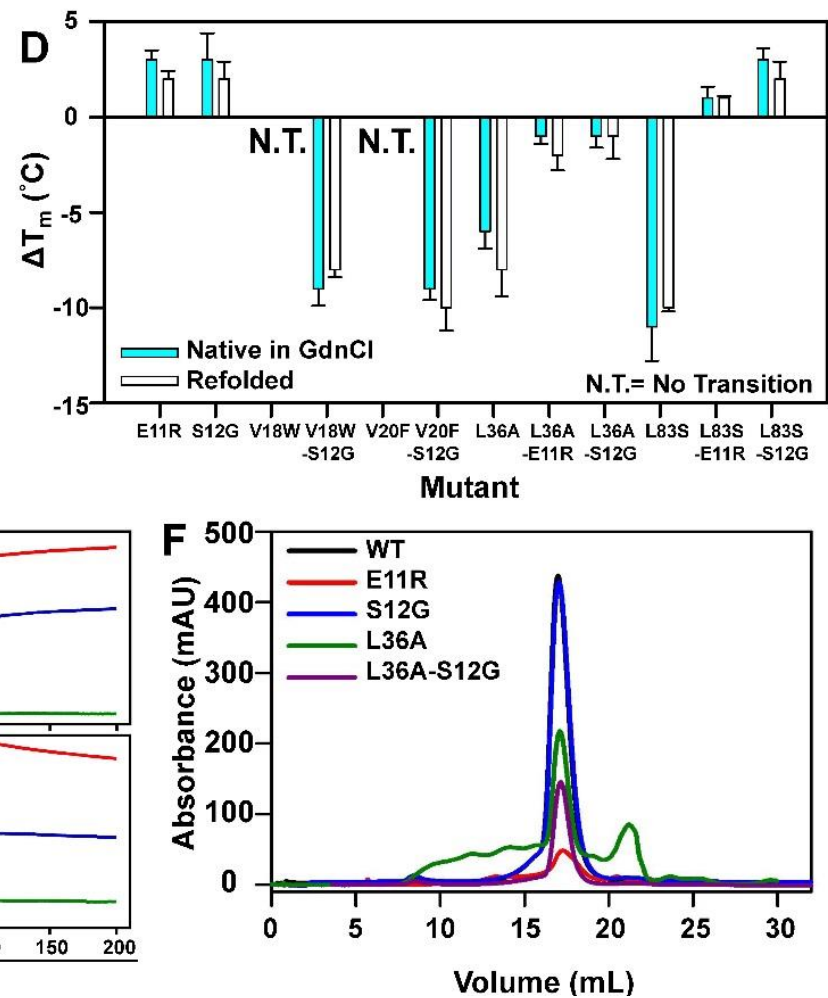

Figure 2: Kinetic and thermodynamic stabilisation by the CcdB suppressor mutants. (A) CcdB proteins exhibit biphasic refolding kinetics with a fast and slow phase whereas (B) unfolding of CcdB proteins follows single exponential kinetics. Representative kinetic traces at $5 \mu \mathrm{M}$ protein concentration of WT and selected CcdB mutants are shown. The experimental kinetic traces obtained at different $\mathrm{GdnCl}$ concentrations are shown in black, while the fits are shown in red. The measured kinetic parameters are listed in Table 2. (C) Interaction between native (black), native protein in $\mathrm{GdnCl}$ (grey) and refolded (white) CcdB mutant proteins and labeled GyrA14 (70 nM) analyzed by MST. (D) 
The difference in apparent thermal melting temperatures $\left(\Delta \mathrm{T}_{\mathrm{m}}=\right.$ Mutant-WT $)$ for native proteins in $\mathrm{GdnCl}$ (cyan), and refolded proteins (grey). The error bars represent the standard deviation from two independent experiments, each performed in duplicates. (E) Binding of $500 \mathrm{nM}$ WT and mutant CcdB to immobilised GyrA14 measured by passing the same concentrations of the analyte (CcdB proteins), after heat stress at two different temperature $\left(40\right.$ and $\left.80{ }^{\circ} \mathrm{C}\right)$, followed by cooling back to $25^{\circ} \mathrm{C}$. A room temperature control $\left(25^{\circ} \mathrm{C}\right)$ was also used. The residual active fraction was calculated as described in the materials section. (see Additional file 11: Table S5). (F) The SEC profiles of a few of the CcdB mutants are shown. The PIM L36A shows aggregation as well as degradation as compared to the WT and E11R, S12G suppressors. The L36A-S12G has a similar profile like the WT and S12G. See also Additional file 1-4: Figure S1-S4. 

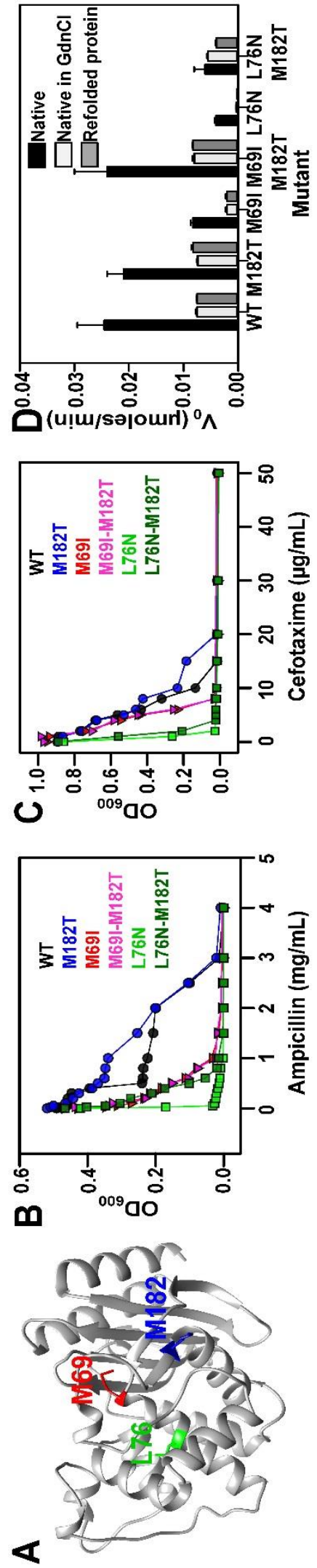

$($ - - -
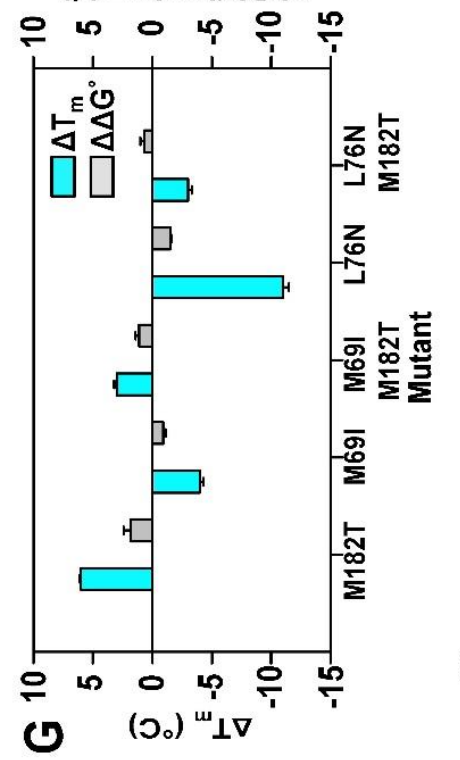

(1-s) ㄱuęsuoo әㄹe әseyd Mols

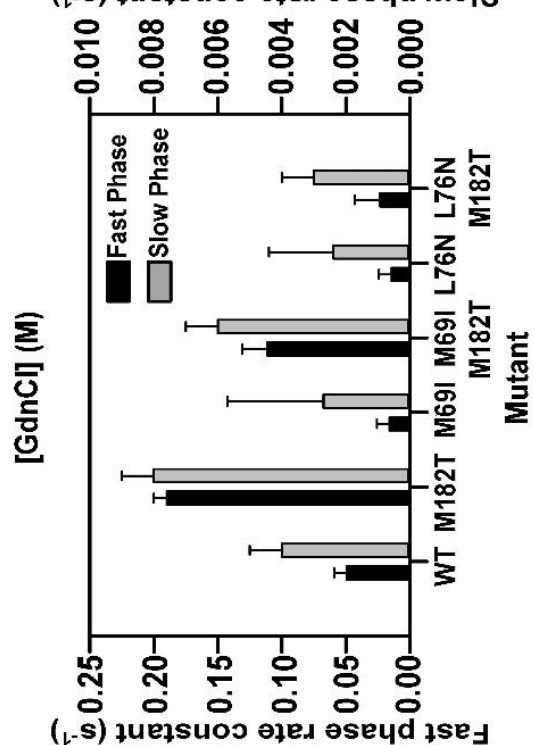

L
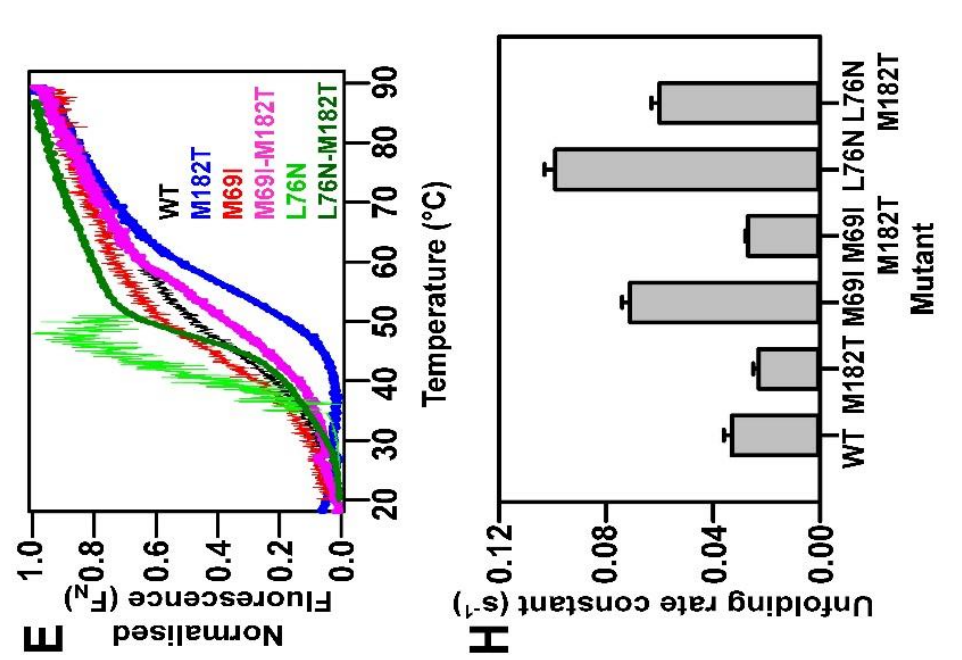

Figure 3. Enhancement of protein stability by M182T global suppressor in extended spectrum

TEM-1 $\boldsymbol{\beta}$ lactamases. (A) Inactive mutants and distal suppressor M182T mapped onto the crystal 
structure of TEM-1 (PDB ID 1XPB (77)). The TEM-1 protein is shown in ribbon with the distal suppressor M182T, mapped on an exposed region, while the inactive mutants L76N and M69I are present in the core of the protein. (B-C) Influence of M182T substitution on TEM-1 mediated MIC levels using ampicillin (B) and cefotaxime (C) broth dilutions and pET24a plasmid. (D) The initial velocity $\left(\mathrm{V}_{0}\right)$ of the native enzyme (black), protein in $0.5 \mathrm{M} \mathrm{GdnCl}$ (light grey) and refolded protein in $0.5 \mathrm{M} \mathrm{GdnCl}$ (dark grey) at $25{ }^{\circ} \mathrm{C}$ with $10 \mathrm{nM}$ protein and $50 \mu \mathrm{M}$ of nitrocefin. (E-F) Thermal unfolding profile and equilibrium $\mathrm{GdnCl}$ denaturation of $10 \mu \mathrm{M}$ of purified WT, and TEM-1 $\beta$ lactamase mutants. (G) The difference in thermal stability, $\Delta \mathrm{T}_{\mathrm{m}}$ of native proteins (in cyan), and thermodynamic stability assayed by chemical denaturation, $\Delta \Delta \mathrm{G}^{\circ}$ (in grey) of the different TEM-1 mutants (Mutant-WT). (H-I) The observed rate constants of unfolding (2.5 M GdnCl) and the observed rate constants of the fast phase (black) and slow phase (grey) of refolding ( $0.5 \mathrm{M} \mathrm{GdnCl})$ of different mutants is represented (Additional file 12: Table S6). $(\mathrm{J})$ The difference in thermal stability $\left(\Delta \mathrm{T}_{\mathrm{m}}=\right.$ Mutant-WT) of $10 \mu \mathrm{M}$ of native proteins (white) and refolded proteins in $0.5 \mathrm{M} \mathrm{GdnCl}$ (grey). The error bars wherever shown represent the standard deviation from two independent experiments, each performed in duplicates. See also Additional file 5: Figure S5. 

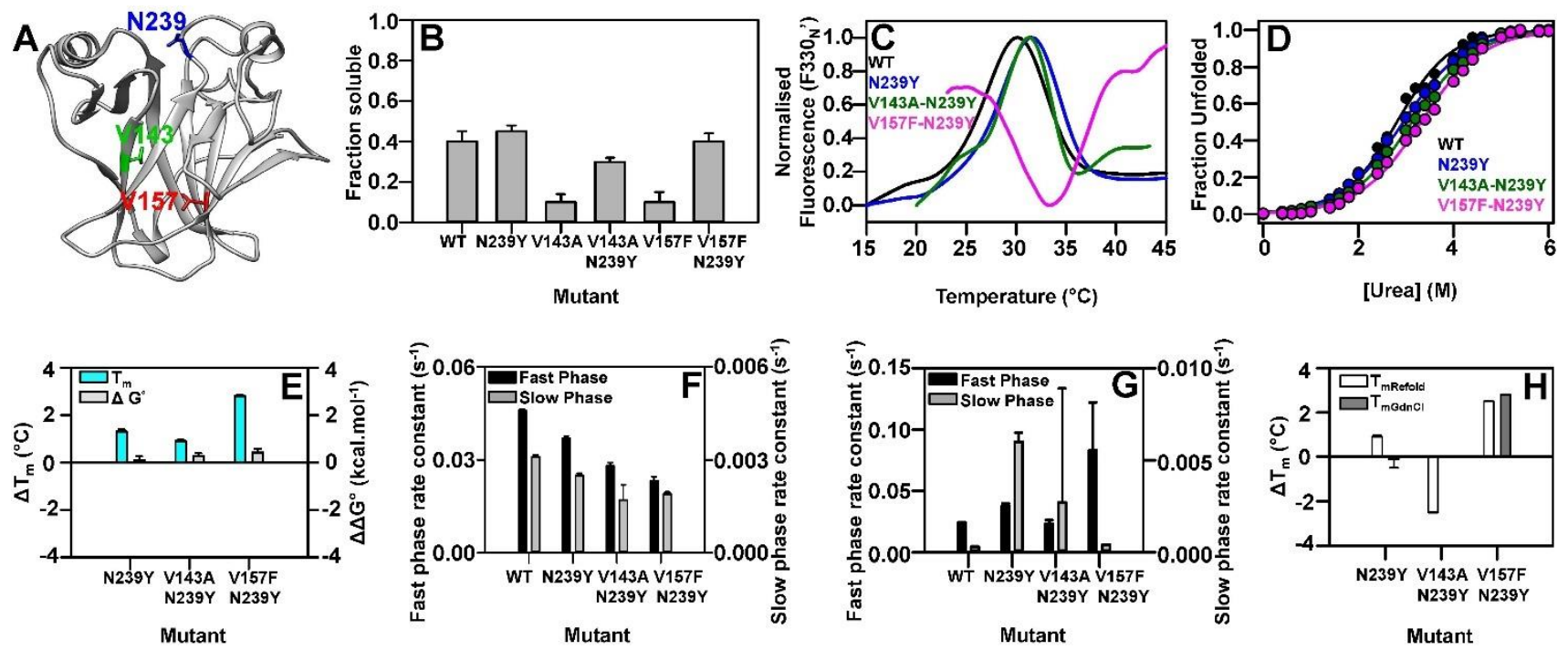

Figure 4. Characterisation of an N239Y global suppressor in DNA Binding Domain of p53. (A)

Inactive mutants and distal suppressor N239Y mapped onto the crystal structure of p53-DBD (PDB ID 2OCJ (78)). The p53-DBD is shown in ribbon with the suppressor N239Y, mapped on an exposed region, while the inactive mutants $\mathrm{V} 143 \mathrm{~A}$ and $\mathrm{V} 157 \mathrm{~F}$ are present in the core of the protein. (B) Influence of N239Y substitution on p53-DBD solubility levels. (C-D) Thermal unfolding profile and equilibrium Urea denaturation respectively of $10 \mu \mathrm{M}$ of purified WT and p53-DBD mutants. (E) The difference in thermal stability, $\Delta \mathrm{T}_{\mathrm{m}}$ of native proteins (in cyan), and thermodynamic stability assayed by chemical denaturation, $\Delta \Delta \mathrm{G}^{\circ}$ (in grey) of the different p53-DBD mutants (Mutant-WT). (F-G) The observed rate constants of the fast phase (black) and slow phase (grey) of unfolding in $4.4 \mathrm{M}$ Urea (F) and of refolding in $2 \mathrm{M}$ Urea $(\mathrm{G})$ of different mutants is represented (Additional file 13: Table S7). (H) The difference in thermal stability $\left(\Delta \mathrm{T}_{\mathrm{m}}=\right.$ Mutant-WT) of $10 \mu \mathrm{M}$ of native proteins (white) and refolded proteins in $0.5 \mathrm{M}$ Urea (grey). The error bars wherever shown represent the standard deviation from two independent experiments, each performed in duplicates. See also Additional file 5: Figure S5. 

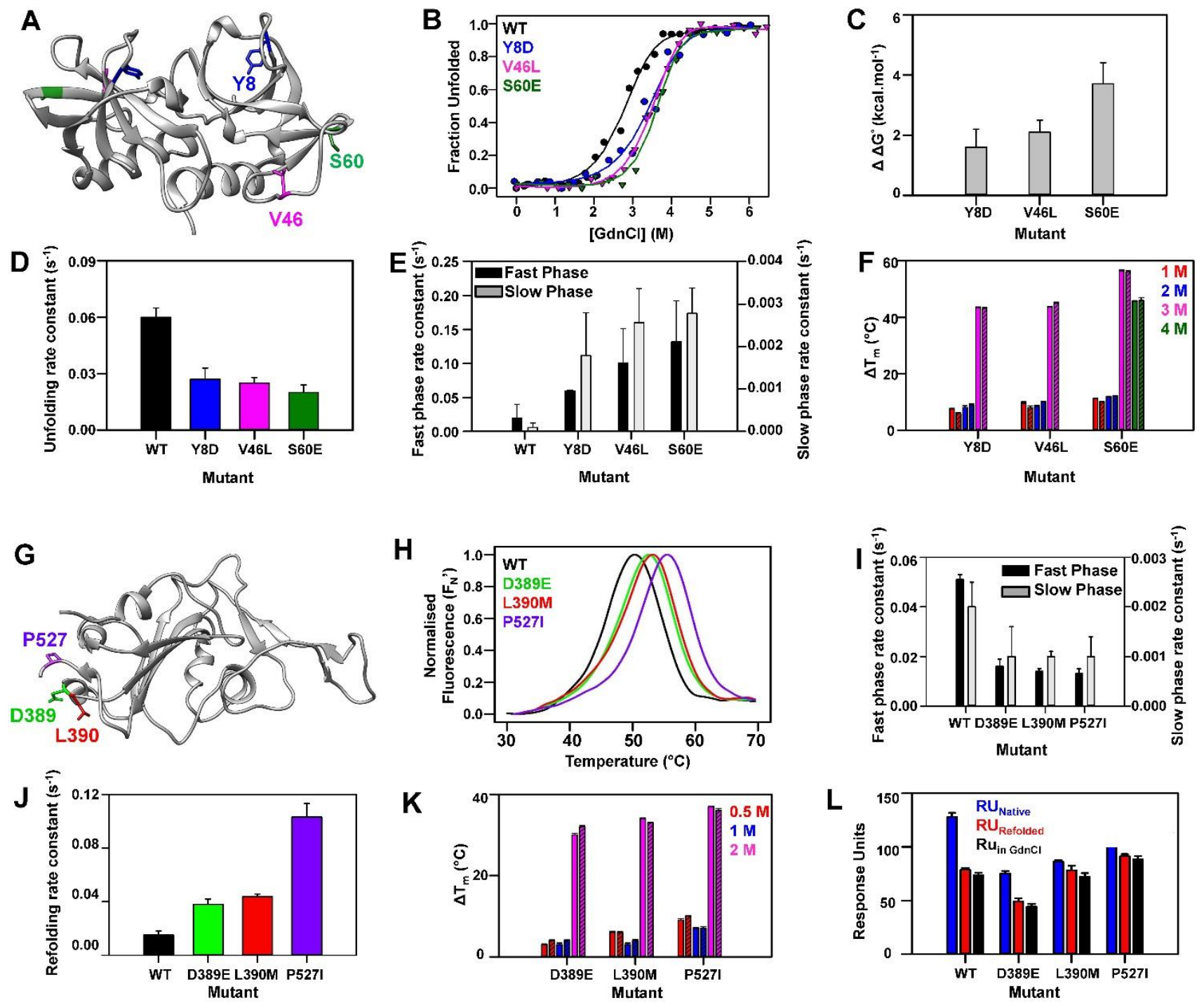

Figure 5. Enhancement in protein stability by highly stable suppressor mutations in CcdB and mRBD.

(A-F) CcdB: (A) The distal suppressors Y8D, V46L, S60E on an exposed region mapped onto the crystal structure of CcdB (PDB ID 3VUB (72)). (B) Equilibrium GdnCl denaturation profiles of $5 \mu \mathrm{M}$ of CcdB-WT and mutants carried out by nanoDSF. (C) Difference in thermodynamic stability assayed by chemical denaturation, $\Delta \Delta \mathrm{G}^{\circ}$ (in grey) of the different CcdB suppressor mutants are plotted. (D-E) The observed rate constants of unfolding $(4.5 \mathrm{M} \mathrm{GdnCl})$ and the observed rate constants of the fast phase (black) and slow phase (grey) of refolding $(2 \mathrm{M} \mathrm{GdnCl})$ of different mutants (see also Additional file 15: Table S9). (F) The difference in thermal stability, $\left(\Delta \mathrm{T}_{\mathrm{m}}=\right.$ Mutant-WT $)$ of $5 \mu \mathrm{M}$ of native proteins in $1 \mathrm{M}, 2 \mathrm{M}, 3 \mathrm{M}, 4 \mathrm{M} \mathrm{GdnCl}$ (solid bars), and refolded $\mathrm{CcdB}$ proteins in the same 
concentrations of $\mathrm{GdnCl}$ (striped bars). The error bars wherever shown represent the standard deviation from two independent experiments, each performed in duplicates. See also Additional file 6: Figure S6.

(G-M) mRBD: (G) The distal suppressors D389E, L390M, P527I on an exposed region mapped onto the crystal structure of RBD (PDB ID 6ZER (79)). (H) Thermal unfolding profile of $10 \mu \mathrm{M}$ of purified WT and mRBD mutants. (I-J) The observed rate constants of fast phase (black) and slow phase (grey) of unfolding $(3 \mathrm{M} \mathrm{GdnCl})$ and the observed rate constants of refolding $(0.5 \mathrm{M} \mathrm{GdnCl})$ of different mutants (see also Additional file 15: Table S9). (K) The difference in thermal stability, $\left(\Delta \mathrm{T}_{\mathrm{m}}=\right.$ MutantWT) of $5 \mu \mathrm{M}$ of native mRBD proteins in $0.5 \mathrm{M}$ (red), $1 \mathrm{M}$ (blue), $2 \mathrm{M}$ (pink) $\mathrm{GdnCl}$ (solid bars), and refolded mRBD proteins in the same concentrations of $\mathrm{GdnCl}$ (striped bars). (L) Binding of $50 \mathrm{nM}$ of native $\mathrm{mRBD}$ proteins (blue), native $\mathrm{mRBD}$ proteins in $0.5 \mathrm{M} \mathrm{GdnCl}$ (red solid) and refolded mRBD proteins in $0.5 \mathrm{M} \mathrm{GdnCl}$ (red striped) with $\mathrm{ACE} 2-\mathrm{hFc}$ neutralizing antibody is shown. The error bars wherever shown represent the standard deviation from two independent experiments, each performed in duplicates. See also Additional file 6: Figure S6. 

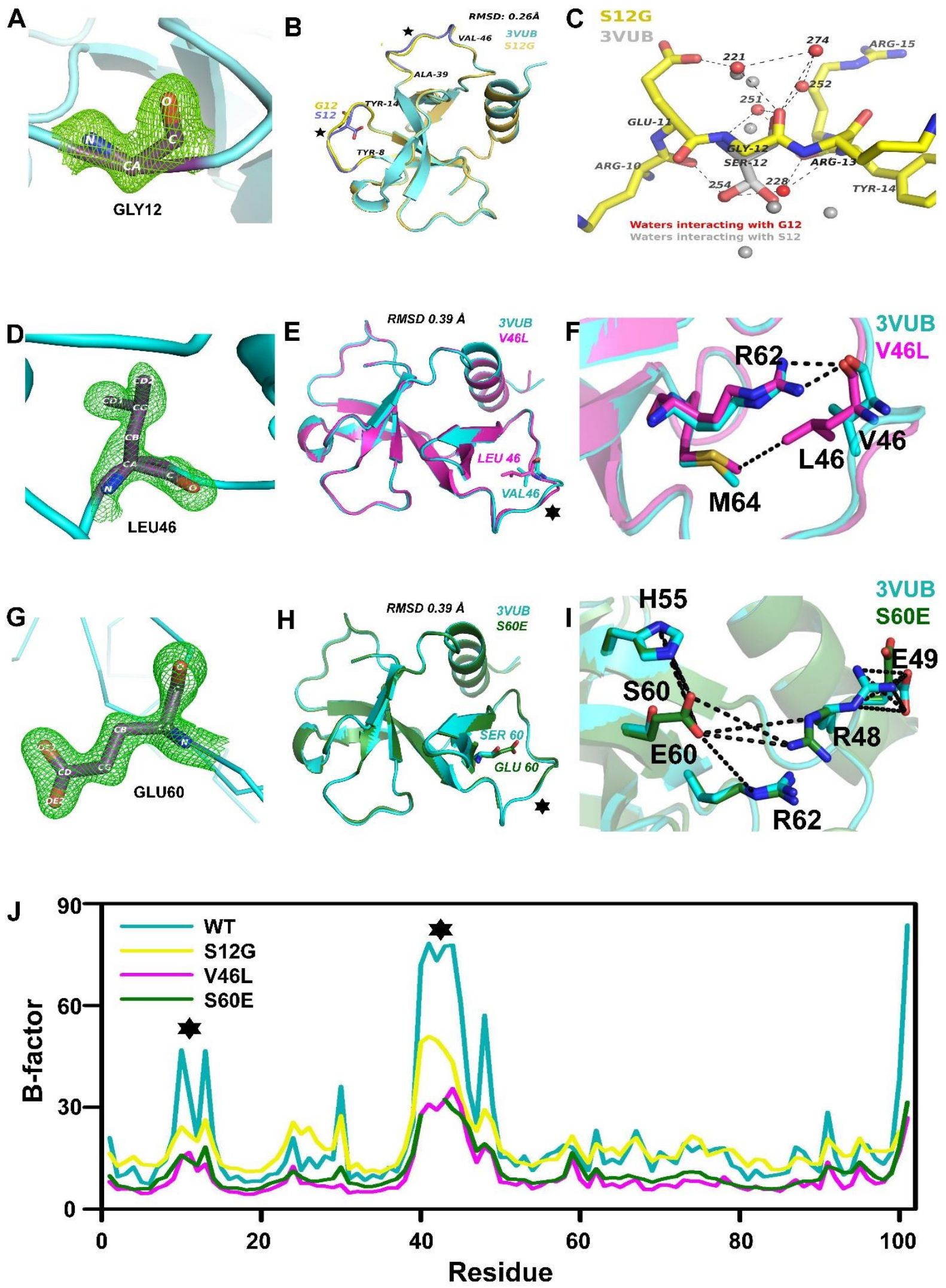

Figure 6. Structures of stabilised CcdB mutants. (A) Composite omit map at residue 12. (B) Structural superposition of WT (3VUB) and S12G monomers, regions displaying deviation are 
indicated by $\star$. (C) Network of interactions at the 12th position in S12G. WT structure is shown with a grey backbone. S12 in 3VUB adopts two conformations with partial occupancy, the position of the corresponding hydroxyl group in each conformation is taken up by two water molecules in S12G. Water molecules directly interacting with G12 is shown in red and the corresponding water in 3 VUB in grey. (D) Composite omit map at residue 46. (E) Structural superposition of WT and V46L monomers, regions displaying deviation are indicated by $\star$. (F) Network of interactions at the 46th position in V46L. WT structure is shown in cyan. Main chain of L46 is involved in H-bond interactions with side chain nitrogen of R62 and the side chain of L46 is involved in hydrophobic interactions with side chain of M64. (G) Composite omit map at residue 60. (H) Structural superposition of WT and S60E monomers, regions displaying deviation are indicated by $\star$. (I) Network of interactions at the 60th position in S60E. WT structure is shown in cyan. E60 is involved in salt bridge interactions with R48, H55 and R62. (J) Average B-factor plot of the residues in WT, S12G and S60E. Regions with large variability are indicated by " $\star$. 


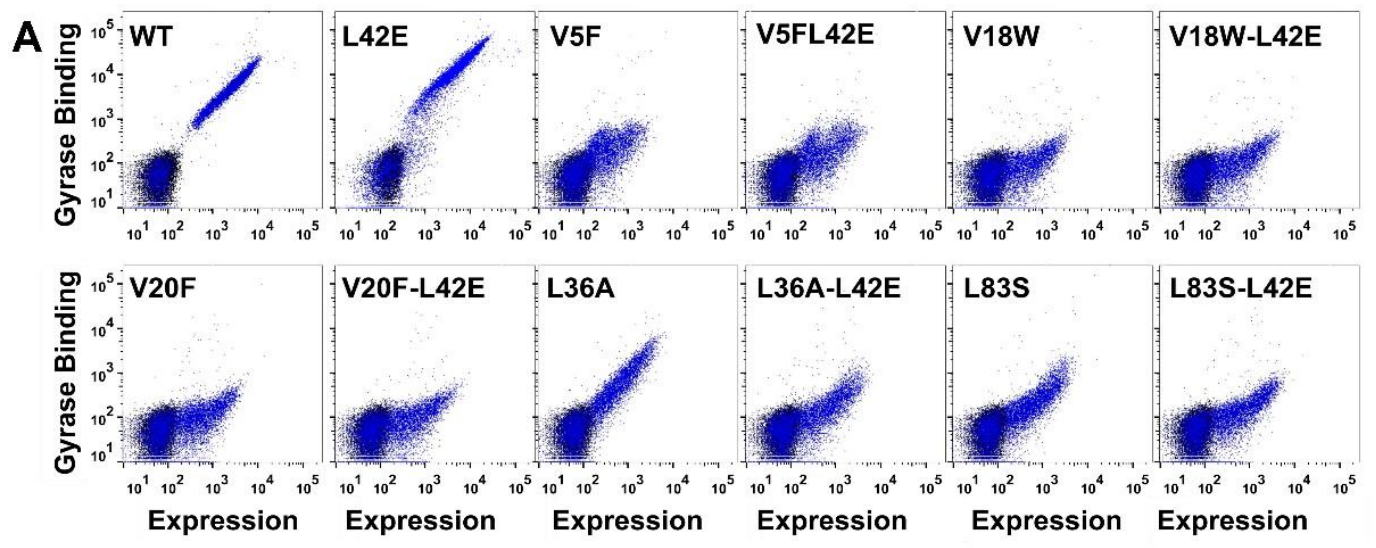

B
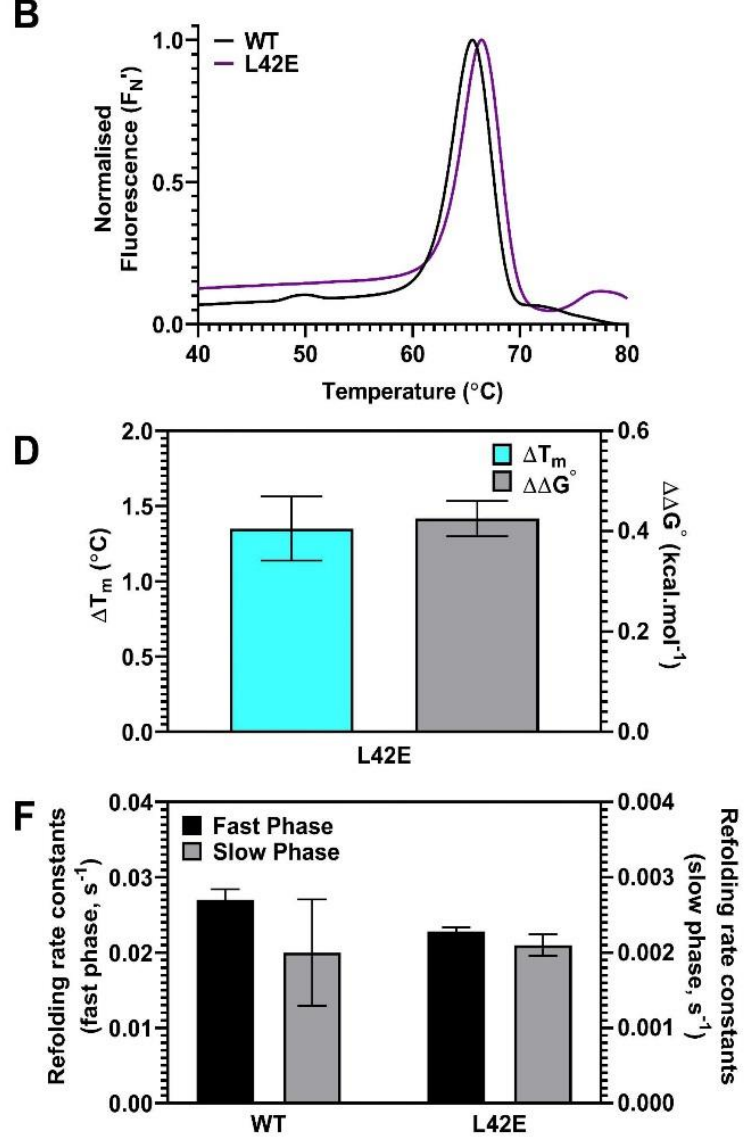

C
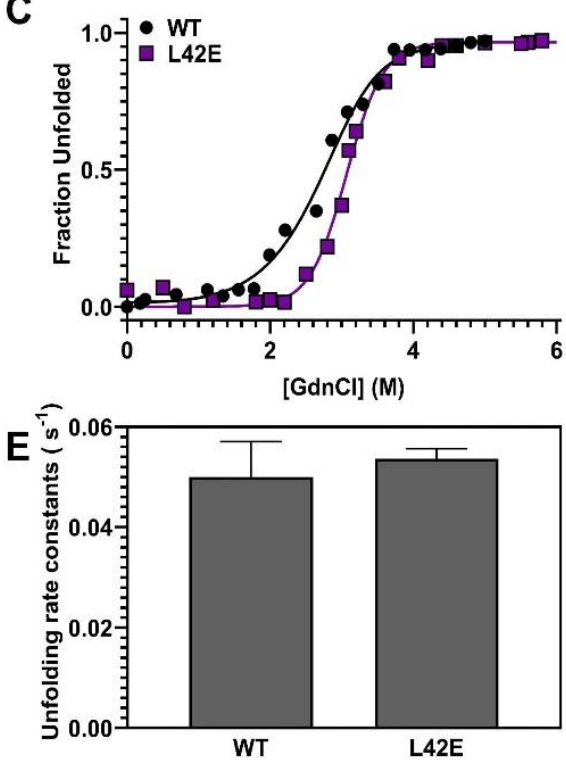

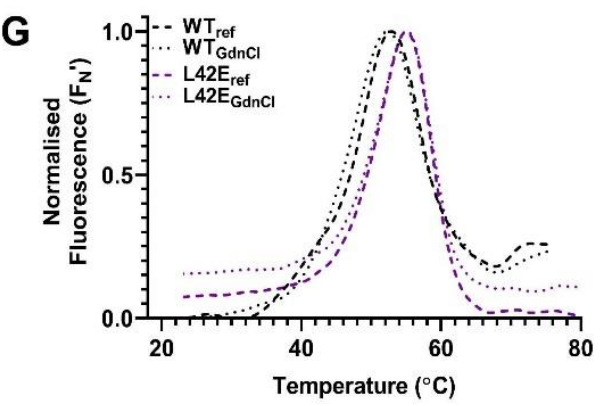

Figure 7. Characterisation of L42E CcdB mutant. (A) Analysis of yeast cell surface expression and GyrA14 binding of different CcdB mutants and WT. CcdB mutant plot (blue) is overlaid with plot of uninduced cells (black) in each case. (B-G) Kinetic and thermodynamic characterisation of L42E CcdB mutant. (B) Thermal unfolding profiles of $5 \mu \mathrm{M}$ of CcdB-WT and L42E mutant carried out by nanoDSF. (C) Equilibrium $\mathrm{GdnCl}$ denaturation profiles of $5 \mu \mathrm{M}$ of $\mathrm{CcdB}-\mathrm{WT}$ and L42E mutant carried out by nanoDSF. (D) Difference (Mutant-WT) in thermal $\Delta \mathrm{T}_{\mathrm{m}}$ (in cyan), and thermodynamic stability assayed by chemical denaturation, $\Delta \Delta \mathrm{G}^{\circ}$ (in grey) of the CcdB L42E mutant. (E-F) The 
observed rate constants of unfolding $(3.5 \mathrm{M} \mathrm{GdnCl})$ and the observed rate constants of the fast phase (black) and slow phase (grey) of refolding $(1.5 \mathrm{M} \mathrm{GdnCl}$ ) of WT and L42E CcdB (see also Additional file 16: Table S10). (G) Thermal unfolding profiles of $5 \mu \mathrm{M}$ of native proteins in $1.5 \mathrm{M} \mathrm{GdnCl}$ (dotted lines) and refolded $\mathrm{CcdB}$ proteins in the same concentration of $\mathrm{GdnCl}$ (dashed lines). The error bars wherever shown represent the standard deviation from two independent experiments, each performed in duplicates. See also Figure S7. 
A

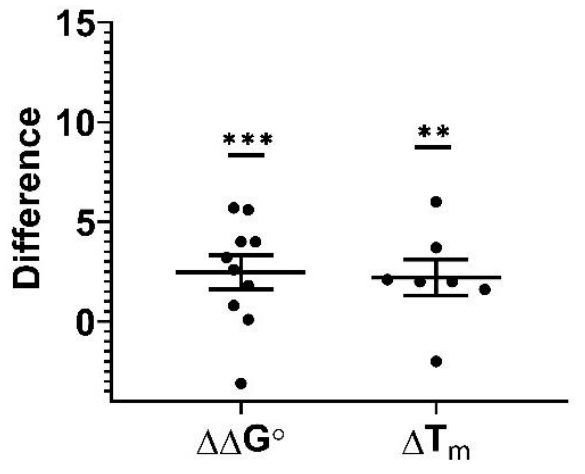

Thermodynamic parameters

C

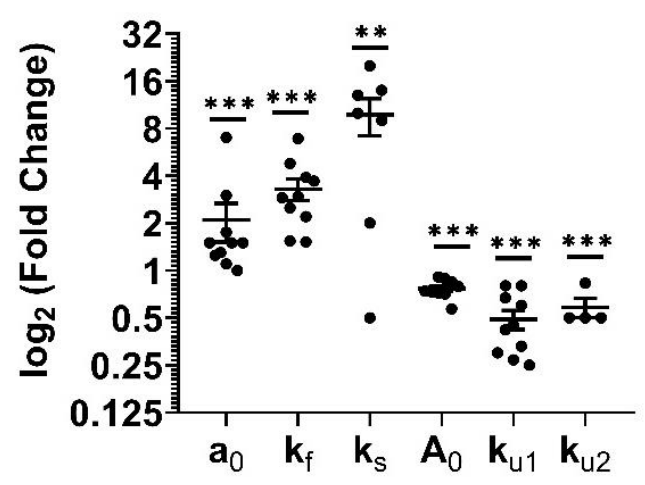

Kinetic parameters
B

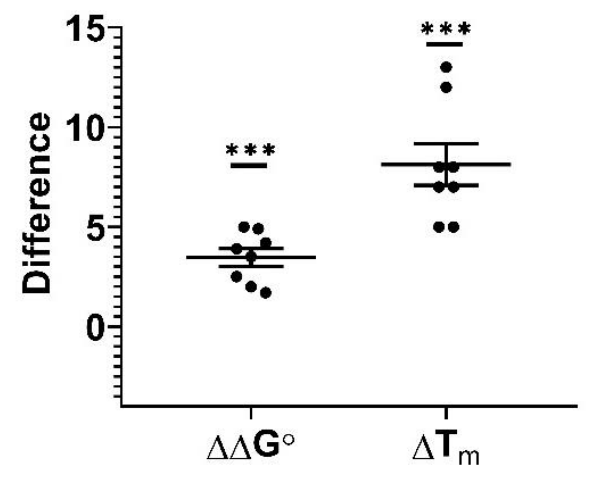

Thermodynamic parameters

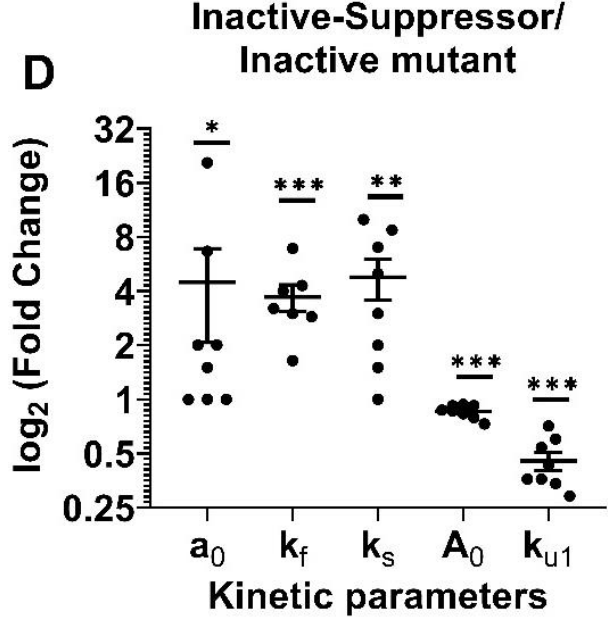

Figure 8. Mechanism of action of suppressor mutations. (A-B) Distribution of $\Delta \mathrm{T}_{\mathrm{m}}$ and $\Delta \Delta \mathrm{G}^{\circ}$ (Mean \pm SEM) for the suppressor mutations in the background of WT (A) or inactive mutant (B). Mann Whitney non-parametric test was performed for each of these parameters to examine if they are significantly different from zero. (C-D) $\log _{2}$ fold change of various parameters (Mean \pm SEM) for the suppressor mutations in the background of WT (A) or inactive mutant (B). Mann Whitney non-parametric test was performed for each of these parameters. The mean of the distributions of the values for each of the parameters are significantly higher than $\log _{2}(2)$ for refolding, and lower than $\log _{2}(2)$ for unfolding. P value indicated with $* * *$ and $* * *$ indicates $<0.05,<0.005$ and $<0.0005$ respectively. 
Table 1 (Related to Figure 8). Average fold change of various parameters (Mean \pm SEM) by the suppressor mutations.

\begin{tabular}{|c|c|c|c|c|c|c|}
\hline \multirow{2}{*}{ Ratio } & \multicolumn{4}{|c|}{$\begin{array}{c}\text { Refolding kinetic } \\
\text { parameter ratio }\end{array}$} & \multicolumn{3}{c|}{$\begin{array}{c}\text { Unfolding kinetic parameter } \\
\text { ratio }\end{array}$} \\
\cline { 2 - 7 } & \multicolumn{2}{|c|}{ Fast } & Slow & \multicolumn{2}{c|}{ Fast } & Slow \\
\cline { 2 - 7 } & $\mathbf{a 0}$ & $\mathbf{k}_{\mathbf{f}}$ & $\mathbf{k}_{\mathbf{s}}$ & $\mathbf{A}_{\mathbf{0}}$ & $\mathbf{k}_{\mathbf{u} 1}$ & $\mathbf{k}_{\mathbf{u}} \mathbf{2}$ \\
\hline $\begin{array}{c}\text { WT/ } \\
\text { Suppressor }\end{array}$ & $2.1 \pm 0.6$ & $3.3 \pm 0.5$ & $9.8 \pm 2.6$ & $0.77 \pm 0.03$ & $0.5 \pm 0.07$ & $0.6 \pm 0.08$ \\
\hline $\begin{array}{c}\text { PIM/ } \\
\text { PIM-Suppressor }\end{array}$ & $4.5 \pm 2.4$ & $3.7 \pm 0.6$ & $4.8 \pm 1.2$ & $0.86 \pm 0.03$ & $0.45 \pm 0.05$ & - \\
\hline
\end{tabular}


bioRxiv preprint doi: https://doi org/10.1101/2021.11.18.469098; this version posted February 7, 2022. The copyright holder for this

\section{Additional Figures and Tables}
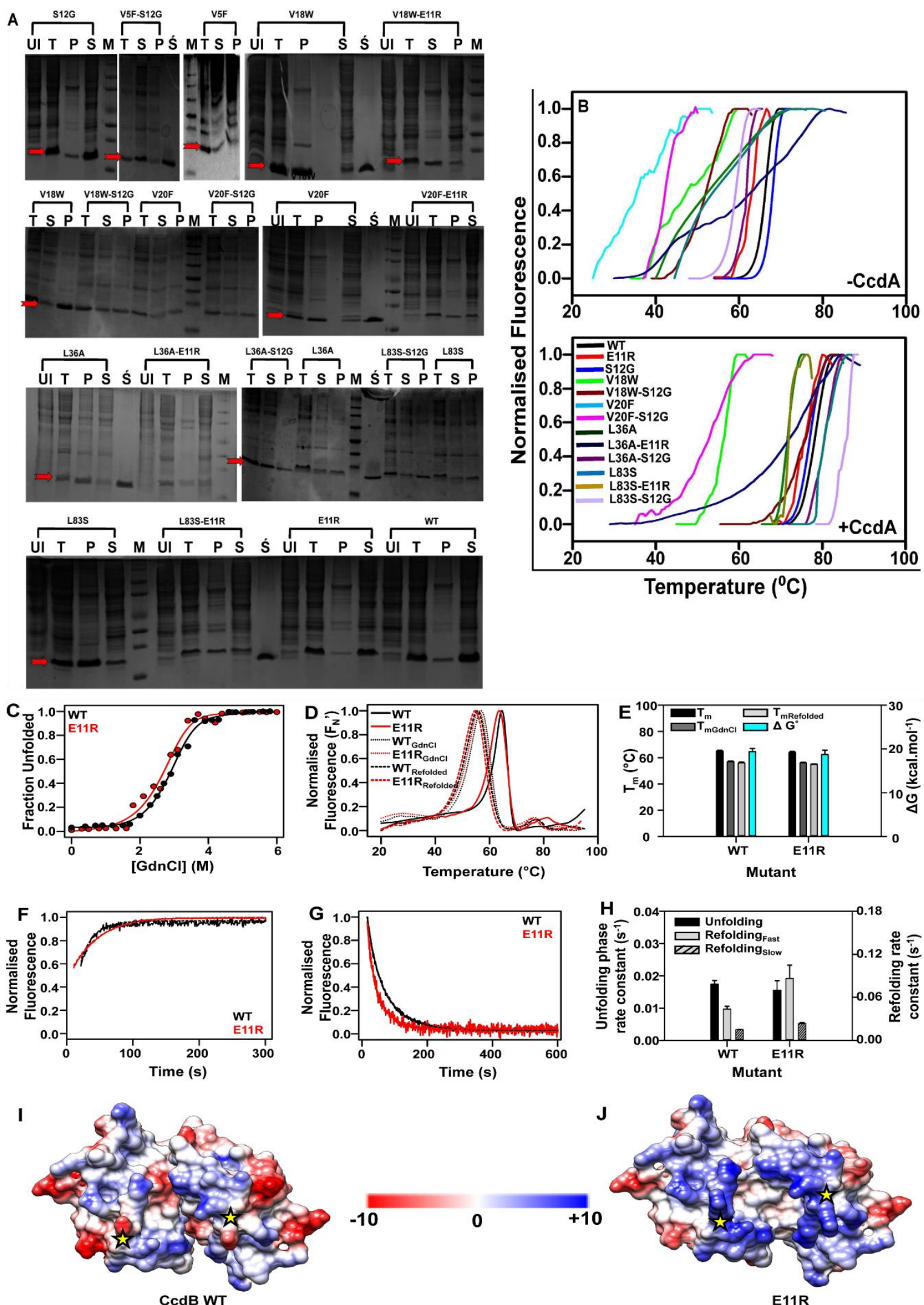

Additional file 1: Figure S1. Enhancement of solubility and stability by the suppressors (related to Figure 1). (A-B) Solubility and thermal stabilities of CcdB mutants, in presence and absence 
of the suppressors. (A) In vivo solubility estimates for CcdB mutants. UI, T, S and P are uninduced, total cell lysate, supernatant and pellet respectively. Ś is the purified CcdB WT protein used as standard and $\mathrm{M}$ is the molecular weight marker lane. The relative estimates of protein present in the soluble fraction and inclusion bodies for all mutants are shown in Additional file 7: Table S1. The red arrow indicates the band for the induced protein. (B) Thermal unfolding profile of purified WT CcdB and CcdB mutants in the absence and presence of $8 \mu \mathrm{M}$ CcdA peptide (45-72) measured by a thermal shift assay (TSA).L83S-E11R and V20F are omitted in the top and bottom panels as they do not show clear thermal transitions in the absence and presence of CcdA respectively.

(C-J) Effect of E11R suppressor substitution on CcdB stability and folding. (C-H): Enhanced stability and folding of suppressor E11R in PBS, pH7.4. (C) Equilibrium GdnCl denaturation profiles using $5 \mu \mathrm{M}$ of purified WT $\mathrm{CcdB}$ and E11R are shown. (D) Thermal unfolding profile of $5 \mu \mathrm{M}$ of purified WT CcdB and E11R in native form (solid lines), native in $\mathrm{GdnCl}$ (dotted lines) and refolded protein (dashed lines) are shown. (E) Thermal stability of native protein, native protein in $1.5 \mathrm{M} \mathrm{GdnCl}$, refolded protein, and thermodynamic stability, $\Delta \mathrm{G}^{\circ}$ of the WT CcdB and E11R are shown. (F-G) Representative kinetic traces at $5 \mu \mathrm{M}$ protein concentration of WT CcdB and E11R are shown in presence of $4 \mathrm{M} \mathrm{GdnCl}$ for unfolding $(\mathrm{F})$ and $1.5 \mathrm{M} \mathrm{GdnCl}$ for refolding $(\mathrm{G})$. (H) The observed rate constants of fast phase and slow phase of refolding in $1.5 \mathrm{M} \mathrm{GdnCl}$ and the observed rate constants of unfolding in $4 \mathrm{M} \mathrm{GdnCl}$ of WT and E11R (see also Additional file 10: Table S4). The error bars wherever shown represent the standard deviation from two independent experiments, each performed in duplicates. (I-J) Coulombic potential surfaces generated for CcdB WT and E11R using the UCSF Chimera. The coulombic potential surfaces generated were coloured using the colour gradation range from red $\left(-10 \mathrm{kcal} \mathrm{mol}^{-1} \varepsilon^{-1}\right)$ to white $\left(0 \mathrm{kcal} \mathrm{mol}^{-1} \varepsilon^{-1}\right)$ to blue $\left(+10 \mathrm{kcal} \mathrm{mol}^{-1} \varepsilon^{-1}\right)$, where $\varepsilon$ is the dielectric constant of the medium (Pettersen et al, 2004). Residue 11 is highlighted by a yellow star. Potential surface maps of (I) CcdB WT and (J) E11R mutant highlight the appearance of a positive potential patch in the 8-15 loop surrounding the residue 11 in the E11R mutant. 

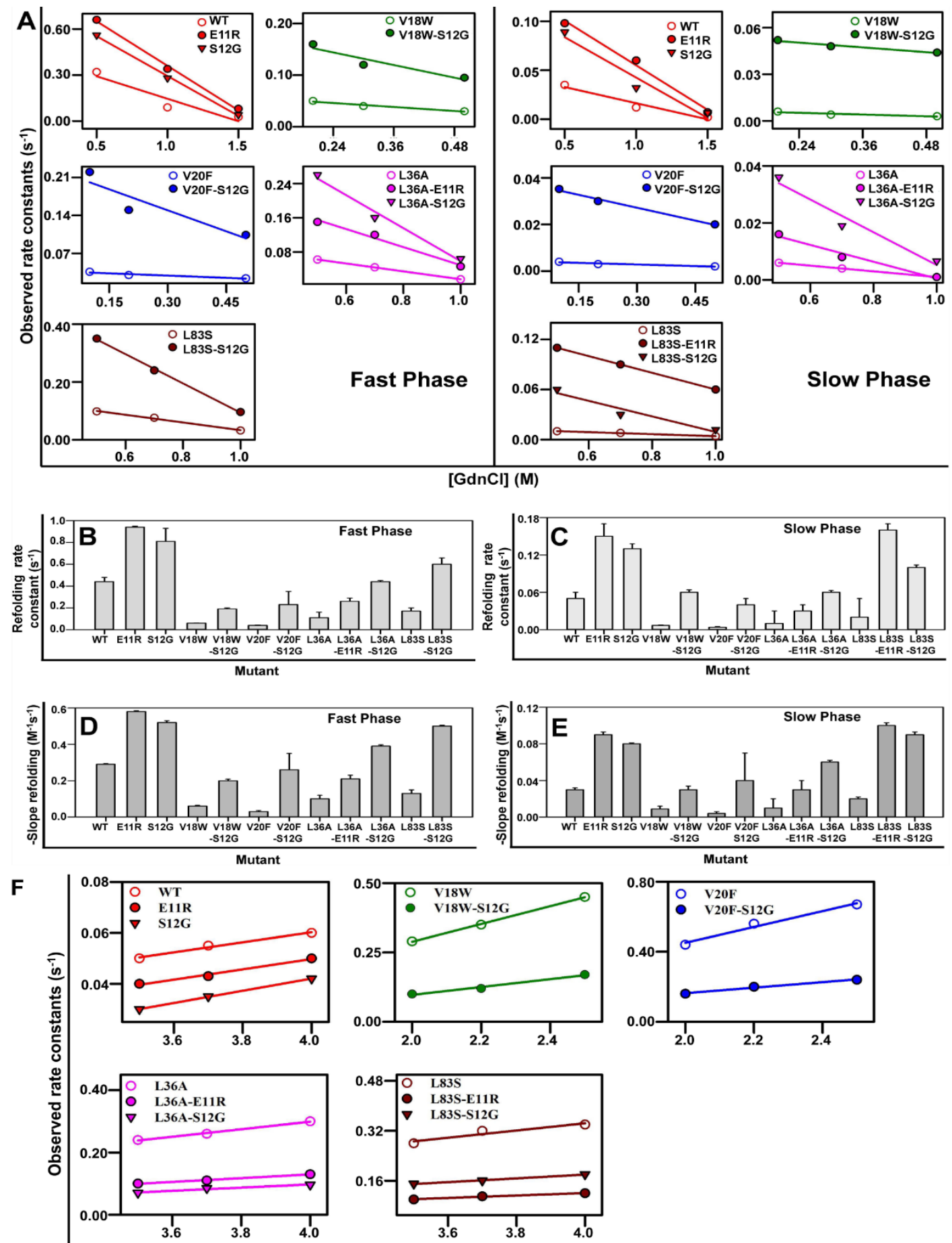

$[\mathrm{GdnCl}](\mathrm{M})$
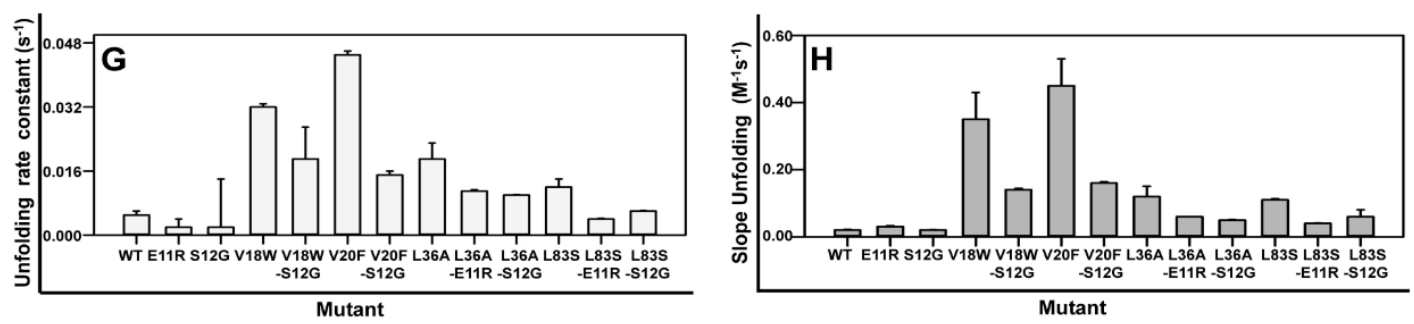

Additional file 2: Figure S2. Denaturant-dependent refolding and unfolding kinetics of CcdB

mutant proteins (related to Figure 2). (A-E) Representative refolding rate constants of fast phase 
(left side) and slow phase (right panel) and (F-H) unfolding rate constants at $5 \mu \mathrm{M}$ protein concentration of the WT and mutants are shown. The experimental rate constants (for refolding and unfolding) obtained at increasing final $\mathrm{GdnCl}$ concentrations are shown in dots, while fits are shown in solid lines. For refolding kinetics, the extrapolated rate constants and the magnitude of refolding mvalues of the transition states at zero denaturant concentration of fast phase (B and D respectively) and slow phase (C and E respectively) are shown. Suppressor mutations significantly accelerate the refolding rate constants. For unfolding kinetics, the extrapolated rate constants $(\mathrm{G})$ and the magnitude of unfolding m-values $(\mathrm{H})$ at zero denaturant concentration are shown. Suppressor mutations decrease the unfolding rate constants. The error bars wherever shown represent the standard deviation from two independent experiments, each performed in duplicates (see also Additional file 9: Table S3). 

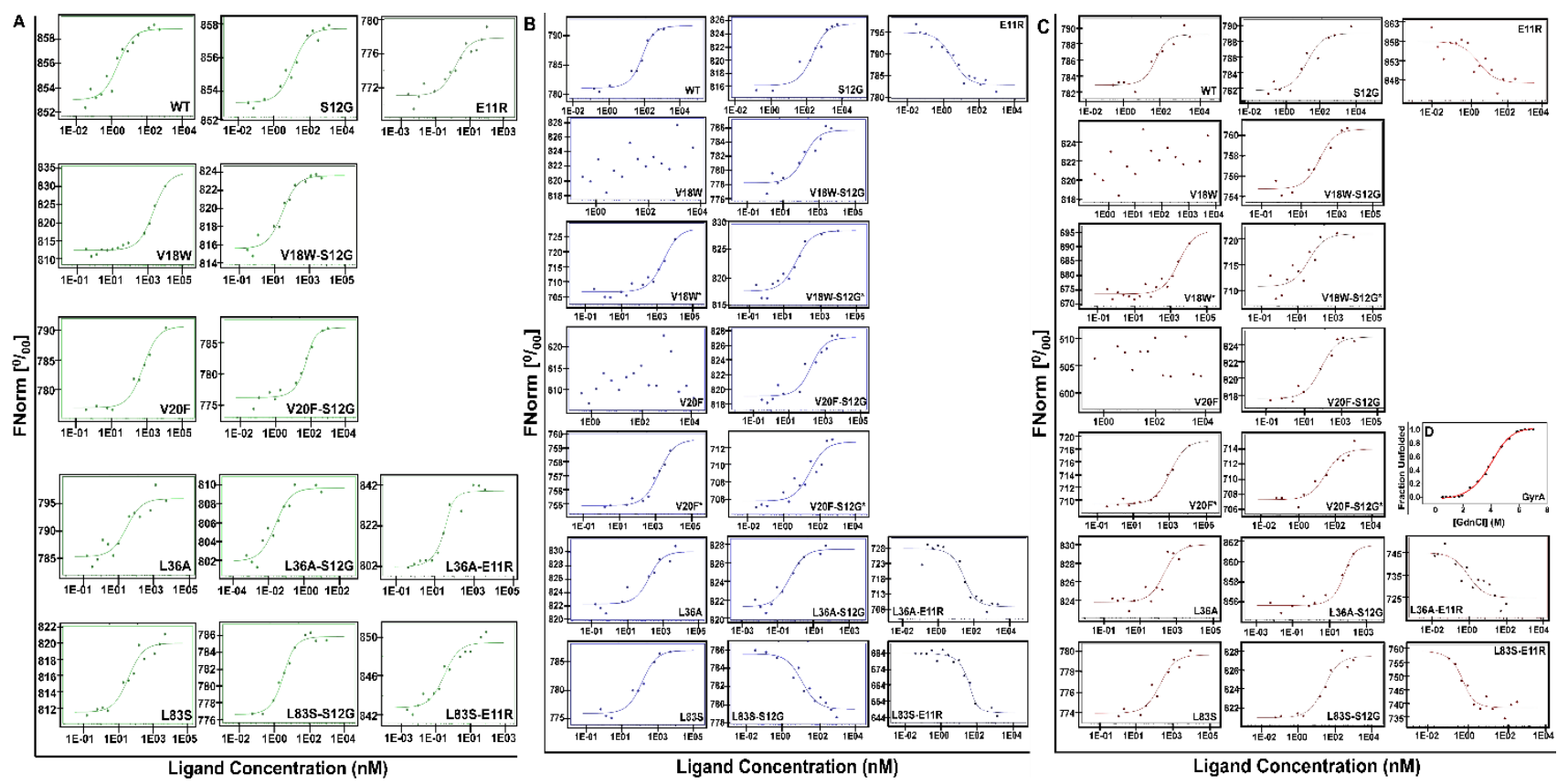

Additional file 3: Figure S3. Interaction of native, native in the presence of GdnCl and refolded

\section{CcdB WT and mutant proteins with labeled GyrA14 analyzed by MicroScale Thermophoresis}

(related to Figure 2). GyrA14 was labeled and used at a concentration of $70 \mathrm{nM}$ and titrated with different concentrations of native (A), native in the presence of $\mathrm{GdnCl}(\mathrm{B})$ and refolded (C) WT and CcdB mutants. All studies were carried out in $200 \mathrm{mM}$ HEPES, pH 8.4, at $27^{\circ} \mathrm{C}$. The normalised fluorescence FNorm $[\% 0]$ is plotted as a function of $[\mathrm{CcdB}]$. For each capillary (each measuring point), an MST trace is recorded. All traces are then normalised to start at 1000 . For each trace, the FNorm value for the dose- response curve is calculated from Fhot (MST laser on)/Fcold (MST laser off). The dissociation constants $\left(\mathrm{K}_{\mathrm{D}}\right)$ listed in Additional file 7: Table S1, were determined employing standard data analysis with MO.Affinity Analysis Software (80). (D) Equilibrium GdnCl denaturation profile of $5 \mu \mathrm{M}$ of GyrA14 carried out in $1 \mathrm{XPBS}, \mathrm{pH} 7.5$ at $25^{\circ} \mathrm{C}$ using nanoDSF. The experimental data is shown in black dots, while the fit is shown in a red line. The Cm of GyrA14 is $4.48 \mathrm{M}$ thus proving it to be stable and folded in the MST studies carried out in the presence of $1.5 \mathrm{M} \mathrm{GdnCl}$. 


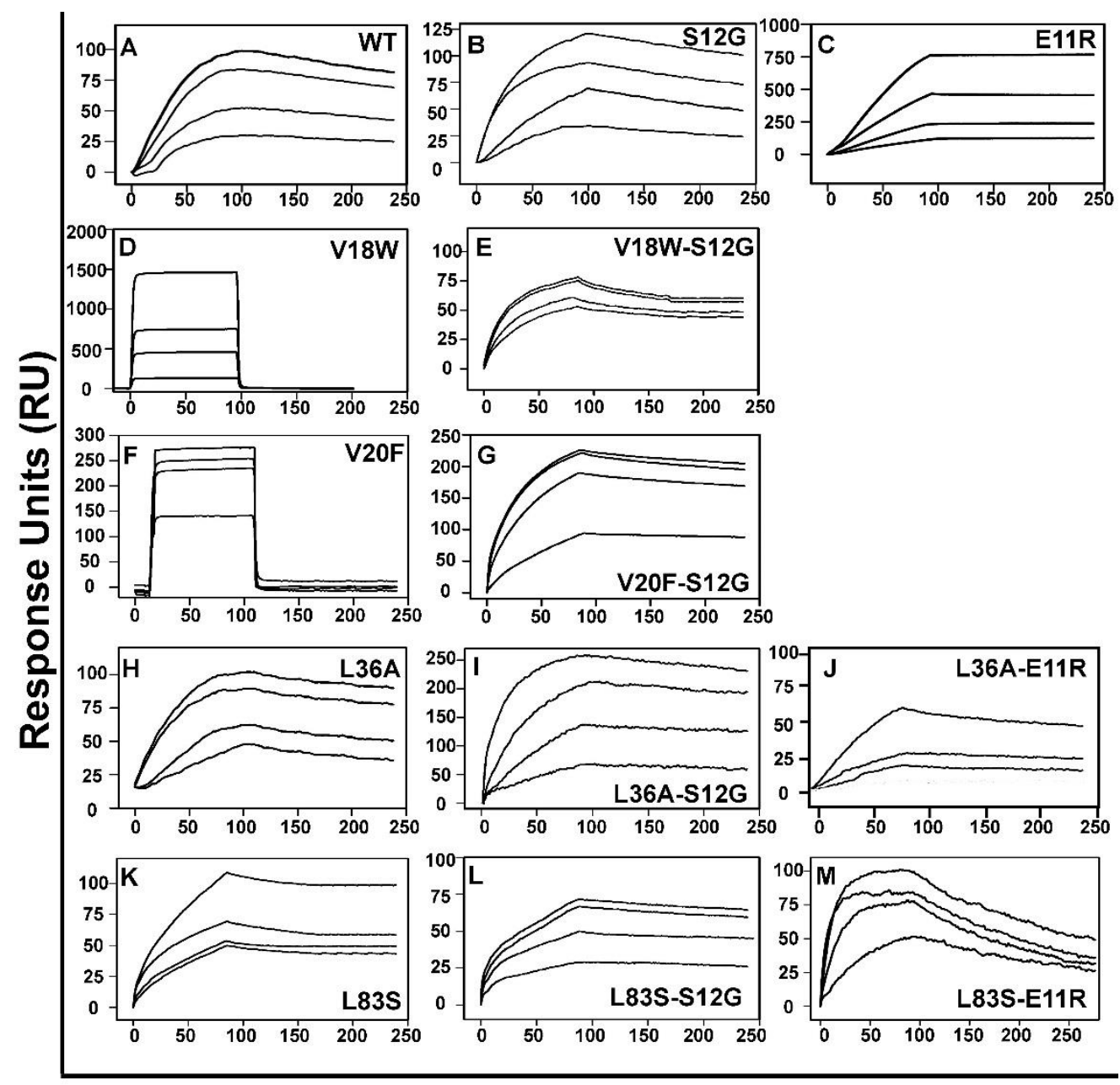

\section{Time (s)}

Additional file 4: Figure S4. Binding of GyrA14 to CcdB proteins (related to Figure 2). Overlays show the binding kinetics with analyte concentration increasing from the bottom to the top curve in all cases of (A) WT CcdB (3, 6, 12.5, $25 \mathrm{nM})$; (B) S12G (3, 6, 25, $50 \mathrm{nM})$; (C) E11R (50, 100, 200, 500 nM); (D) V18W (200, 500, 1000, 2000 nM); (E) V18W-S12G (200, 500, 1000, $2000 \mathrm{nM})$; (F) V20F (200, 1000, 2000, $5000 \mathrm{nM})$; (G) V20F-S12G (100, 200, 500, $1000 \mathrm{nM})$; (H) L36A (12.5, 25, 100, $200 \mathrm{nM})$; (I) L36A-S12G (3, 6, 12.5, $25 \mathrm{nM})$; (J) L36A-E11R (10, 21.4, 32, $64.2 \mathrm{nM})$; (K) L83S (200, 500, 1000, 2000 nM); (L) L83S-S12G (200, 500, 1000, 2000 nM); (M) L83S-E11R (50, 100, 200, 500 $\mathrm{nM})$. The ligand GyrA14 was immobilized on the CM5 chip by standard amine coupling. Binding was measured by passing varying concentrations of the analyte (CcdB proteins) over the ligand (GyrA14) immobilised chip and the data was fitted to the 1:1 Langmuir Interaction model to obtain the kinetic parameters (Additional file 7: Table S1). 

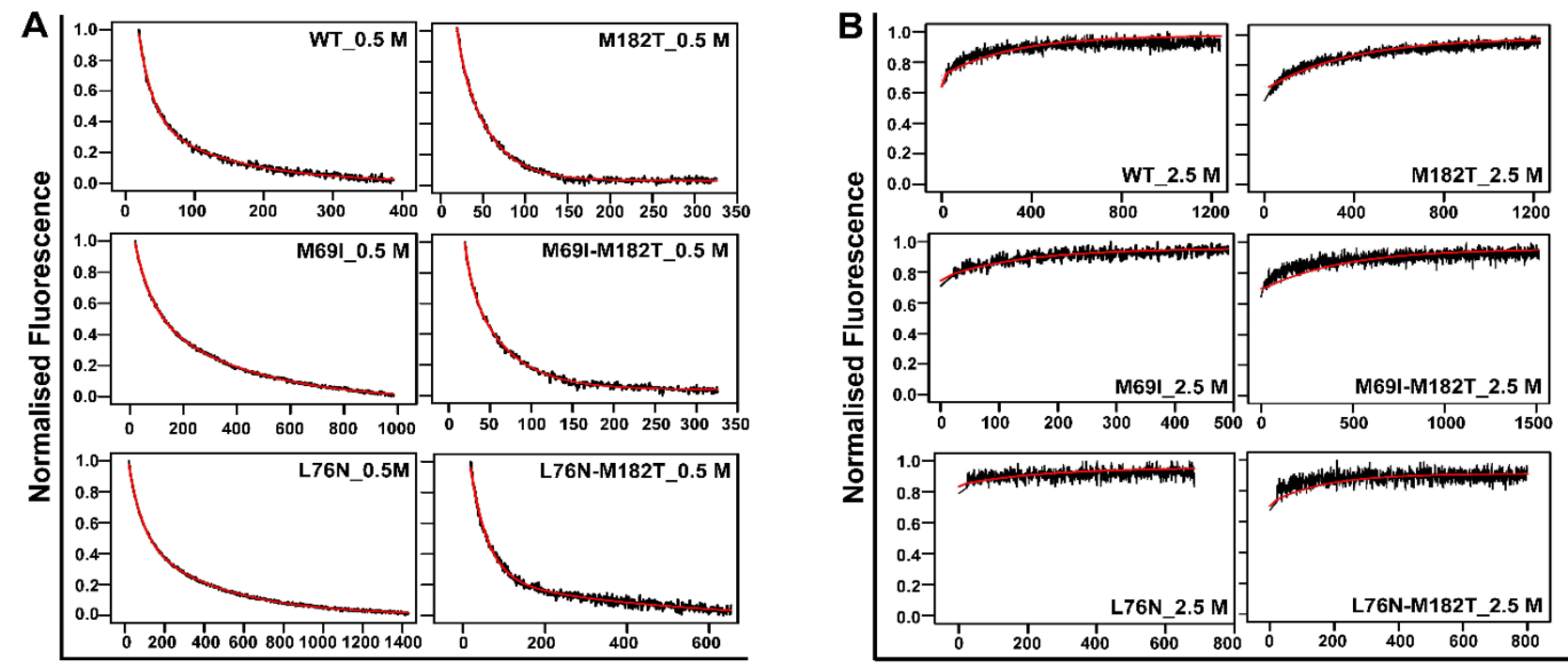

Time (s)

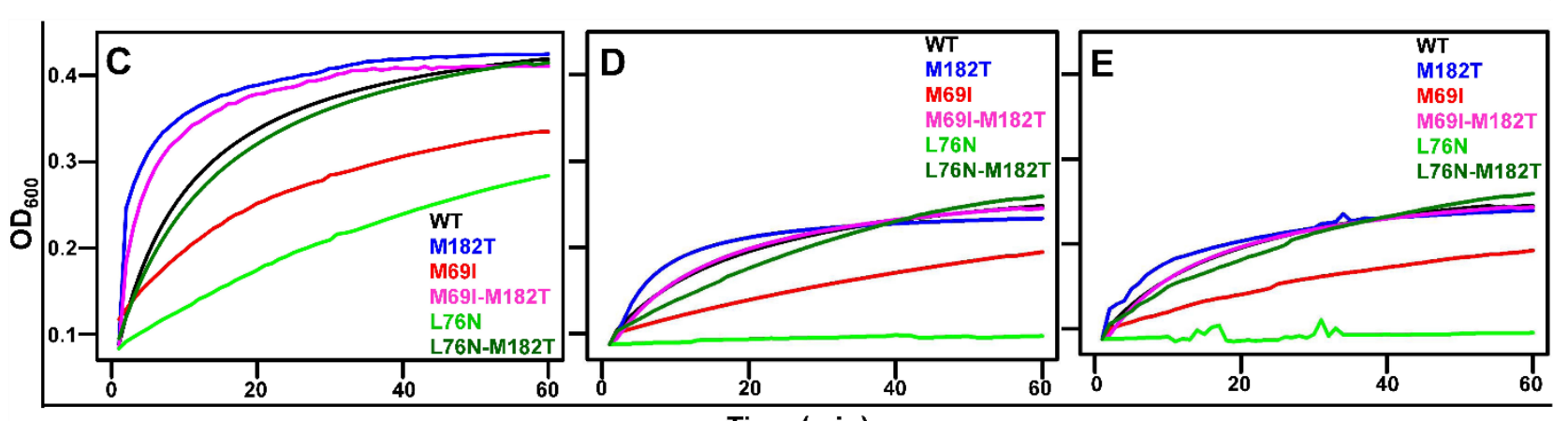

Time (min)
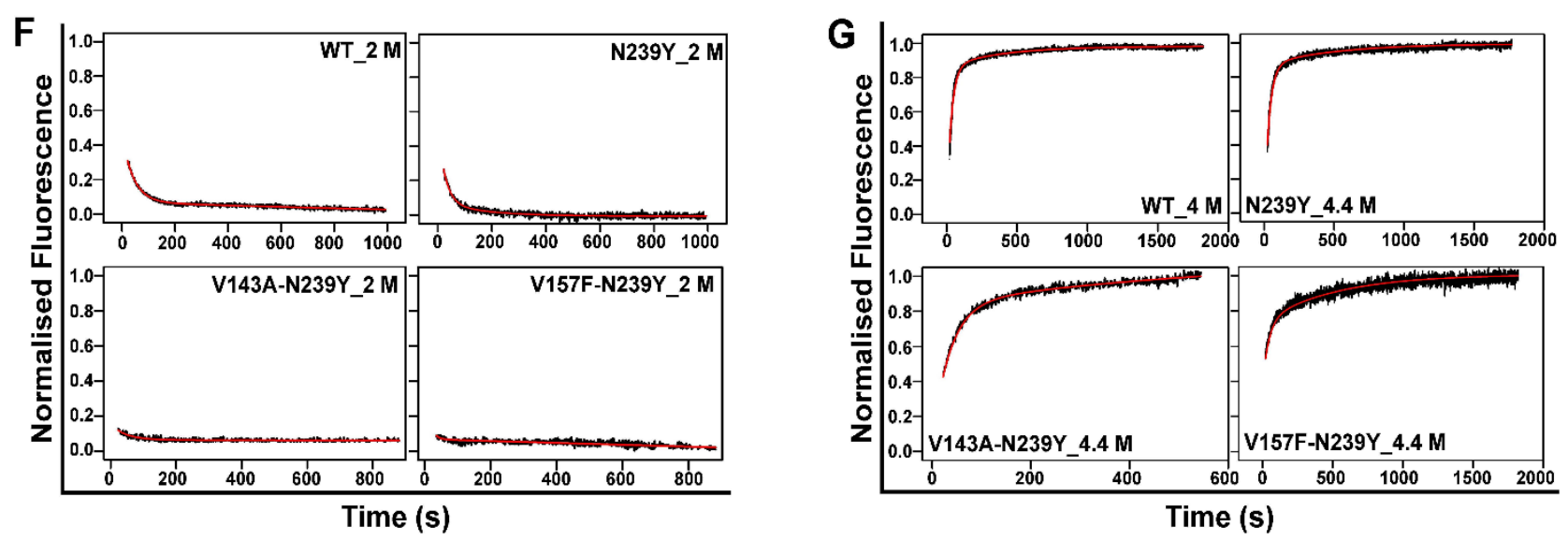

Additional file 5: Figure S5. Refolding and unfolding kinetics, and hydrolysis activities of TEM-

\section{$1 \beta$-lactamase mutant proteins (related to Figure 3) as well as refolding and unfolding kinetics of}

p53-DBD mutant proteins (related to Figure 4). (A) TEM-1 proteins exhibit biphasic refolding kinetics with a fast and slow phase whereas (B) unfolding follows single exponential kinetics. Representative kinetic traces at $5 \mu \mathrm{M}$ protein concentrations of WT and TEM-1 mutants are shown in presence of $0.5 \mathrm{M} \mathrm{GdnCl}$ for refolding and $2.5 \mathrm{M} \mathrm{GdnCl}$ for unfolding. The experimental kinetic traces 
obtained at the indicated $\mathrm{GdnCl}$ concentration are shown in black, while the fits are shown in red. The measured kinetic parameters are listed in Additional file 12: Table S6. The lactamase activities of the WT and mutants in the following conditions - (C) native, (D) native proteins in $0.5 \mathrm{M} \mathrm{GdnCl}$ and (E) refolded proteins in $0.5 \mathrm{M} \mathrm{GdnCl}$, were assayed by observing the rate of nitrocefin hydrolysis $(50 \mu \mathrm{M})$ at $486 \mathrm{~nm}$ at $25^{\circ} \mathrm{C}$ at a protein concentration of $10 \mathrm{nM}$. The M182T suppressor rescues the activity of M69I and L76N mutants. (F) p53-DBD proteins exhibit biphasic refolding kinetics with a significant burst, fast and slow phase whereas (G) unfolding of p53-DBD follows biphasic exponential kinetics with fast and slow phases. Representative kinetic traces at $5 \mu \mathrm{M}$ protein concentration of WT and p53DBD mutants are shown in the presence of $2 \mathrm{M}$ Urea for refolding and 4.4 M Urea for unfolding. The experimental kinetic traces obtained are shown in black, while the fits are shown in red. The measured kinetic parameters are listed in Additional file 13: Table S7. 

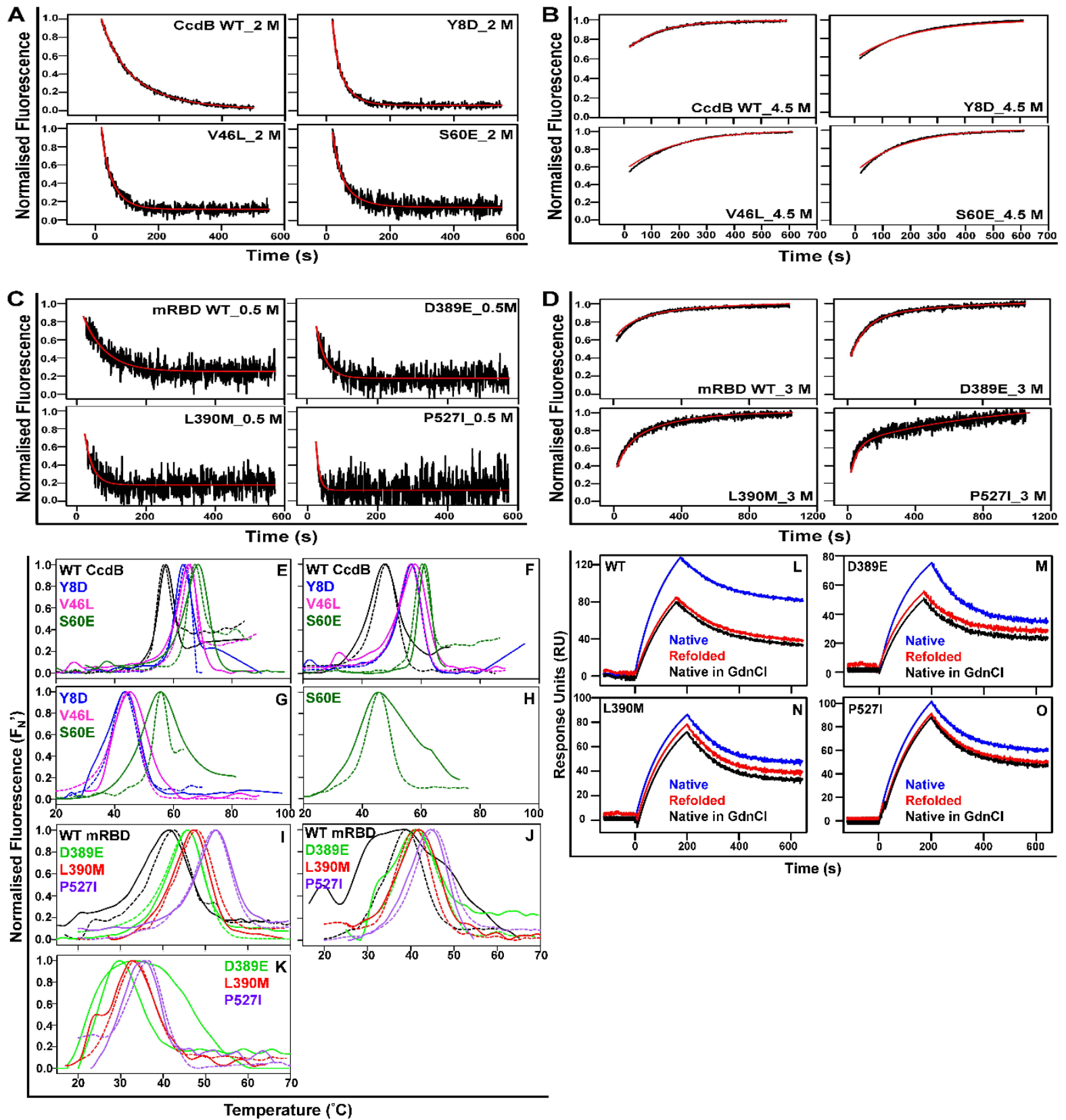

Additional file 6: Figure S6. Refolding and unfolding kinetics, and thermal denaturation studies of stabilised CcdB and mRBD proteins with suppressor mutations; binding studies of the mRBD proteins to ACE2-hFc neutralizing antibody (related to Figure 5). (A) Biphasic refolding kinetics with a fast and slow phase and (B) single exponential unfolding kinetics of CcdB mutant proteins. Representative kinetic traces at $5 \mu \mathrm{M}$ protein concentration of WT CcdB; Y8D; V46; S60E are shown. (C) mRBD proteins exhibit single phase refolding kinetics with a significant burst phase whereas (D) unfolding of mRBD proteins follows biphasic exponential kinetics with burst, fast and slow phases. Representative kinetic traces at $5 \mu \mathrm{M}$ protein concentration of WT mRBD; D389E; L390M; P527I are 
shown. The experimental kinetic traces obtained at different $\mathrm{GdnCl}$ concentrations are shown in black, while the fits are shown in red. The measured kinetic parameters are listed in Tables S9 for CcdB and mRBD mutants.

(E-H) Thermal denaturation traces of $5 \mu \mathrm{M}$ of native CcdB proteins in (E) $1 \mathrm{M}$, (F) $2 \mathrm{M},(\mathrm{G}) 3 \mathrm{M}$ and (H) $4 \mathrm{M} \mathrm{GdnCl}$ (represented by dashed lines) and refolded CcdB proteins in the same concentrations of $\mathrm{GdnCl}$ (represented by solid lines). WT CcdB failed to show any transition at $3 \mathrm{M}$, whereas Y8D and V46L failed to show a thermal unfolding transition at $4 \mathrm{M}$. S60E showed a thermal transition at 4 M. (I-K) Thermal denaturation traces of $5 \mu \mathrm{M}$ of native mRBD proteins in (I) $0.5 \mathrm{M}$, (J) $1 \mathrm{M}$ and (K) $2 \mathrm{M}$ (represented by dashed lines) and refolded mRBD proteins in same concentrations of $\mathrm{GdnCl}$ (represented by solid lines). mRBD WT failed to show any transition at $2 \mathrm{M}$, whereas the stabilised mutants show thermal unfolding upto $2 \mathrm{M} \mathrm{GdnCl}$. (L-O) Overlays show the ACE2-hFc binding of the WT and mRBD mutants in the following conditions - native, native in $0.5 \mathrm{M} \mathrm{GdnCl}$ and refolded in 0.5 M GdnCl for (L) WT mRBD, (M) D389E, (N) L390M and (O) P27I. The ligand ACE2-hFc was immobilized on Protein-G immobilised GLM sensor chip. Binding was measured by passing $50 \mathrm{nM}$ of the analyte (mRBD proteins) over the ligand (ACE2-hFc) immobilised chip. 
Additional file 7: Table S1 (Related to Figure 1 and 2). Fractional solubilities, thermal stabilities (determined by nanoDSF) and GyrA14 binding affinities (determined by SPR and MST) of different CcdB mutants ${ }^{1}$. Binding affinities of refolded proteins and proteins in $\mathrm{GdnCl}$ were also measured by MST. SPR experiments were carried out at $25^{\circ} \mathrm{C}, \mathrm{pH} 7.4$ and MST experiments were carried out at 25 ${ }^{\circ} \mathrm{C}, \mathrm{pH} 8.4$.

\begin{tabular}{|c|c|c|c|c|c|c|}
\hline \multirow[b]{2}{*}{ Mutants } & \multirow{2}{*}{$\begin{array}{l}\text { Fraction } \\
\text { Soluble }\end{array}$} & \multirow{2}{*}{$\begin{array}{c}\mathbf{T}_{\mathbf{m}} \\
\left({ }^{\circ} \mathbf{C}\right)\end{array}$} & \multirow{2}{*}{$\begin{array}{c}\text { KD } \\
(\mathbf{n M}) \\
\text { SPR }\end{array}$} & \multicolumn{3}{|c|}{ MST Studies } \\
\hline & & & & $\begin{array}{c}\text { KD }(\mathbf{n M}) \\
\text { Native }\end{array}$ & $\begin{array}{c}K_{D}(n M) \\
\text { Native in } \\
\text { GdnCl }\end{array}$ & $\begin{array}{l}K_{D}(n M) \\
\text { Refolded }\end{array}$ \\
\hline WT & 1.0 & $66 \pm 0.8$ & $1.4 \pm 0.6$ & $2.2 \pm 0.6$ & $41.8 \pm 3.2$ & $32.2 \pm 2.7$ \\
\hline E11R & 0.9 & $64 \pm 1.0$ & $2.5 \pm 0.3$ & $1.2 \pm 0.3$ & $3.2 \pm 0.3$ & $2.4 \pm 0.4$ \\
\hline S12G & 0.9 & $68 \pm 0.8$ & $2.6 \pm 1.4$ & $2.3 \pm 0.8$ & $74.5 \pm 10$ & $99 \pm 15$ \\
\hline V18W & 0.2 & $54 \pm 09$ & NB & $2046.9 \pm 132$ & $2241.8^{3} \pm 168$ & $2577.4^{\mathrm{a}} \pm 196$ \\
\hline V18W-E11R ${ }^{2}$ & 0.6 & - & - & - & - & - \\
\hline V18W-S12G & 0.6 & $66 \pm 0.9$ & $57 \pm 13.2$ & $30.2 \pm 4$ & $132.2 \pm 12$ & $149.3 \pm 16$ \\
\hline V20F & 0.3 & $47 \pm 0.8$ & NB & $623.5 \pm 92$ & $1465.1^{4} \pm 117$ & $1078.0^{\mathrm{b}} \pm 102$ \\
\hline V20F-E11R & 0.5 & - & - & - & - & - \\
\hline V20F-S12G & 0.4 & $60 \pm 0.8$ & $12.7 \pm 4$ & $20.9 \pm 12$ & $130.9 \pm 48$ & $103.6 \pm 29$ \\
\hline L36A & 0.3 & $58 \pm 1.0$ & $9.5 \pm 4$ & $17.5 \pm 7$ & $125.2 \pm 30$ & $162.0 \pm 54$ \\
\hline L36A-E11R & 0.6 & $63 \pm 1.0$ & $3.0 \pm 1.3$ & $13 \pm 1.3$ & $16.0 \pm 1.3$ & $1.3 \pm 1.0$ \\
\hline L36A-S12G & 0.7 & $63 \pm 0.2$ & $0.4 \pm 0.7$ & $0.3 \pm 1.4$ & $1.5 \pm 0.6$ & $2.3 \pm 2$ \\
\hline L83S & 0.4 & $59 \pm 0.8$ & $75.0 \pm 15.3$ & $88.7 \pm 19$ & $175.3 \pm 63$ & $199.4 \pm 45$ \\
\hline L83S-E11R & 0.5 & $67 \pm 0.5$ & $6.8 \pm 2.9$ & $0.30 \pm 0.1$ & $16 \pm 2.9$ & $0.4 \pm 0.1$ \\
\hline L83S-S12G & 0.5 & $66 \pm 0.7$ & $7.2 \pm 11.3$ & $4.12 \pm 2.3$ & $11.9 \pm 9.4$ & $13 \pm 7.2$ \\
\hline
\end{tabular}

${ }^{1}$ Reported standard errors are derived from two independent experiments, each performed in duplicates.

${ }^{2}$ Mutants could not be purified.

${ }^{3,4}$ Refolded in $0.1 \mathrm{M} \mathrm{GdnCl}$. All the other proteins were refolded in $1.5 \mathrm{M} \mathrm{GdnCl}$.

NB: No Binding. 
Additional file 8: Table S2 (Related to Figure 2). Kinetic Parameters for refolding and unfolding of $\mathrm{CcdB}$ mutants measured under different buffer conditions at $25^{\circ} \mathrm{C}, \mathrm{pH} 8.4^{1}$.

\begin{tabular}{|c|c|c|c|c|c|c|c|c|c|}
\hline \multirow{3}{*}{ Mutant } & \multirow{3}{*}{$\begin{array}{c}\text { [GdnCl] } \\
\text { (Refold/ } \\
\text { Unfold) (M) }\end{array}$} & \multicolumn{5}{|c|}{ Refolding } & \multicolumn{3}{|c|}{ Unfolding } \\
\hline & & \multicolumn{3}{|c|}{ Fast Phase } & \multicolumn{2}{|c|}{ Slow Phase } & \multirow{2}{*}{ A0 } & \multirow{2}{*}{ A1 } & \multirow{2}{*}{$\mathbf{k u}_{1}\left(\mathrm{~s}^{-1}\right)$} \\
\hline & & a0 & a1 & $\mathbf{k f} \mathbf{f}_{1}\left(\mathrm{~s}^{-1}\right)$ & $\mathbf{a} 2$ & $k f_{2}\left(s^{-1}\right)$ & & & \\
\hline WT & $(1.5 / 3.5)$ & $\begin{array}{c}0.02 \pm \\
0.02\end{array}$ & $\begin{array}{c}0.55 \pm \\
0.03\end{array}$ & $\begin{array}{l}0.027 \\
\pm 0.02\end{array}$ & $\begin{array}{c}0.43 \pm \\
0.03\end{array}$ & $\begin{array}{c}0.002 \pm \\
0.001\end{array}$ & $\begin{array}{c}0.60 \pm \\
0.03\end{array}$ & $\begin{array}{c}0.40 \pm \\
0.01\end{array}$ & $\begin{array}{c}0.05 \pm \\
0.05\end{array}$ \\
\hline E11R & $(1.5 / 3.5)$ & $\begin{array}{c}0.14 \pm \\
0.03\end{array}$ & $\begin{array}{c}0.44 \pm \\
0.08\end{array}$ & $\begin{array}{l}0.080 \\
\pm 0.01\end{array}$ & $\begin{array}{c}0.42 \pm \\
0.04\end{array}$ & $\begin{array}{l}0.02 \pm \\
0.0066\end{array}$ & $\begin{array}{l}0.51 \pm \\
0.04\end{array}$ & $\begin{array}{c}0.49 \pm \\
0.04\end{array}$ & $\begin{array}{l}0.04 \pm \\
0.08\end{array}$ \\
\hline S12G & $(1.5 / 3.5)$ & $\begin{array}{c}0.03 \pm \\
0.03\end{array}$ & $\begin{array}{c}0.79 \pm \\
0.02\end{array}$ & $\begin{array}{l}0.041 \\
\pm 0.05\end{array}$ & $\begin{array}{c}0.18 \pm \\
0.02\end{array}$ & $\begin{array}{c}0.001 \pm \\
0.003\end{array}$ & $\begin{array}{c}0.44 \pm \\
0.02\end{array}$ & $\begin{array}{c}0.56 \pm \\
0.03\end{array}$ & $\begin{array}{c}0.03 \pm \\
0.03\end{array}$ \\
\hline V18W & $(0.5 / 2.0)$ & $\begin{array}{c}0.03 \pm \\
0.06\end{array}$ & $\begin{array}{l}0.52 \pm \\
0.03\end{array}$ & $\begin{array}{l}0.030 \\
\pm 0.03\end{array}$ & $\begin{array}{c}0.45 \pm \\
0.06\end{array}$ & $\begin{array}{c}0.003 \pm \\
0.01\end{array}$ & $\begin{array}{c}0.63 \pm \\
0.09\end{array}$ & $\begin{array}{c}0.37 \pm \\
0.09\end{array}$ & $\begin{array}{c}0.29 \pm \\
0.03\end{array}$ \\
\hline V18W-S12G & $(0.5 / 2.0)$ & $\begin{array}{c}0.20 \pm \\
0.01\end{array}$ & $\begin{array}{c}0.40 \pm \\
0.08\end{array}$ & $\begin{array}{l}0.095 \\
\pm 0.13\end{array}$ & $\begin{array}{c}0.40 \pm \\
0.06\end{array}$ & $\begin{array}{c}0.015 \pm \\
0.044\end{array}$ & $\begin{array}{l}0.46 \pm \\
0.03\end{array}$ & $\begin{array}{c}0.54 \pm \\
0.03\end{array}$ & $\begin{array}{l}0.10 \pm \\
0.05\end{array}$ \\
\hline V20F & $(0.5 / 2.0)$ & $\begin{array}{l}0.02 \pm \\
0.05\end{array}$ & $\begin{array}{c}0.71 \pm \\
0.06\end{array}$ & $\begin{array}{l}0.024 \\
\pm 0.01\end{array}$ & $\begin{array}{c}0.27 \pm \\
0.06\end{array}$ & $\begin{array}{c}0.002 \pm \\
0.07\end{array}$ & $\begin{array}{c}0.76 \pm \\
0.01\end{array}$ & $\begin{array}{c}0.24 \pm \\
0.01\end{array}$ & $\begin{array}{c}0.44 \pm \\
0.08\end{array}$ \\
\hline V20F-S12G & $(0.5 / 2.0)$ & $\begin{array}{c}0.02 \pm \\
0.07\end{array}$ & $\begin{array}{c}0.67 \pm \\
0.15\end{array}$ & $\begin{array}{l}0.104 \\
\pm 0.09\end{array}$ & $\begin{array}{c}0.31 \pm \\
0.08\end{array}$ & $\begin{array}{l}0.02 \pm \\
0.002\end{array}$ & $\begin{array}{c}0.66 \pm \\
0.04\end{array}$ & $\begin{array}{c}0.34 \pm \\
0.03\end{array}$ & $\begin{array}{c}0.16 \pm \\
0.04\end{array}$ \\
\hline L36A & $(1.0 / 3.5)$ & $\begin{array}{c}0.05 \pm \\
0.09\end{array}$ & $\begin{array}{l}0.55 \pm \\
0.04\end{array}$ & $\begin{array}{l}0.016 \\
\pm 0.08\end{array}$ & $\begin{array}{c}0.40 \pm \\
0.08\end{array}$ & $\begin{array}{c}0.001 \pm \\
0.001\end{array}$ & $\begin{array}{c}0.77 \pm \\
0.08\end{array}$ & $\begin{array}{c}0.27 \pm \\
0.09\end{array}$ & $\begin{array}{c}0.24 \pm \\
0.02\end{array}$ \\
\hline L36A-E11R & $(1.0 / 3.5)$ & $\begin{array}{c}0.10 \pm \\
0.02\end{array}$ & $\begin{array}{c}0.53 \pm \\
0.03\end{array}$ & $\begin{array}{l}0.046 \\
\pm 0.02\end{array}$ & $\begin{array}{c}0.36 \pm \\
0.03\end{array}$ & $\begin{array}{c}0.001 \pm \\
0.001\end{array}$ & $\begin{array}{c}0.61 \pm \\
0.01\end{array}$ & $\begin{array}{c}0.39 \pm \\
0.01\end{array}$ & $\begin{array}{c}0.17 \pm \\
0.08\end{array}$ \\
\hline L36A-S12G & $(1.0 / 3.5)$ & $\begin{array}{l}0.10 \pm \\
0.01\end{array}$ & $\begin{array}{l}0.54 \pm \\
0.07\end{array}$ & $\begin{array}{l}0.064 \\
\pm 0.01\end{array}$ & $\begin{array}{c}0.34 \pm \\
0.05\end{array}$ & $\begin{array}{l}0.007 \pm \\
0.0066\end{array}$ & $\begin{array}{l}0.64 \pm \\
0.02\end{array}$ & $\begin{array}{l}0.36 \pm \\
0.02\end{array}$ & $\begin{array}{c}0.07 \pm \\
0.03\end{array}$ \\
\hline L83S & $(1.0 / 3.5)$ & $\begin{array}{c}0.03 \pm \\
0.01\end{array}$ & $\begin{array}{c}0.62 \pm \\
0.01\end{array}$ & $\begin{array}{l}0.032 \\
\pm 0.05\end{array}$ & $\begin{array}{c}0.35 \pm \\
0.02\end{array}$ & $\begin{array}{c}0.004 \pm \\
0.006\end{array}$ & $\begin{array}{c}0.77 \pm \\
0.03\end{array}$ & $\begin{array}{c}0.23 \pm \\
0.03\end{array}$ & $\begin{array}{c}0.28 \pm \\
0.09\end{array}$ \\
\hline L83S-E11R & $(1.0 / 3.5)$ & $\begin{array}{c}0.62 \pm 0 . \\
04\end{array}$ & - & - & $\begin{array}{c}0.38 \pm \\
0.04\end{array}$ & $\begin{array}{c}0.035 \pm \\
0.001\end{array}$ & $\begin{array}{c}0.72 \pm \\
0.01\end{array}$ & $\begin{array}{c}0.28 \pm \\
0.02\end{array}$ & $\begin{array}{c}0.10 \pm \\
0.03\end{array}$ \\
\hline L83S-S12G & $(1.0 / 3.5)$ & $\begin{array}{l}0.02 \pm \\
0.07\end{array}$ & $\begin{array}{c}0.62 \pm \\
0.02\end{array}$ & $\begin{array}{l}0.096 \\
\pm 0.08\end{array}$ & $\begin{array}{c}0.36 \pm \\
0.01\end{array}$ & $\begin{array}{c}0.012 \pm \\
0.01\end{array}$ & $\begin{array}{c}0.71 \pm \\
0.06\end{array}$ & $\begin{array}{c}0.29 \pm \\
0.06\end{array}$ & $\begin{array}{c}0.15 \pm \\
0.08\end{array}$ \\
\hline
\end{tabular}

${ }^{1}$ Reported standard errors are derived from two independent experiments, each performed in duplicates. 
Additional file 9: Table S3 (Related to Figure 2). Relative Kinetic Parameters for in vitro Refolding and Unfolding of CcdB mutants extrapolated to zero denaturant ${ }^{1}$.

\begin{tabular}{|c|c|c|c|c|c|c|}
\hline \multirow{3}{*}{ Mutants } & \multicolumn{4}{|c|}{ Refolding } & \multicolumn{2}{|c|}{ Unfolding } \\
\hline & \multicolumn{2}{|c|}{ Fast Phase } & \multicolumn{2}{|c|}{ Slow Phase } & \multirow[b]{2}{*}{$\begin{array}{c}\mathbf{m}_{\text {kinetic (U) }} \\
\text { value }\left(\mathbf{M}^{-1} \mathbf{s}^{-1}\right)\end{array}$} & \multirow{2}{*}{$\begin{array}{c}\text { rate } \\
\text { constant }^{2}\left(\mathrm{~s}^{-}\right. \\
1)\end{array}$} \\
\hline & $\begin{array}{c}\mathbf{m}_{\text {kinetic fast }} \\
\text { value }\left(\mathbf{M}^{-1} \mathbf{s}^{-1}\right)\end{array}$ & $\begin{array}{c}\text { rate } \\
\text { constant }{ }^{2} \\
\left(\mathrm{~s}^{-1}\right)\end{array}$ & $\begin{array}{c}\mathbf{m}_{\text {kinetic slow value }} \\
\left(\mathbf{M}^{-1} \mathbf{s}^{-1}\right)\end{array}$ & $\begin{array}{c}\text { rate } \\
\text { constant }^{2} \\
\left(\mathbf{s}^{-1}\right)\end{array}$ & & \\
\hline WT & $0.29 \pm 0.004$ & $0.44 \pm 0.04$ & $0.03 \pm 0.002$ & $0.05 \pm 0.01$ & $0.02 \pm 0.002$ & $0.005 \pm 0.01$ \\
\hline E11R & $0.58 \pm 0.005$ & $0.94 \pm 0.009$ & $0.09 \pm 0.003$ & $0.15 \pm 0.02$ & $0.02 \pm 0.003$ & $0.002 \pm 0.02$ \\
\hline S12G & $0.52 \pm 0.010$ & $0.81 \pm 0.12$ & $0.08 \pm 0.001$ & $0.13 \pm 0.008$ & $0.02 \pm 0.001$ & $0.002 \pm 0.008$ \\
\hline V18W & $0.06 \pm 0.005$ & $0.06 \pm 0.001$ & $9 e-3 \pm 0.003$ & $7 e-3 \pm 0.001$ & $0.35 \pm 0.08$ & $0.032 \pm 0.08$ \\
\hline $\begin{array}{l}\text { V18W- } \\
\text { S12G }\end{array}$ & $0.20 \pm 0.009$ & $0.19 \pm 0.01$ & $0.03 \pm 0.004$ & $0.06 \pm 0.004$ & $0.14 \pm 0.004$ & $0.019 \pm 0.004$ \\
\hline V20F & $0.03 \pm 0.006$ & $0.04 \pm 0.004$ & $4 e-3 \pm 0.002$ & $4 e-3 \pm 0.001$ & $0.45 \pm 0.08$ & $0.045 \pm 0.01$ \\
\hline $\begin{array}{l}\text { V20F- } \\
\text { S12G }\end{array}$ & $0.26 \pm 0.09$ & $0.23 \pm 0.12$ & $0.04 \pm 0.03$ & $0.04 \pm 0.01$ & $0.16 \pm 0.004$ & $0.015 \pm 0.01$ \\
\hline L36A & $0.10 \pm 0.02$ & $0.11 \pm 0.05$ & $0.01 \pm 0.01$ & $0.01 \pm 0.02$ & $0.12 \pm 0.03$ & $0.019 \pm 0.04$ \\
\hline $\begin{array}{l}\text { L36A- } \\
\text { E11R }\end{array}$ & $0.21 \pm 0.02$ & $0.26 \pm 0.03$ & $0.03 \pm 0.01$ & $0.03 \pm 0.01$ & $0.06 \pm 0.0001$ & $0.011 \pm 0.003$ \\
\hline $\begin{array}{l}\text { L36A- } \\
\text { S12G }\end{array}$ & $0.39 \pm 0.007$ & $0.44 \pm 0.01$ & $0.06 \pm 0.002$ & $0.06 \pm 0.04$ & $0.05 \pm 0.001$ & $0.010 \pm 0.001$ \\
\hline L83S & $0.13 \pm 0.02$ & $0.17 \pm 0.03$ & $0.02 \pm 0.002$ & $0.02 \pm 0.003$ & $0.11 \pm 0.003$ & $0.012 \pm 0.02$ \\
\hline $\begin{array}{l}\text { L83S- } \\
\text { E11R }\end{array}$ & -3 & -3 & $0.10 \pm 0.003$ & $0.16 \pm 0.01$ & $0.04 \pm 0.0008$ & $0.004 \pm 2 \mathrm{e}-3$ \\
\hline $\begin{array}{l}\text { L83S- } \\
\text { S12G }\end{array}$ & $0.50 \pm 0.005$ & $0.60 \pm 0.057$ & $0.09 \pm 0.003$ & $0.10 \pm 0.004$ & $0.06 \pm 0.02$ & $0.006 \pm 0.001$ \\
\hline
\end{tabular}

${ }^{1}$ Reported standard errors are derived from two independent experiments, each performed in duplicates.

${ }^{2}$ Reported rate constants are extrapolated to $0 \mathrm{M} \mathrm{GdnCl}$ for relative comparison among different mutants.

${ }^{3}$ Fast phase of refolding couldn't be captured. 
Additional file 10: Table S4 (Related to Figure 2, S1). Top: Thermodynamic parameters $\left(\mathrm{C}_{\mathrm{m}}, \Delta \mathrm{G}^{0}\right.$,

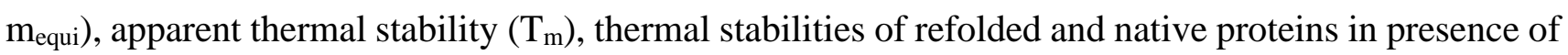
1.5 M GdnCl ( $\left.\mathrm{T}_{\mathrm{mRefold}}, \mathrm{T}_{\mathrm{mGdnCl}}\right)$. Bottom: Kinetic parameters for refolding and unfolding of CcdB WT and $\mathrm{E} 11 \mathrm{R}$ in $1.5 \mathrm{M}$ and $4 \mathrm{M} \mathrm{GdnCl}$ in $1 \mathrm{X} \mathrm{PBS}$ at $25^{\circ} \mathrm{C}^{1}$.

\begin{tabular}{|c|c|c|c|c|c|c|c|c|c|}
\hline Mutants & $\begin{array}{l}\mathbf{C}_{\mathbf{m}} \\
(\mathbf{M})\end{array}$ & \multicolumn{2}{|c|}{$\begin{array}{c}\Delta G^{0} \\
\left(k^{\prime} c a l . m o l^{-1}\right)\end{array}$} & \multicolumn{2}{|c|}{$\begin{array}{c}\text { mequi } \\
\left(\text { kcal.mol }^{-1} \mathbf{M}^{-1}\right)\end{array}$} & $\begin{array}{l}\mathbf{T}_{\mathbf{m}} \\
\left({ }^{\circ} \mathbf{C}\right)\end{array}$ & \multicolumn{2}{|c|}{$\begin{array}{c}\text { TmRefold } \\
\left({ }^{\circ} \mathbf{C}\right)\end{array}$} & $\begin{array}{c}\text { TmGdnCl }_{\text {mat }} \\
\left({ }^{\circ} \mathrm{C}\right)\end{array}$ \\
\hline WT & $2.9 \pm 0.2$ & \multicolumn{2}{|c|}{$19.4 \pm 0.7$} & \multicolumn{2}{|c|}{$4.2 \pm 0.3$} & $\begin{array}{l}65 \pm \\
0.6\end{array}$ & \multicolumn{2}{|c|}{$56 \pm 0.5$} & $57 \pm 0.5$ \\
\hline E11R & $2.8 \pm 0.1$ & \multicolumn{2}{|c|}{$18.7 \pm 1.0$} & \multicolumn{2}{|c|}{$4.1 \pm 0.5$} & $64 \pm$ & \multicolumn{2}{|c|}{$55 \pm 0.6$} & $56 \pm 0.6$ \\
\hline \multirow{3}{*}{ Mutants } & \multicolumn{6}{|c|}{ Refolding } & \multicolumn{3}{|c|}{ Unfolding } \\
\hline & \multicolumn{3}{|c|}{ Fast Phase } & \multicolumn{3}{|c|}{ Slow Phase } & \multirow[b]{2}{*}{ A0 } & \multirow[b]{2}{*}{ A1 } & \multirow{2}{*}{$\begin{array}{l}\mathbf{k u} \mathbf{1}_{1} \\
\left(\mathrm{~s}^{-1}\right)\end{array}$} \\
\hline & a0 & a1 & $\begin{array}{l}\mathbf{k f _ { 1 }} \\
\left(\mathbf{s}^{-1}\right)\end{array}$ & a2 & & $\mathbf{f}_{2}$ & & & \\
\hline \multirow{2}{*}{ WT } & $0.03 \pm$ & $0.56 \pm$ & 0.044 & $0.41 \pm$ & & $15 \pm$ & $0.58 \pm$ & $0.42 \pm$ & $0.017 \pm$ \\
\hline & 0.001 & 0.03 & \pm 0.004 & 0.04 & & 003 & 0.02 & 0.01 & 0.001 \\
\hline \multirow{2}{*}{ E11R } & $0.08 \pm$ & $0.53 \pm$ & 0.09 & $0.39 \pm$ & & $24 \pm$ & $0.57 \pm$ & $0.43 \pm$ & $0.016 \pm$ \\
\hline & 0.001 & 0.02 & \pm 0.01 & 0.04 & & 001 & 0.009 & 0.04 & 0.002 \\
\hline
\end{tabular}

${ }^{1}$ Reported standard errors are derived from two independent experiments, each performed in duplicates. 
Additional file 11: Table S5 (Related to Figure 2). Thermodynamic stability parameters $\left(\mathrm{C}_{\mathrm{m}}, \Delta \mathrm{G}^{0}\right.$,

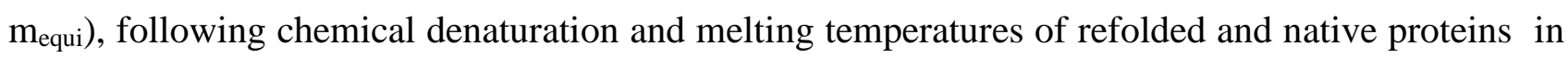
presence of $1.5 \mathrm{M} \mathrm{GdnCl}$ ( $\left.\mathrm{T}_{\mathrm{mRefold}}, \mathrm{T}_{\mathrm{mGdnCl}}\right)$ determined by nanoDSF, of different $\mathrm{CcdB}$ mutants ${ }^{1}$. Residual activity after high temperature incubation of CcdB mutants was determined by SPR at room temperature.

\begin{tabular}{|c|c|c|c|c|c|c|c|}
\hline \multirow{2}{*}{ Mutants } & \multirow{2}{*}{$\begin{array}{l}\mathbf{C}_{\mathbf{m}} \\
(\mathbf{M})\end{array}$} & \multirow{2}{*}{$\begin{array}{c}\Delta G^{0} \\
\left(\text { kcal.mol }^{-1}\right)\end{array}$} & \multirow{2}{*}{$\begin{array}{c}\mathrm{m}_{\text {equi }} \\
\left(\text { kcal.mol }^{-1} \mathbf{M}^{-1}\right)\end{array}$} & \multirow{2}{*}{$\begin{array}{c}\mathbf{T}_{\text {mRefold }} \\
\left({ }^{\circ} \mathbf{C}\right)\end{array}$} & \multirow{2}{*}{$\begin{array}{c}\mathbf{T}_{\mathbf{m G d n C l}} \\
\left({ }^{\circ} \mathrm{C}\right)\end{array}$} & \multicolumn{2}{|c|}{$\begin{array}{c}\text { Residual } \\
\text { activity }(\%)\end{array}$} \\
\hline & & & & & & $40^{\circ} \mathrm{C}$ & $\begin{array}{l}80 \\
80 \\
{ }^{\circ} \mathrm{C}\end{array}$ \\
\hline WT & $2.8 \pm 0.1$ & $21.1 \pm 0.7$ & $4.97 \pm 0.5$ & $53 \pm 0.5$ & $52 \pm 0.8$ & 24 & 0.8 \\
\hline E11R & $2.3 \pm 0.2$ & $18.0 \pm 1.8$ & $4.55 \pm 0.5$ & $55 \pm 0.4$ & $55 \pm 0.5$ & 1.2 & 0.6 \\
\hline S12G & $3.0 \pm 0.3$ & $21.9 \pm 1.4$ & $4.90 \pm 0.2$ & $55 \pm 0.9$ & $55 \pm 1.4$ & 61 & 3.7 \\
\hline V18W & $0.8 \pm 0.7$ & $11.0 \pm 1.8$ & $4.00 \pm 1.2$ & 2 & 2 & - & - \\
\hline V18W-S12G & $1.3 \pm 0.09$ & $13.5 \pm 0.8$ & $4.87 \pm 0.2$ & $45 \pm 0.4$ & $43 \pm 0.9$ & - & - \\
\hline V20F & $0.3 \pm 0.02$ & $8.6 \pm 1.8$ & $4.06 \pm 0.2$ & 3 & 3 & - & - \\
\hline V20F-S12G & $1.0 \pm 0.4$ & $12.1 \pm 1.4$ & $4.88 \pm 0.2$ & $43 \pm 1.2$ & $43 \pm 0.6$ & - & - \\
\hline L36A & $1.5 \pm 0.4$ & $13.9 \pm 0.3$ & $4.45 \pm 1.4$ & $45 \pm 1.4$ & $46 \pm 0.9$ & 11.7 & 0.4 \\
\hline L36A-E11R & $2.4 \pm 0.4$ & $18.9 \pm 1.2$ & $4.50 \pm 0.5$ & $51 \pm 0.8$ & $51 \pm 0.4$ & 34 & 2.4 \\
\hline L36A-S12G & $2.4 \pm 0.3$ & $18.8 \pm 0.9$ & $4.82 \pm 0.7$ & $52 \pm 1.2$ & $51 \pm 0.6$ & 47.6 & 9.1 \\
\hline L83S & $1.6 \pm 0.1$ & $14.4 \pm 1.7$ & $4.43 \pm 0.8$ & $43 \pm 0.2$ & $41 \pm 1.8$ & - & - \\
\hline L83S-E11R & $2.1 \pm 0.2$ & $18.3 \pm 3.2$ & $4.73 \pm 0.5$ & $54 \pm 0.1$ & $53 \pm 0.6$ & - & - \\
\hline L83S-S12G & $2.3 \pm 0.9$ & $18.6 \pm 1.3$ & $4.70 \pm 0.9$ & $55 \pm 0.9$ & $55 \pm 0.6$ & - & - \\
\hline
\end{tabular}

${ }^{1}$ Reported standard errors are derived from two independent experiments, each performed in duplicates.

${ }^{2,3}$ Could not be refolded in $1.5 \mathrm{M} \mathrm{GdnCl}$. All the other proteins were refolded in $1.5 \mathrm{M} \mathrm{GdnCl}$.

-Not determined. 
Additional file 12: Table S6 (Related to Figure 3). Top: MIC and $\mathrm{IC}_{90}$ for ampicillin and cefotaxime from $\mathrm{OD}_{600}$ and plate data measurements, thermodynamic stability parameters $\left(\mathrm{C}_{\mathrm{m}}, \Delta \mathrm{G}^{0}, \mathrm{~m}_{\text {equi }}\right)$, apparent thermal stability $\left(\mathrm{T}_{\mathrm{m}}\right)$, thermal stabilities of refolded proteins and native proteins in presence of $0.5 \mathrm{M} \mathrm{GdnCl}$ ( $\left.\mathrm{T}_{\mathrm{mRefold}}, \mathrm{T}_{\mathrm{mGdnCl}}\right)$, of different TEM-1 $\beta$-lactamase mutants ${ }^{1}$. Bottom: Kinetic Parameters for refolding and unfolding of TEM-1 $\beta$-lactamase mutants measured in $0.5 \mathrm{M}$ and $2.5 \mathrm{M}$ $\mathrm{GdnCl}$ respectively carried out in $10 \mathrm{mM}$ HEPES, $300 \mathrm{mM} \mathrm{NaCl}, 10 \%$ glycerol, $\mathrm{pH} 7.0$, at $25^{\circ} \mathrm{C}^{1}$.

\begin{tabular}{|c|c|c|c|c|c|c|c|c|c|c|c|}
\hline \multirow[t]{2}{*}{ Mutants } & \multicolumn{2}{|c|}{$\begin{array}{l}\text { Ampicillin } \\
(\mu \mathrm{g} / \mathrm{mL})\end{array}$} & \multicolumn{2}{|c|}{$\begin{array}{c}\text { Cefotaxime } \\
(\mu \mathrm{g} / \mathrm{mL})\end{array}$} & \multirow{2}{*}{$\begin{array}{l}\mathrm{C}_{\mathrm{m}} \\
(\mathrm{M})\end{array}$} & \multirow{2}{*}{$\begin{array}{c}\Delta G^{0} \\
\left(k_{c c a l . m o l}^{-1}\right)\end{array}$} & \multirow{2}{*}{\multicolumn{2}{|c|}{$\begin{array}{c}\mathrm{m}_{\text {equi }} \\
\left(\text { kcal.mol }^{-1} \mathbf{M}^{-1}\right)\end{array}$}} & \multirow{2}{*}{$\begin{array}{c}\mathbf{T}_{\mathbf{m}} \\
\left({ }^{\circ} \mathbf{C}\right)\end{array}$} & \multirow{2}{*}{$\begin{array}{c}\text { TmRefold } \\
\left({ }^{\circ} \mathbf{C}\right)\end{array}$} & \multirow{2}{*}{$\begin{array}{c}\mathbf{T}_{\mathbf{m G d n C l},}, \\
\left({ }^{\circ} \mathbf{C}\right)\end{array}$} \\
\hline & MIC & $\mathrm{IC}_{90}$ & MIC & IC90 & & & & & & & \\
\hline WT & $\approx 3000$ & 4000 & 16 & 10 & $1.2 \pm 0.1$ & $2.9 \pm 0.5$ & $2.4 \pm 0.1$ & & $51 \pm 0.2$ & $41 \pm 0.4$ & $41 \pm 0.2$ \\
\hline M182T & $\approx 3000$ & 4000 & 16 & 15 & $1.9 \pm 0.3$ & $4.7 \pm 0.6$ & $3.1 \pm 0.3$ & & $57 \pm 0.1$ & $47 \pm 0.3$ & $48 \pm 0.5$ \\
\hline M69I & $\approx 800$ & 1000 & 8 & 6 & $0.6 \pm 0.1$ & $2.0 \pm 0.2$ & $2.1 \pm 0.2$ & & $47 \pm 0.3$ & $31 \pm 0.1$ & $32 \pm 0.4$ \\
\hline $\begin{array}{l}\text { M69I- } \\
\text { M182T }\end{array}$ & $\approx 800$ & 1000 & 8 & 6 & $1.4 \pm 0.2$ & $4.0 \pm 0.3$ & $2.8 \pm 0.1$ & & $54 \pm 0.2$ & $44 \pm 0.2$ & $44 \pm 0.3$ \\
\hline L76N & $\approx 50$ & 20 & 2 & $<1$ & $0.5 \pm 0.1$ & $1.1 \pm 0.1$ & $1.8 \pm 0.2$ & & $40 \pm 0.5$ & NT & NT \\
\hline $\begin{array}{l}\text { L76N- } \\
\text { M182T }\end{array}$ & $\approx 1500$ & 1500 & 4 & 4 & $1.1 \pm 0.2$ & $2.8 \pm 0.3$ & $2.3 \pm 0.4$ & & $48 \pm 0.3$ & $39 \pm 0.1$ & $39 \pm 0.5$ \\
\hline \multirow{3}{*}{ Mutants } & \multicolumn{6}{|c|}{ Refolding } & \multicolumn{5}{|c|}{ Unfolding } \\
\hline & \multicolumn{3}{|c|}{ Fast Phase } & & \multicolumn{2}{|c|}{ Slow Phase } & \multirow{2}{*}{ A0 } & \multirow{2}{*}{\multicolumn{2}{|c|}{ A1 }} & \multirow{2}{*}{\multicolumn{2}{|c|}{$\mathbf{k u}_{1}\left(\mathrm{~s}^{-1}\right)$}} \\
\hline & a0 & a1 & $\mathbf{k} \mathbf{f}_{1}\left(\mathbf{s}^{-1}\right)$ & & $\mathbf{a} 2$ & $\mathbf{k} \mathbf{f}_{2}\left(\mathrm{~s}^{-1}\right)$ & & & & & \\
\hline WT & $\begin{array}{c}0.01 \pm \\
0.02\end{array}$ & $\begin{array}{c}0.51 \pm \\
0.03\end{array}$ & $\begin{array}{l}0.049 \\
\pm 0.01\end{array}$ & & $\begin{array}{c}0.48 \pm \\
0.03\end{array}$ & $\begin{array}{c}0.004 \pm \\
0.001\end{array}$ & $\begin{array}{c}0.65 \pm \\
0.03\end{array}$ & 0.3 & $5 \pm 0.01$ & & \\
\hline M182T & $\begin{array}{c}0.03 \pm \\
0.03\end{array}$ & $\begin{array}{c}0.53 \pm \\
0.08\end{array}$ & $\begin{array}{c}0.19 \\
\pm 0.01\end{array}$ & & $\begin{array}{c}0.44 \pm \\
0.04\end{array}$ & $\begin{array}{c}0.008 \pm \\
0.001\end{array}$ & $\begin{array}{c}0.56 \pm \\
0.04\end{array}$ & & $4 \pm 0.04$ & & \\
\hline M69I & $\begin{array}{c}0.03 \pm \\
0.03\end{array}$ & $\begin{array}{c}0.55 \pm \\
0.02\end{array}$ & $\begin{array}{l}0.016 \\
\pm 0.01\end{array}$ & & $\begin{array}{c}0.42 \pm \\
0.02\end{array}$ & $\begin{array}{c}0.003 \pm \\
0.004\end{array}$ & $\begin{array}{c}0.71 \pm \\
0.02\end{array}$ & & $9 \pm 0.03$ & $\begin{array}{l}0 . \mathrm{C} \\
0 . \mathrm{C}\end{array}$ & \\
\hline $\begin{array}{l}\text { M69I- } \\
\text { M182T }\end{array}$ & $\begin{array}{c}0.03 \pm \\
0.06\end{array}$ & $\begin{array}{c}0.52 \pm \\
0.03\end{array}$ & $\begin{array}{c}0.11 \\
\pm 0.02\end{array}$ & & $\begin{array}{c}0.45 \pm \\
0.06\end{array}$ & $\begin{array}{c}0.006 \pm \\
0.001\end{array}$ & $\begin{array}{c}0.65 \pm \\
0.09\end{array}$ & 0.3 & $5 \pm 0.09$ & & \\
\hline L76N & $\begin{array}{c}0.02 \pm \\
0.01\end{array}$ & $\begin{array}{c}0.60 \pm \\
0.08\end{array}$ & $\begin{array}{l}0.014 \\
\pm 0.01\end{array}$ & & $\begin{array}{c}0.38 \pm \\
0.06\end{array}$ & $\begin{array}{c}0.002 \pm \\
0.002\end{array}$ & $\begin{array}{c}0.79 \pm \\
0.03\end{array}$ & 0.2 & $1 \pm 0.03$ & & \\
\hline $\begin{array}{l}\text { L76N- } \\
\text { M182T }\end{array}$ & $\begin{array}{c}0.03 \pm \\
0.05\end{array}$ & $\begin{array}{c}0.68 \pm \\
0.06\end{array}$ & $\begin{array}{l}0.023 \\
\pm 0.02\end{array}$ & & $\begin{array}{c}0.29 \pm \\
0.06\end{array}$ & $\begin{array}{c}0.003 \pm \\
0.001\end{array}$ & $\begin{array}{c}0.68 \pm \\
0.01\end{array}$ & 0.3 & $2 \pm 0.01$ & & \\
\hline
\end{tabular}

${ }^{1}$ Reported standard errors are derived from two independent experiments, each performed in duplicates.

NT- No Transition: Not refolded in $0.5 \mathrm{M} \mathrm{GdnCl}$. All the other proteins were refolded in $0.5 \mathrm{M}$ GdnCl. 
Additional file 13: Table S7 (Related to Figure 4). Top: Fractional solubilities, thermodynamic stability parameters $\left(\mathrm{C}_{\mathrm{m}}, \Delta \mathrm{G}^{0}, \mathrm{~m}_{\text {equi }}\right)$, apparent thermal stabilities $\left(\mathrm{T}_{\mathrm{m}}\right)$, thermal stabilities of refolded and native proteins in the presence of $0.5 \mathrm{M}$ Urea $\left(\mathrm{T}_{\mathrm{mRefold}}, \mathrm{T}_{\mathrm{m}, \text { urea }}\right)$ determined by nanoDSF, of different p53 mutants ${ }^{1}$. Bottom: Kinetic Parameters for refolding and unfolding of p53 mutants measured in 2 $\mathrm{M}$ and 4.4 $\mathrm{M}$ Urea respectively carried out in $50 \mathrm{mM} \mathrm{NaH}_{2} \mathrm{PO}_{4}, 500 \mathrm{mM} \mathrm{NaCl}, 500 \mathrm{mM}$ imidazole, 10 mM DTT, pH 7.2 at $15^{\circ} \mathrm{C}^{1}$.

\begin{tabular}{|c|c|c|c|c|c|c|c|c|c|c|}
\hline Mutants & \multicolumn{2}{|c|}{$\begin{array}{c}\text { Fraction } \\
\text { soluble }\end{array}$} & $\begin{array}{l}\mathbf{C}_{\mathrm{m}} \\
(\mathbf{M})\end{array}$ & \multicolumn{2}{|c|}{$\begin{array}{c}\Delta \mathrm{G}^{0} \\
\left({\left.\mathrm{kcal} . \mathrm{mol}^{-1}\right)}^{-1}\right)\end{array}$} & \multicolumn{2}{|c|}{$\begin{array}{c}\mathbf{m}_{\text {equi }} \\
\left(\text { kcal.mol }^{-1} \mathbf{M}^{-1}\right)\end{array}$} & $\begin{array}{l}\mathbf{T}_{\mathbf{m}} \\
\left({ }^{\circ} \mathbf{C}\right)\end{array}$ & $\begin{array}{c}\mathbf{T}_{\mathbf{m}, \text { refold }} \\
\left({ }^{\circ} \mathbf{C}\right)\end{array}$ & $\begin{array}{c}\mathbf{T}_{\mathbf{m}, \text { urea }} \\
\left({ }^{\circ} \mathbf{C}\right)\end{array}$ \\
\hline WT & \multicolumn{2}{|c|}{$0.4 \pm 0.05$} & $2.8 \pm 0.02$ & \multicolumn{2}{|r|}{$2.5 \pm 0.1$} & \multicolumn{2}{|c|}{$0.9 \pm 0.01$} & $30 \pm 0.1$ & $29 \pm 0.1$ & $29 \pm 0.1$ \\
\hline N239Y & \multicolumn{2}{|c|}{$0.5 \pm 0.05$} & $3.0 \pm 0.05$ & \multicolumn{2}{|r|}{$2.6 \pm 0.2$} & \multicolumn{2}{|c|}{$0.9 \pm 0.02$} & $32 \pm 0.1$ & $29 \pm 0.4$ & $30 \pm 0.1$ \\
\hline V143A & \multicolumn{2}{|c|}{$0.1 \pm 0.04$} & ND & \multicolumn{2}{|r|}{ ND } & \multicolumn{2}{|c|}{ ND } & ND & ND & ND \\
\hline $\begin{array}{l}\text { V143A- } \\
\text { N239Y }\end{array}$ & \multicolumn{2}{|c|}{$0.3 \pm 0.02$} & $3.1 \pm 0.1$ & \multicolumn{2}{|r|}{$2.7 \pm 0.1$} & \multicolumn{2}{|c|}{$0.9 \pm 0.002$} & $31 \pm 0.1$ & $29 \pm 0.1$ & $27 \pm 0.1$ \\
\hline V157F & \multicolumn{2}{|c|}{$0.1 \pm 0.05$} & ND & \multicolumn{2}{|r|}{ ND } & \multicolumn{2}{|c|}{ ND } & ND & ND & ND \\
\hline $\begin{array}{l}\text { V157F - } \\
\text { N239Y }\end{array}$ & \multicolumn{2}{|c|}{$0.4 \pm 0.04$} & $3.3 \pm 0.05$ & \multicolumn{2}{|r|}{$2.9 \pm 0.1$} & \multicolumn{2}{|c|}{$0.9 \pm 0.005$} & $33 \pm 0.1$ & $32 \pm 0.1$ & $32 \pm 0.1$ \\
\hline \multirow{3}{*}{ Mutants } & \multicolumn{5}{|c|}{ Refolding } & \multicolumn{5}{|c|}{ Unfolding } \\
\hline & \multicolumn{3}{|c|}{ Fast Phase } & \multicolumn{2}{|c|}{ Slow Phase } & \multirow[b]{2}{*}{ A0 } & \multirow[b]{2}{*}{ A1 } & & & \\
\hline & a0 & a1 & $\begin{array}{l}\mathbf{k f _ { 1 }} \\
\left(s^{-1}\right)\end{array}$ & $\mathbf{a} 2$ & $\begin{array}{l}\mathbf{k f}_{2} \\
\left(\mathrm{~s}^{-1}\right)\end{array}$ & & & $\left(\mathbf{s}^{-1}\right)$ & A2 & $\left(\mathbf{s}^{-1}\right)$ \\
\hline van & $0.68 \pm$ & $0.14 \pm$ & 0.024 & $0.18 \pm$ & $0.0003 \pm$ & $0.35 \pm$ & $0.53 \pm$ & $0.046 \pm$ & $0.12 \pm$ & $0.003 \pm$ \\
\hline W & 0.01 & 0.0004 & \pm 0.0003 & 0.005 & 0.00001 & 0.01 & 0.01 & 0.0005 & 0.002 & 0.00005 \\
\hline ax & $0.73 \pm$ & $0.14 \pm$ & 0.037 & $0.13 \pm$ & $0.006 \pm$ & $0.32 \pm$ & $0.56 \pm$ & $0.037 \pm$ & $0.12 \pm$ & $0.0025 \pm$ \\
\hline & 0.002 & 0.0004 & \pm 0.0003 & 0.007 & 0.005 & 0.009 & 0.009 & 0.0006 & 0.002 & 0.00007 \\
\hline V143A & $0.86 \pm$ & $0.05 \pm$ & 0.023 & $0.09 \pm$ & $0.003 \pm$ & $0.40 \pm$ & $0.37 \pm$ & $0.028 \pm$ & $0.23 \pm$ & $0.0017 \pm$ \\
\hline N239Y & 0.003 & 0.0003 & \pm 0.003 & 0.005 & 0.006 & 0.01 & 0.01 & 0.001 & 0.007 & 0.0005 \\
\hline V157F & $0.87 \pm$ & $0.02 \pm$ & 0.083 & $0.11 \pm$ & $0.0004 \pm$ & $0.49 \pm$ & $0.23 \pm$ & $0.023 \pm$ & $0.28 \pm$ & $0.0019 \pm$ \\
\hline N239Y & 0.002 & 0.001 & \pm 0.04 & 0.002 & 0.00001 & 0.003 & 0.003 & 0.0015 & 0.003 & 0.00006 \\
\hline
\end{tabular}

${ }^{1}$ Reported standard errors are derived from two independent experiments, each performed in duplicates.

ND - Not determined as the corresponding proteins could not be purified. 
Additional file 14: Table S8 (Related to Figure 5). Thermodynamic parameters $\left(\mathrm{C}_{\mathrm{m}}, \Delta \mathrm{G}^{0}, \mathrm{~m}_{\text {equi }}\right)$, determined by nanoDSF, of CcdB mutants ${ }^{1}$.

\begin{tabular}{|c|c|c|c|}
\hline Mutants & $\mathrm{C}_{\mathrm{m}}(\mathrm{M})$ & $\Delta G^{0}\left(\right.$ kcal.mol $\left.^{-1}\right)$ & $\mathrm{m}_{\text {equi }}\left(\right.$ kcal.mol $\left.^{-1} \mathbf{M}^{-1}\right)$ \\
\hline CcdB WT & $2.8 \pm 0.1$ & $21.1 \pm 0.7$ & $4.97 \pm 0.5$ \\
\hline CcdB Y8D & $3.1 \pm 0.3$ & $22.7 \pm 1.2$ & $5.00 \pm 0.1$ \\
\hline CcdB V46L & $3.2 \pm 0.3$ & $23.2 \pm 1.4$ & $5.01 \pm 0.3$ \\
\hline CcdB S60E & $3.5 \pm 0.5$ & $24.8 \pm 1.1$ & $5.03 \pm 0.2$ \\
\hline
\end{tabular}

${ }^{1}$ Reported standard errors are derived from two independent experiments, each performed in duplicates. WT values are taken from Additional file 11: Table S5. 
Additional file 15: Table S9 (Related to Figure 5). Top: Kinetic Parameters for refolding and unfolding of stabilised $\mathrm{CcdB}$ mutants measured in $2 \mathrm{M}$ and $4.5 \mathrm{M} \mathrm{GdnCl}$ respectively, carried out in $200 \mathrm{mM}$ HEPES, pH 8.4 at $25^{\circ} \mathrm{C}^{1}$. Bottom: Kinetic Parameters for refolding and unfolding of stabilised mRBD mutants in $0.5 \mathrm{M}$ and $3 \mathrm{M}$ GdnCl respectively, carried out in $1 \mathrm{XPBS}, \mathrm{pH} 7.0$ at 25 ${ }^{\circ} \mathrm{C}^{1}$.

\begin{tabular}{|c|c|c|c|c|c|c|c|c|}
\hline \multirow{3}{*}{ Mutants } & \multicolumn{5}{|c|}{ Refolding (2 M) } & \multicolumn{3}{|c|}{ Unfolding (4.5 M) } \\
\hline & \multicolumn{3}{|c|}{ Fast Phase } & \multicolumn{2}{|c|}{ Slow Phase } & \multirow[b]{2}{*}{ A0 } & \multirow[b]{2}{*}{$\mathbf{A 1}$} & \multirow{2}{*}{$\begin{array}{l}\mathbf{k u} 1 \\
\left(\mathrm{~s}^{-1}\right)\end{array}$} \\
\hline & a0 & a1 & $\begin{array}{l}\mathbf{k f} \mathbf{f}_{1} \\
\left(\mathbf{s}^{-1}\right)\end{array}$ & $\mathbf{a} 2$ & $\begin{array}{r}\mathbf{k f _ { 2 }} \\
\left(\mathbf{s}^{-1}\right)\end{array}$ & & & \\
\hline \multirow{2}{*}{ CcdB WT } & $0.03 \pm$ & $0.50 \pm$ & 0.020 & $0.47 \pm$ & $0.001 \pm$ & $0.73 \pm$ & $0.27 \pm$ & $0.060 \pm$ \\
\hline & 0.01 & 0.02 & \pm 0.01 & 0.02 & 0.001 & 0.01 & 0.02 & 0.05 \\
\hline \multirow{2}{*}{ CcdB Y8D } & $0.01 \pm$ & $0.51 \pm$ & 0.06 & $0.48 \pm$ & $0.018 \pm$ & $0.58 \pm$ & $0.42 \pm$ & $0.027 \pm$ \\
\hline & 0.02 & 0.03 & \pm 0.01 & 0.03 & 0.001 & 0.03 & 0.01 & 0.003 \\
\hline \multirow{2}{*}{ CcdB V46L } & $0.03 \pm$ & $0.53 \pm$ & 0.10 & $0.44 \pm$ & $0.026 \pm$ & $0.55 \pm$ & $0.45 \pm$ & $0.025 \pm$ \\
\hline & 0.03 & 0.08 & \pm 0.01 & 0.04 & 0.001 & 0.04 & 0.04 & 0.002 \\
\hline \multirow{2}{*}{ CcdB S60E } & $0.03 \pm$ & $0.55 \pm$ & 0.13 & $0.42 \pm$ & $0.028 \pm$ & $0.52 \pm$ & $0.48 \pm$ & $0.020 \pm$ \\
\hline & 0.03 & 0.02 & \pm 0.01 & 0.02 & 0.004 & 0.02 & 0.03 & 0.003 \\
\hline \multirow{3}{*}{ Mutants } & \multicolumn{3}{|c|}{ Refolding (0.5 M) } & \multicolumn{5}{|c|}{ Unfolding (3 M) } \\
\hline & \multirow{2}{*}{ a0 } & \multirow{2}{*}{ a1 } & \multirow{2}{*}{$k f_{1}\left(s^{-1}\right)$} & \multicolumn{3}{|c|}{ Fast Phase } & \multicolumn{2}{|c|}{ Slow Phase } \\
\hline & & & & A0 & A1 & $k u_{1}\left(s^{-1}\right)$ & $\mathbf{A 2}$ & $k u_{2}\left(s^{-1}\right)$ \\
\hline mRBD & $0.20 \pm$ & $0.80 \pm$ & 0.015 & $0.58 \pm$ & $0.28 \pm$ & 0.051 & $0.14 \pm$ & $0.002 \pm$ \\
\hline WT & 0.01 & 0.02 & \pm 0.003 & 0.02 & 0.03 & \pm 0.002 & 0.03 & 0.0005 \\
\hline \multirow{2}{*}{ mRBD D389E } & $0.26 \pm$ & $0.74 \pm$ & 0.038 & $0.42 \pm$ & $0.48 \pm$ & 0.016 & $0.10 \pm$ & $0.001 \pm$ \\
\hline & 0.03 & 0.01 & \pm 0.004 & 0.03 & 0.08 & \pm 0.003 & 0.04 & 0.0006 \\
\hline \multirow{2}{*}{ mRBD L390M } & $0.25 \pm$ & $0.75 \pm$ & 0.044 & $0.43 \pm$ & $0.47 \pm$ & 0.014 & $0.12 \pm$ & $0.001 \pm$ \\
\hline & 0.02 & 0.03 & \pm 0.002 & 0.03 & 0.08 & \pm 0.001 & 0.04 & 0.001 \\
\hline \multirow{2}{*}{ mRBD P527I } & $0.35 \pm$ & $0.65 \pm$ & 0.103 & $0.33 \pm$ & $0.52 \pm$ & 0.013 & $0.15 \pm$ & $0.001 \pm$ \\
\hline & 0.02 & 0.01 & \pm 0.01 & 0.03 & 0.02 & \pm 0.002 & 0.02 & 0.0007 \\
\hline
\end{tabular}

${ }^{1}$ Reported standard errors are derived from two independent experiments, each performed in duplicates. 
Additional file 16: Table S10 (Related to Figure 7). Top: Thermodynamic parameters $\left(\mathrm{C}_{\mathrm{m}}, \Delta \mathrm{G}^{0}\right.$,

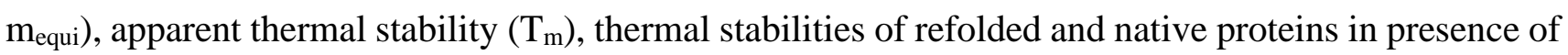
1.5 M GdnCl ( $\left.\mathrm{T}_{\mathrm{mRefold}}, \mathrm{T}_{\mathrm{mGdnCl}}\right)$. Bottom: Kinetic parameters for refolding and unfolding of CcdB WT and L42E in $1.5 \mathrm{M}$ and $3.5 \mathrm{M} \mathrm{GdnCl}$ respectively of CcdB WT and L42E carried out in $200 \mathrm{mM}$ HEPES, pH 8.4 at $25^{\circ} \mathrm{C}^{1}$.

\begin{tabular}{|c|c|c|c|c|c|c|c|c|c|}
\hline Mutants & $\begin{array}{l}\mathrm{Cm}_{\mathrm{m}} \\
(\mathrm{M})\end{array}$ & \multicolumn{2}{|c|}{$\begin{array}{c}\Delta G^{0} \\
\left(k_{c a l . m o l}{ }^{-1}\right)\end{array}$} & \multicolumn{2}{|c|}{$\begin{array}{c}\text { mequi } \\
\left(\text { kcal.mol-1 }^{-1} \mathbf{M}^{-1}\right)\end{array}$} & $\begin{array}{l}\mathbf{T}_{\mathbf{m}} \\
\left({ }^{\circ} \mathbf{C}\right)\end{array}$ & $\begin{array}{c}\text { TmRefold } \\
\left({ }^{\circ} \mathbf{C}\right)\end{array}$ & \multicolumn{2}{|c|}{$\begin{array}{c}\text { TmGdnCl } \\
\left({ }^{\circ} \mathbf{C}\right)\end{array}$} \\
\hline WT & $2.8 \pm 0.1$ & \multicolumn{2}{|c|}{$21.1 \pm 0.7$} & \multicolumn{2}{|c|}{$4.97 \pm 0.5$} & $\begin{array}{c}66 \pm 0 . \\
8\end{array}$ & $53.0 \pm 0.5$ & \multicolumn{2}{|c|}{$52.0 \pm 0.8$} \\
\hline L42E & $3.1 \pm 0.1$ & \multicolumn{2}{|c|}{$21.5 \pm 0.03$} & \multicolumn{2}{|c|}{$4.60 \pm 0.3$} & $\begin{array}{c}67.4 \pm \\
0.2\end{array}$ & $54.9 \pm 0.1$ & \multicolumn{2}{|c|}{$55.1 \pm 0.1$} \\
\hline \multirow{3}{*}{ Mutants } & \multicolumn{6}{|c|}{ Refolding } & \multicolumn{3}{|c|}{ Unfolding } \\
\hline & & ast Ph & & & & & & & \\
\hline & a0 & a1 & $\begin{array}{l}\text { kf1 } \\
\left(s^{-1}\right)\end{array}$ & a2 & & $\begin{array}{l}\mathbf{k f} 2 \\
\left(\mathbf{s}^{-1}\right)\end{array}$ & A0 & A1 & $\left(\mathrm{s}^{-1}\right)$ \\
\hline & $0.02 \pm$ & $0.55 \pm$ & 0.027 & $0.43 \pm$ & & $.002 \pm$ & $0.60 \pm$ & $0.40 \pm$ & $0.050 \pm$ \\
\hline I & 0.02 & 0.03 & \pm 0.02 & 0.03 & & 0.001 & 0.03 & 0.01 & 0.05 \\
\hline & $0.03 \pm$ & $0.67 \pm$ & 0.023 & $0.33 \pm$ & & $.002 \pm$ & $0.63 \pm$ & $0.37 \pm$ & $0.054 \pm$ \\
\hline & 0.001 & 0.01 & \pm 0.01 & 0.01 & & 0.001 & 0.02 & 0.01 & 0.001 \\
\hline
\end{tabular}

${ }^{1}$ Reported standard errors are derived from two independent experiments, each performed in duplicates. WT values of thermodynamic parameters are taken from Additional file 11: Table S5 and kinetic parameters are taken from Additional file 8: Table S2. 
Additional file 17: Table S11 (Related to Figure 6). Data collection and refinement statistics for CcdB mutants.

\begin{tabular}{|c|c|c|c|}
\hline Data collection & S12G & V46L & S60E \\
\hline Space group & I2 & $\mathrm{C} 2$ & $\mathrm{C} 2$ \\
\hline $\mathrm{a}, \mathrm{b}, \mathrm{c}(\AA)$ & $35.57,36.53,67.53$ & $75.10,36.76,35.91$ & $74.81,36.64,35.67$ \\
\hline$\alpha, \beta, \gamma\left({ }^{\circ}\right)$ & $90,93.69,90$ & $90,115.19,90$ & $90,114.97,90$ \\
\hline Wavelength $(\AA)$ & 1.5418 & 1.0358 & 1.5418 \\
\hline Resolution range $(\AA)$ & $33.69-1.63(1.72-1.63)$ & $33.98-1.35(1.43-1.35)$ & $10.00-1.93(2.03-1.93)$ \\
\hline Total No. of reflections & $48336(6679)$ & $114256(14182)$ & $22462(2937)$ \\
\hline No. of unique reflections & $9822(1360)$ & $19433(2799)$ & 6557 (890) \\
\hline Multiplicity & $4.9(4.9)$ & $5.9(5.1)$ & $3.4(3.3)$ \\
\hline Completeness (\%) & $90.6(86.9)$ & $100(100)$ & $97.5(91.6)$ \\
\hline$\langle\mathrm{I} / \sigma(\mathrm{I})\rangle$ & $9.8(4.8)$ & $11.6(3.7)$ & $9.6(3.8)$ \\
\hline Wilson B factor $\left(\AA^{2}\right)$ & 11.66 & 5.78 & 8.6 \\
\hline$R_{\text {p.i.m. }}$ & $0.041(0.097)$ & $0.043(0.141)$ & |0.081 (0.268) \\
\hline$R_{\text {merge }}$ & $0.083(0.195)$ & $0.098(0.288)$ & $0.130(0.424)$ \\
\hline$R_{\text {meas }}$ & $0.093(0.218)$ & $0.108(0.322)$ & $0.154(0.504)$ \\
\hline $\mathrm{CC} 1 / 2$ & $0.995(0.967)$ & $0.994(0.928)$ & $0.99(0.801)$ \\
\hline \multicolumn{4}{|l|}{ Refinement } \\
\hline$R_{\text {Work }}(\%)$ & 22.8 & 16.2 & $\mid 17.0$ \\
\hline$R_{\text {free }}(\%)$ & 26.9 & 18.4 & 21.4 \\
\hline \multicolumn{4}{|l|}{ RMSD } \\
\hline Bond $(\AA)$ & 0.0072 & 0.0138 & 0.0051 \\
\hline Angle $\left(^{\circ}\right)$ & 1.4844 & 1.9222 & 1.3247 \\
\hline \multicolumn{4}{|l|}{ Ramachandran plot } \\
\hline Ramachandran favoured (\%) & 98 & 100.0 & 99 \\
\hline Ramachandran allowed (\%) & 2 & 0 & 1 \\
\hline Ramachandran outliers (\%) & 0 & 0 & 0 \\
\hline \multicolumn{4}{|l|}{ Average $B$ factor $\left(\AA^{2}\right)$} \\
\hline Overall & 18.85 & 11.19 & 11.37 \\
\hline Protein & 18.05 & 9.13 & 10.57 \\
\hline Solvent & 25.77 & 21.25 & $\mid 18.08$ \\
\hline Other & 17.70 & 8.71 & 11.53 \\
\hline \multicolumn{4}{|l|}{ Total no of atoms } \\
\hline Protein atoms & 816 & 814 & 820 \\
\hline Solvent & 95 & 167 & 98 \\
\hline Other & $2 \mathrm{Cl}^{-}$ & $2 \mathrm{Cl}^{-}$ & $2 \mathrm{Cl}^{-}$ \\
\hline $\mathrm{Z}$ & 1 & 1 & 1 \\
\hline
\end{tabular}

* : values within brackets are for highest resolution shell. 